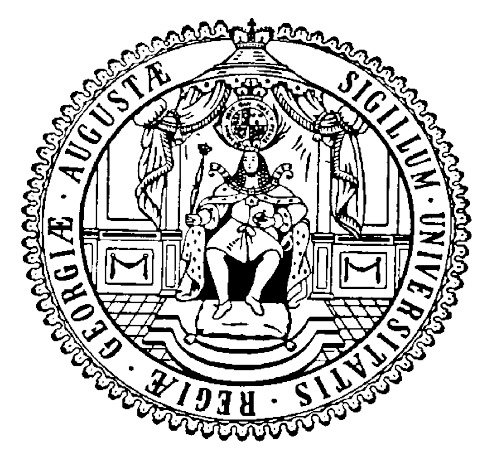

\title{
A Contribution to the Empirics of Development and Globalization
}

Dissertation zur Erlangung des wirtschaftswissenschaftlichen Doktorgrades der Wirtschaftswissenschaftlichen Fakultät der Universität Göttingen

vorgelegt von

Steffen Lohmann

aus

Lohne 
Erstgutachter:

Zweitgutachter:

Drittprüferin:
Prof. Stephan Klasen, Ph.D.

Prof. Dr. Axel Dreher

Prof. Inmaculada Martínez-Zarzoso, Ph.D.

Tag der mündlichen Prüfung: 8. Mai 2015 


\section{Danksagung}

Eine Dissertation zu schreiben ist eine Sache. Mit guten Erinnerungen daran zurückzudenken, eine andere. Beides wäre ohne die Unterstützung meiner Freunde und Kollegen in Göttingen sowie meiner Familie nicht möglich gewesen.

Zuallererst möchte ich meinen Doktorvätern Stephan Klasen und Axel Dreher danken. Ihr Vertrauensvorschuss hat mir überhaupt erst die Möglichkeit und die finanziellen Freiheiten zu einer Promotion gegeben. Im Alltag ein Teil ihrer Forschungsgruppen in Göttingen und Heidelberg zu sein hat letztlich nicht nur zu dieser Dissertation geführt, sondern hat auch mein persönliches Leben in den vergangenen drei Jahren geprägt. Die schönen Erinnerungen an Forschungsaufenthalte in Vietnam und Uganda oder an Kneipenabende und Wanderungen mit Kollegen werden mich sicher eine lange Zeit nach Abgabe dieser Dissertation begleiten. Inma Martínez-Zarzoso bin ich darüber hinaus für Ihre Bereitschaft als Drittgutachterin für diese Arbeit zu fungieren dankbar.

Nicht weniger wichtig war die Unterstützung von Merle und meiner Familie, insbesondere in Momenten gelegentlicher Zweifel. Beispielhaft erinnere ich mich noch gut an eine E-Mail meiner Großeltern, die mich gegen Mitternacht in Ha Tinh, Nordvietnam, erreichte, nachdem ich in der achten Stunde auf einem für Vietnamesen genormten Plastikstuhl Fragebögen kontrollierte: "Steffen, wir haben deinen Ort gerade auf Google Maps gefunden. Du bist wirklich im Niemandsland - andererseits, wo sonst würde die Arbeit auch Sinn machen?"

Steffen Lohmann

Göttingen, März 2015 


\section{Acknowledgements}

Writing a dissertation is one thing. Spending an enjoyable time while doing so, is another. Both would certainly not have been possible without the support and company of my friends and colleagues here in Göttingen as well as my family.

First of all, I am thankful to Stephan Klasen and Axel Dreher for accepting me as a doctoral student in the first place. Their credit of trust gave me the opportunity and, more importantly, the freedom and financial support to write this dissertation. Having been part of their research groups, both in Göttingen and Heidelberg, not only fed this dissertation but my personal life during the past three years. The good memories of field work in Vietnam and Uganda or of drinks and hikes out around Göttingen with colleagues will accompany me long after handing in this dissertation. I would further like to thank Inma Martínez-Zarzoso for agreeing to participate in my examination committee.

The backing of Merle and my family was not less important, particularly in moments when occasional doubts popped up. Exemplarily, I still remember well one e-mail of my grandparents reaching me in Ha Tinh, Northern Vietnam, around midnight after I had checked questionnaires sitting on a Vietnamese-sized plastic chair for eight hours: "Steffen, we checked Google Maps. You really are in the middle of nowhere - but then, where else would the work make sense?"

Steffen Lohmann

Göttingen, March 2015 


\section{Table of Contents}

$\begin{array}{lll}\text { Acknowledgements } & \text { i }\end{array}$

List of Abbreviations $\quad$ v

List of Figures $\quad$ vi

List of Tables $\quad$ vii

1 Introduction 1

2 Information Technologies and Subjective Well-being: Does the Internet $\begin{array}{ll}\text { Raise Material Aspirations? } & 7\end{array}$

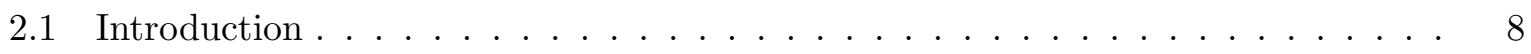

2.2 Theoretical considerations . . . . . . . . . . . . . . . . . . 11

2.3 Empirical Analysis . . . . . . . . . . . . . . . . . . . . 13

2.3.1 The effect of ICT possession on material aspirations . . . . . . . . . . . 14

2.3.1.1 Empirical strategy and data . . . . . . . . . . . . 14

2.3.1.2 Results ..................... 17

2.3.2 Does internet access affect life satisfaction through material aspirations? . 19

2.3.2.1 Empirical strategy and data . . . . . . . . . . . . . . . 19

2.3 .2 .2 Results . . . . . . . . . . . . . . . . . 23

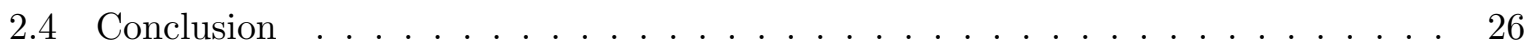

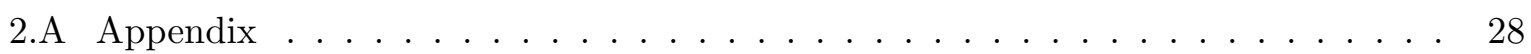

3 The Effect of Drought on Health Outcomes and Health Expenditures in Rural Vietnam 33

3.1 Introduction . . . . . . . . . . . . . . . . . . . . . . 34

3.2 Rural Vietnam's vulnerability to drought and health shocks . . . . . . . . . . . 37

3.3 Empirical strategy . . . . . . . . . . . . . . . . . . . . 39

3.4 Data . . . . . . . . . . . . . . . . . . . . . 42

3.4 .1 Survey data . . . . . . . . . . . . . . . . . . . 42

3.4 .2 Data on drought incidence . . . . . . . . . . . . . . . . . . 43

3.4.3 Descriptive statistics of the sample . . . . . . . . . . . . . . . . . 45

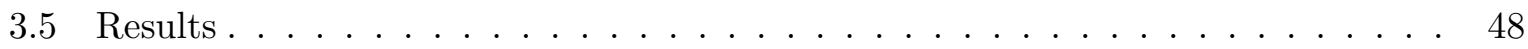

3.5.1 Drought and the agricultural sector f . . . . . . . . . . . 48

3.5.2 The impact of drought on the incidence of diseases . . . . . . . . . . . . . 49 
3.5.3 Coping through formal and informal insurance mechanisms . . . . . . . 52

3.5.4 The impact of drought on the household budget . . . . . . . . . . . . 54

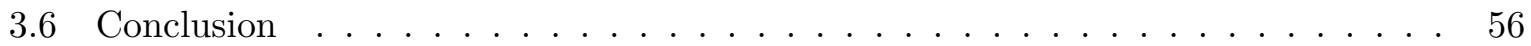

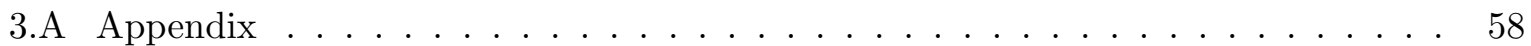

4 Aid and Growth at the Regional Level $\quad 64$

4.1 Introduction . . . . . . . . . . . . . . . . . 65

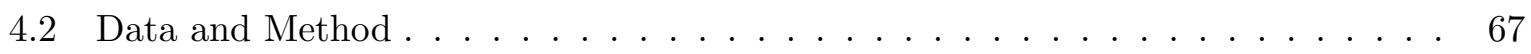

4.3 Results. . . . . . . . . . . . . . . . . . . . 78

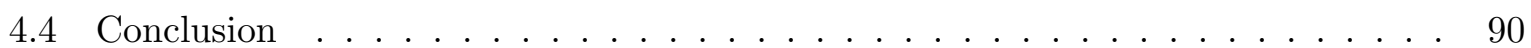

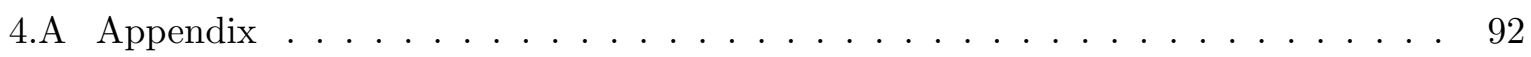

$\begin{array}{ll}\text { Bibliography } & 95\end{array}$

Eidesstattliche Erklärung viii 


\section{List of Abbreviations}

2SLS

ADM1

ADM2

AIC

DHS

EU-SILC

GADM

GPCC

GDP

GMM

GSOEP

HCFP

IBRD

ICT

IDA

IEG

IV

LATE

NOAA

OLS

PPS

SPI

USD

VND

WVS
Two-stage Least Squares

first-level administrative areas

second-level administrative areas

Akaike Information Criterion

Demographic and Health Survey

European Union Statistics on Income and Living Conditions

Global Administrative Areas

Global Precipitation Climatology Centre

Gross Domestic Product

General Method of Moments

German Socio-Economic Panel

Health Care Fund for the Poor

International Bank for Reconstruction and Development

information and communication technology

International Development Association

Independent Evaluation Group

Instrumental Variable

Local Average Treatment Effect

National Oceanic and Atmospheric Administration

Ordinary Least Squares

probability proportional to size

Standard Precipitation Index

United States Dollar

Vietnamese Dong

World Values Survey 


\section{List of Figures}

2.A.1 Response to minimum-income question and actual household income, in USD 30

2.A.2 Difference in response to minimum-income question by computer possession 30

2.A.3 Computer possession over the sample period . . . . . . . . . . . . 31

2.A.4 Contrast in marginal effects of income by sources of information . . . . . . . 32

3.1 Rainfall and drought in Vietnam in the year before the third survey wave . 47

3.2 The effect of drought on health for varying crop revenues . . . . . . . . . . 52

3.A.1 Study area of the "Vulnerability to poverty in Southeast Asia" survey . . . 61

3.A.2 Drought severity at the district level, by province and wave . . . . . . 62

3.A.3 The effect of drought on health for varying crop revenues . . . . . . . . . 63

4.1 Location-specific World Bank disbursements in Africa, ADM1 regions, 2000-

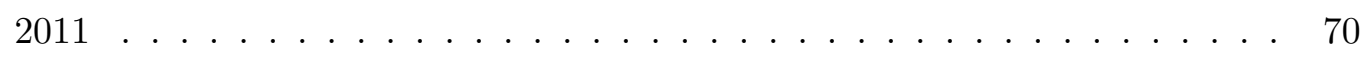

4.2 Raw versus intercalibrated nighttime light, $2000-2012 \ldots \ldots \ldots$. . . . 73

4.3 Regional growth in Africa, ADM1 regions, 2000-2002 to 2003-2005 . . . . 74

4.4 Change in location-specific disbursements after International Development Association (IDA) income threshold crossing . . . . . . . . . . . . . . 77 


\section{List of Tables}

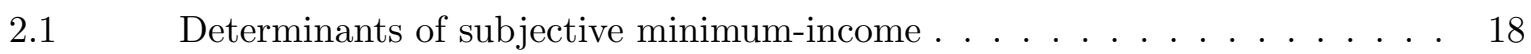

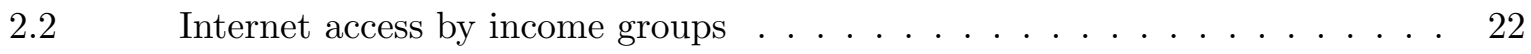

2.3 Determinants of life satisfaction - Least squares and ordered probit . . . . . 24

$2.4 \quad$ Marginal effects of income on life satisfaction by internet users . . . . . . . . 25

2.A.1 The minimum-income question and life satisfaction $\ldots \ldots \ldots \ldots$

2.A.2 The differential in satisfaction derived from income by internet access . . . . 29

2.A.3 Determinants of subjective minimum-income, Robustness checks . . . . . 31

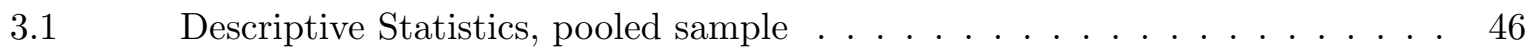

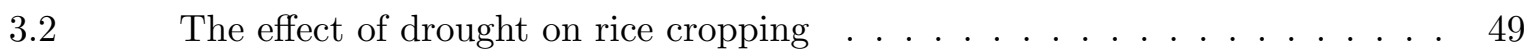

3.3 The relationship between drought and health conditions at the individual level 50

$3.4 \quad$ Formal and informal insurance schemes as coping strategies . . . . . . . 53

3.5 The effect of drought-related health shocks on health expenditures . . . . 55

3.A.1 Average disease incidence and insurance coverage by province $\ldots \ldots \ldots$

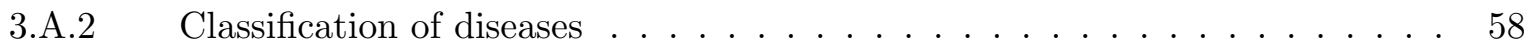

3.A.3 Different measures of drought, standardized coefficients . . . . . . . . . . 59

3.A.4 The effect of drought on health for varying crop revenues . . . . . . . . . . 60

$4.1 \quad$ OLS and Region-Fixed Effects, ADM1, 2000-2012 . . . . . . . . . . 79

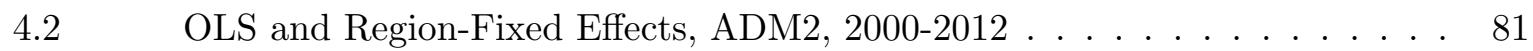

$4.3 \quad$ 2SLS estimates using rainfall as IV, 2000-2011 . . . . . . . . . . . . 84

4.4 2SLS estimates based on the IDA income threshold crossing, ADM1, 2000-2012 86

4.5 2SLS estimates based on the IDA income threshold crossing, ADM2, 2000-2012 87

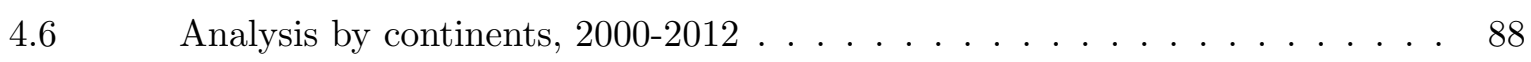

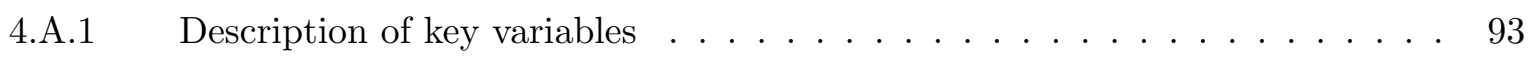

4.A.2 Descriptive Statistics, ADM1, Estimation sample (2000-2012) _ . . . . . . 94

4.A.3 Specification at country-level, $2000-2012 \ldots \ldots \ldots \ldots$. . . . . . 94 


\section{Introduction}

There are arguably few topics in current global economic policy as intensely debated as the impact of different facets of globalization on human development. Few would credibly contest the potential benefits of an increasing integration of markets, services, and spaces in terms of higher global value added - but at the same time, even the greatest advocates of globalization acknowledge the existence of winners and losers. It becomes clear that it is essentially impossible to provide a universal answer to whether globalization promotes or impedes human development for it depends on the fundamental questions of who is exposed to which facet of globalization. Commonly, the focus in the debates lies on the consequences of economic globalization for social welfare and inequality. To the extent that globalization reflects a multitude of economic and societal transformations, however, the answer to the questions needs to be sufficiently nuanced. Empirical economic research can help shed light on some of the channels through which globalization affects human lives. It can point to potential advantages and disadvantages, benefits and costs, which ultimately should be traded off in the formulation of economic policy. From the six dimensions of globalization that Dreher et al. (2008) distinguish - namely capitalism, technology, politics, the environment and social and cultural life -, this dissertation examines empirical issues around the latter three.

Specifically, the first essay scrutinizes the role of informational globalization, characterized by the exchange of information rather than material goods. It focuses on the spread of modern information and telecommunication technologies (ICTs), such as the internet, and sheds light on the intersection between globalization and social standards, subjective well-being and the perception of happiness.

The second essay deals with the implications of environmental globalization - more precisely, with climate change as its most perceptible phenomenon and the consequential increased prevalence of extreme weather events in many parts of the world. Focusing on the impact of drought conditions on health outcomes, the results reveal one component of the costs of environmental globalization for a population vulnerable to poverty.

Emanating from the long-debated question whether development aid is effective in increasing economic growth, the third essay has primarily a methodological focus, but is concerned with the role of the World Bank as one key player of political globalization in alleviating poverty and fostering development and the role of cross-border official capital flows in the form of development aid.

Being grounded on economic theory, a unifying feature of all essays in this dissertation is an evidence-based approach to economic problems. Their research method is the use of empirical 
data in order to draw quantitative conclusions on the effects of different aspects of globalization on human development. Since each chapter deals with an individual research topic, the remainder of this chapter provides non-technical synopses of the individual research questions, including their underlying motivation and main results. Similarly, conclusions for economic policy and future research are provided on a paper-by-paper basis.

\section{Synopsis of "Information Technologies and Subjective Well-Being: Does the Internet Raise Material Aspirations?"}

The starting point for the research presented in the first essay is the simple observation that, to explain if they are satisfied with the life they lead, it does not suffice to look at people's own living conditions in isolation. Importantly, individual happiness or subjective well-being, as it is henceforth referred to, has been found to be affected by how people see themselves within their social environment. So-called positionality concerns arise through comparison of individual living conditions to how these compare to prevailing living conditions of a social reference group. These reference groups can theoretically consist of anyone who is - consciously or unconsciously - taken into account in these valuations. Common reference persons that people report in survey waves include, for instance, neighbors (who drive a larger or smaller car) and working colleagues (who earn more or less). While higher living conditions of others can also serve as a positively-evaluated signal for future consumption possibilities, the majority of studies have found that envy effects are predominant.

What is less frequently stressed in existing research, however, is that the formation of a reference group by its very nature requires information about the living conditions of others. In this context, informational globalization potentially has a key role to play for it renders inter-personal comparisons of living standards easier and puts consumption temptations on display. First, firms often market their new products through modern ICTs, meaning that people with access to these technologies are increasingly confronted with material temptations. Second, modern information technologies can affect the formation of reference groups. In the words of van Praag (2011, p. 125): "[W]hen television disseminates on a day to day basis how the rich are living it is obvious that the frequency of comparing and social transparency is increased enormously." What is less frequently stressed in existing research, however, is that the formation of a reference group by its very nature requires information about the living conditions of others. In this context, informational globalization potentially has a key role to play for it renders inter-personal comparisons of living standards easier and puts consumption temptations on display. First, firms often market their new products through modern ICTs, meaning that people with access 
to these technologies are increasingly confronted with material temptations. Second, modern information technologies can affect the formation of reference groups. In the words of van Praag (2011, p. 125): "[W]hen television disseminates on a day to day basis how the rich are living it is obvious that the frequency of comparing and social transparency is increased enormously." The first essay systematically investigates to what extent modern ICTs, in particular the internet, play a role in affecting positionality concerns and, more specifically, the level of material possession that people aspire. The focus on the internet is intriguing for at least two reasons. First, the internet by its very nature is less of a local, but a global medium that connects people separated by national borders. In essence, it allows to travel to other countries and to get to know other people's ways of life with just a computer at one's disposal. Second, the internet is a much more interactive technology than, say, television, and gives users the ability to easily, frequently, and instantaneously exchange information with one another.

Using data on self-reported happiness, a measure of material aspirations, and ICT possession from micro-level household surveys, the results show that people tend to display higher material aspirations if they have access to a computer and live in areas with more advanced internet infrastructure in a sample of 29 European countries. What is more, findings from a broader cross-section of households in 57 countries around the globe reveal that people with access to the internet are also less satisfied with their actual income. In sum, the results indicate the relevance of the internet in driving positionality concerns and suggest that one explanation for this relationship lies in the positive link between internet access and material aspirations against which people evaluate their actual living conditions.

The first essay therefore contributes to existing research on the determinants of subjective well-being and underscores the relevance of internal and external norms for its evaluation. Assessing the importance of information technologies for positionality concerns matters not only to grasp economic decision-making within social environments but to the understanding of how people's feelings about increasing social globalization are formed. Clearly, if ICT access gets increasingly affordable also in developing economies, this also has implications about perceived social inequality and deprivation. Over the 2000-2014 period, the number of internet users has increased more than sevenfold, with the highest growth rates seen in African where the total number of users rose from mere four to almost 300 million. ${ }^{1}$

One limitation of this essay is that it falls short of specifying an exact channel through which ICTs affect the nature of reference group formation, i.e., whether they change positionality concerns vis-à-vis a given reference group or whether they change the entire composition of

\footnotetext{
${ }^{1}$ http://www.internetworldstats.com/stats.htm (accessed March, 10th, 2015)
} 
reference groups. Such detailed analyses provide interesting scope for further research in this field.

\section{Synopsis of "The Effect of Drought on Health Outcomes and Health Expen- ditures in Rural Vietnam"}

One of the most cited consequences of climate change in the developing world is the increasing prevalence of extreme weather events, both in terms of frequency and severity (World Bank, 2010). At the same time, when listing major causes of impoverishment for the developing world in the World Development Report 2014, the World Bank names health and weather shocks as most important, next to economic crises (World Bank, 2013). Thus, policymakers and researchers alike are increasingly interested in the adverse effects of extreme weather events - such as floods, drought, heat waves, typhoons or earthquakes - on human development. Their quantification yields intriguing insights into what climate researchers refer to as the "cost function" of climate change, on which the necessity for policy responses is typically evaluated.

The second essay in this dissertation sheds light on one component of this cost function, namely health outcomes, and how these are linked to the prevalence of drought conditions in an agrarian economy. The setting of rural households in Vietnam offers an interesting case to study since Vietnam is not only among the countries most frequently affected by extreme weather, but in addition $85 \%$ of the rural households rely on farming and rice cropping as a major source of income. While irrigation systems are largely absent for most parts of small farming households, drought conditions can put significant pressure on rural livelihoods through its detrimental effects on agricultural output, food prices, and scarcity of potable water. Effective universal health care, which could potentially alleviate adverse effects on health conditions, does not exist for a large part of the rural population. As a result, most rural Vietnamese households still heavily depend on out-of-pocket health expenditures to finance health care inducing the risk of impoverishment in the aftermath of health shocks.

Linking data on local rainfall with data on health conditions and agricultural output from four panel surveys in rural Vietnamese provinces between 2007 and 2013, the research results reveal that drought conditions significantly raise the likelihood of being affected by diseases. This adverse effect is particularly pronounced for households who suffer from low agricultural output and who have limited access to coping mechanisms, such as tapping off-farm income sources. The results do not indicate that prevailing health insurance schemes substantially abate these effects. In terms of additional financial burden, the estimates suggest that drought-related diseases can cause non-negligible costs, summing up to about 9 to $17 \%$ of what the median household spends 
in terms of total consumption throughout a year.

Embedded in a literature that has so far predominantly focused on the long-term consequences of extreme weather events, this essay points to the additional relevance of their short-term effects on livelihoods in economies affected by climate change. It therefore underpins the necessity to build up effective and universal systems of health care and insurance, should policymakers be aiming to avoid these adverse effects. Consequentially, future research might benefit from piloting interventions aimed at reducing the health effects of climate shocks, while preventing families from falling (deeper) into poverty.

\section{Synopsis of "Aid and Growth at the Regional Level"}

Although shares are on average declining, a large number of the world's poorest countries still receive significant amounts of foreign Official Development Assistance (ODA) relative to their gross national income. In quite some countries governments are highly ODA-dependent, meaning that its share accounts for more than $50 \%$ of total government expenditure (World Bank, 2014). Irrespective of ideological reflexes about the politics of foreign aid, the question of whether aid works therefore seems as warranted as ever.

For the most part, a focus in existing research has been on the impact of aid on economic (GDP) growth becuase of its role as one key driver of social development more broadly. ${ }^{2}$ In a metaanalysis of 97 econometric studies on the effectiveness of development aid in causing economic growth, Doucouliagos and Paldam (2009) conclude that "[a]fter 40 years of development aid, the preponderance of the evidence indicates that aid has not been effective." At the same time, existing research has revealed that development aid as such is likely to be too imprecise of a category, but heterogeneous effects exist by different types of aid as well as by the socio-economic environment of respective receiving countries. More broadly, the aid effectiveness literature is challenged to properly establish causal mechanisms, raising doubts about the validity of such a general statement.

Despite the seeming consensus of at most modest, if any, effects of aid on economic growth at the country-level, those donors that independently evaluate the effectiveness of single development projects report relatively high rates of success. The World Bank's Independent Evaluation Group, for instance, says that $75 \%$ of the Bank's projects performed 'satisfactory' or better. This apparent discrepancy between micro-level effectiveness and macro-level ineffectiveness of aid - coined as the micro-macro paradox of foreign aid by Mosley (1987) - is at the heart of the third essay in this dissertation. The underlying research hypothesis posits that while individual

\footnotetext{
${ }^{2}$ Although debates persist about the size of the effect, most studies reveal evidence that growth, for instance, leads to reductions in poverty (e.g., Dollar and Kraay, 2002).
} 
projects may be successful to increase incomes of people in some targeted areas, their effects might not be statistically discernable at the more aggregate level of nation states.

Making use of the World Bank's and AidData's joint innovative efforts to assign each of its projects to specific locations at the subnational level, the analysis brings the aid effectiveness debate to the subnational level. The World Bank's project- and location-specific disbursements in 130 countries over the 2000-2011 period are related to a regional indicator for economic growth, proxied by the intensity of nighttime light as observable from outer-space satellites. The results, adressing endogeneity of aid through an instrumental variable strategy, suggest the absence of a robust effect of World Bank aid on growth even at the subnational level.

Although this finding might result from aid being truly ineffective in raising economic growth, future work should further contribute to this young field of research, which is inhibited by a lack of detailed empirical data, before drawing definitive conclusions. Promising extensions include the analysis of the role of other donors as well as of receiving governments and, importantly, the effects of aid on broader indicators of social development than growth at the subnational level. 


\title{
2 Information Technologies and Subjective Well-being: Does the Internet Raise Material Aspirations?
}

This essay has been published in Oxford Economic Papers.

\begin{abstract}
This paper examines whether access to modern information technologies, in particular the internet, has an impact on invididual positionality - the degree to which subjective well-being is affected by concerns about relative status and material aspirations. We provide empirical evidence that positionality and internet access are intertwined. Exploiting variation over time in a panel of European households, we find stated material aspirations to be significantly positively related to computer access in areas with advanced internet infrastructure. Furthermore, we report cross-sectional evidence from the World Values Survey suggesting an indirect negative effect of internet access on subjective well-being since people who regularly use the internet as a source of information derive less satisfaction from their income. Together, the empirical findings highlight the importance of information sets for how individuals evaluate their own living conditions relative to others and suggest a vital role for informational globalisation to affect positionality.
\end{abstract}

This paper is a revised and extended version of the author's master thesis at the VU University Amsterdam, entitled "Information technologies and subjective well-being: Do material aspirations change?". I am grateful to Axel Dreher, Chris Elbers, Jan Willem Gunning, Joop Hartog, Stephan Klasen, Merle Kreibaum, and participants of conferences and seminars in Goettingen, Duesseldorf, and Cambridge for helpful suggestions and discussions on this essay. I also thank Jamie Parsons and Jennifer Philips for research assistance. The EU-SILC and GSOEP datasets were kindly provided by EUROSTAT and the German Socio-Economic Panel Study, respectively. The findings, interpretations, and associated conclusions expressed in this paper are entirely those of the author and as such do not necessarily represent the views of these organisations. 


\section{$2.1 \quad$ Introduction}

This paper examines whether access to information and communication technologys (ICTs), in particular access to the internet, has an effect on invididual positionality - the degree to which subjective well-being is affected by how one's own living conditions compare to those of others. We hypothesise that information sets are crucial for how people evaluate their own living conditions relative to their social environment. If the internet provides information about lifestyles of others, this can potentially shift material aspirations upwards. Therefore, subjective well-being of those doing relatively worse might be negatively affected by rising material aspirations triggered by ICTs if envy effects are predominant. ${ }^{3}$ Compared to more conventional information technologies, such as television or radio, the internet is distinct in that it typically transcends national and continental borders and can involve instantaneous interpersonal interactions, both of which increase the volume and frequency of the information it can transmit.

Our research builds on a growing literature documenting that subjective well-being and economic decision-making are affected by how individuals see themselves within their social environment and how their living conditions compare to those of their peers. ${ }^{4}$ Of particular interest in existing theoretical and empirical work is the concept of relative income. It is commonly attributed to Duesenberry (1949) who was among the first to study the implications of relative income preferences for consumption behaviour. Clark et al. (2008) provide a detailed survey of the relative income concept in the context of the Easterlin paradox. ${ }^{5}$

During the last decade, a number of empirical studies have investigated positional concerns in terms of income and their implications. Most analyses report a negative link between subjective well-being and the income of a reference group. This reference group is mostly exogeneously defined and comprises people with similar age, professional and educational background, or in the same geographic environment (see, e.g., Luttmer 2005; Senik 2008; Dynan and Ravina 2007; Clark and Senik 2010a; Fischer and Torgler 2013). Ferrer-i-Carbonell (2005) finds that the negative effect of high reference incomes on perceived well-being can be as high as the positive effect of own income. Experimental work has revealed evidence that the income rank matters for economic decisions independently of absolute income levels (Mujcic and Frijters 2013). Regarding their implications, increasing concerns about relative status are ascribed by

\footnotetext{
${ }^{3}$ Throughout this paper, we use the terms "subjective well-being" and "life satisfaction" interchangeably. Although there may be philosophical and semantic differences, we take the stand of van Praag (2011) and many other economists that both essentially cover a similar empirical concept.

${ }^{4}$ See, e.g., van Praag et al. (1979) for an early empirical illustration and Manski (2000) for a broader overview of the economics behind social interactions.

${ }^{5}$ The Easterlin paradox describes the empirical puzzle that increases in gross national income have not been accompanied by proportional increases in average happiness at the country level.
} 
some authors to influence the degree of social and institutional trust (Gustavsson and Jordahl 2008; Fischer and Torgler 2013) and can also contribute to the discussion on how inequality in incomes and opportunities translates into subjective well-being (see, e.g., Oishi et al. 2011; Bjørnskov et al. 2013).

What has been less considered in existing empirical studies is that relative income concerns require sufficient information about the lifestyles of others. Van Praag (2011) was among the first to put this notion into a theoretical framework synthesising that "the phenomenon of social transparency or lack of transparency plays a role in the evaluation of social subjective well-being" (p. 113). A couple of studies then have recently confirmed the empirical relevance of ICT-driven relative concerns and material aspirations. Hyll and Schneider (2013) provide evidence that television consumption drives material aspirations by using a natural experiment which exploits that in former Eastern Germany only some areas could receive a TV signal from Western Germany due to geographical reasons. They find a positive relationship between watching (West German) TV and material aspirations which are defined by individual assessments of the importance of material possessions. Bruni and Stanca (2006) find suggestive evidence that people who watch TV for more than two hours per day only experience half the increase in life satisfaction from a rise in income compared to low-frequency TV viewers. Finally, Frey et al. (2007) analyse data on life satisfaction and TV consumption in Europe and provide evidence that TV viewers are on average less satisfied with their financial situation even after controlling for actual income.

Clark and Senik (2010a) is, to our knowledge, the only study which looks beyond TV and briefly touches on the internet. They find that respondents with internet access tend to attach greater importance to income comparisons. Similar results hold for the consumption of television. People who watch TV also stated that the primary direction of income comparisons is towards people outside the spheres of family, friends, or working colleagues. Moreover, respondents who find it important to compare their own income report lower happiness levels on average. However, the results are suggestive, rather than definite, as there is no direct analysis on the happiness-internet nexus. Systematic evidence on the role of the internet in determining material aspirations and relative concerns in subjective well-being is therefore missing in the empirical literature so far. The empirical analyses in this paper deliver a systematic test of the relationship between internet access, material aspirations, and positionality concerns. An ideal dataset for the empirical analysis would include information on subjective well-being, individual income positions, and the individual composition of the reference group for different degrees of exposure to ICTs since this would allow to observe how the relevance of income comparisons as well as the composition 
of the reference group change with increasing access to ICTs. Since, to our knowledge, there is no such dataset available, we present a two-part empirical analysis using two different datasets. First, we directly investigate the relationship between ICT possession and a measure of material aspirations using panel data from the European Union Statistics on Income and Living Conditions (EU-SILC). As a measure of material aspirations or reference income, most existing studies calculate the average income of a fixed reference group, such as other people in the same geographic area or from a similar demographic background. This is, however, less meaningful in the context of ICT-induced changes in the income comparison process. On the contrary, the argument of ICT-driven material aspirations implies that reference groups and their composition are - at least to some extent - endogenous and may change with varying access to information technologies. Since we do not observe reference groups of each and every individual, we choose to take a more abstract measure of material aspirations and regard such reference groups as a "black box". ${ }^{6}$ More specifically, we refer to the answer to what people consider as a minimum income to "make ends meet" as an empirical proxy of material aspirations. To underpin this choice, we analyse data from the German Socio-Economic Panel (GSOEP), one of the few surveys that contain both the minimum-income and a life satisfaction question for a number of years, and find that this measure of reference income features a robust negative effect on life satisfaction - and as such behaves like standard measures of reference income based on exogeneously given demographic or geographic characteristics. It therefore seems plausible that the minimum-income question indeed provides one empirical benchmark against which individuals evaluate their actual income position.

Relating this measure to ICT possession, our findings show that households in possession of a computer report needing significantly higher levels of minimum incomes, after controlling for their actual level of income, a range of socio-economic characteristics, as well as household fixed effects in a sample of 29 European countries. The estimated effect prevails in regions which become more advanced in their internet infrastructure.

Subsequently, we explore the implications of access to information technologies for subjective well-being. Based on recent data on life satisfaction, ICT usage, and income from 57 countries in the World Values Survey (WVS), we find that individuals who regularly use the internet as a source of information derive less satisfaction from higher incomes, pointing to an increase in material aspirations driven by the usage of the internet. We find tentative evidence that the internet is distinct from other media, such as newspapers or television. In sum, the empirical

\footnotetext{
${ }^{6}$ Recent empirical evidence on the relationship between subjective well-being and income comparisons suggests that individuals are mostly unaware of the well-being impacts of income comparisons (Mayraz et al. 2009). For the empirical analysis, this dilutes the potential bias that would arise if individuals were to self-select reference groups in a systematic relationship to their ICT usage.
} 
results suggest that internet access lowers the satisfaction that people derive from their income position and that one explanation for this pattern lies in the positive link between internet access and aspired incomes against which actual incomes are evaluated.

Given the limited range of studies on ICT-driven material aspirations, this paper contributes to the existing literature in four ways. First, it is unique in providing systematic evidence on the role of the internet in shaping positionality concerns. Second, different from Bruni and Stanca (2006), this paper takes a closer look at heterogeneous material aspiration effects across different parts of the income distribution. Third, we employ a continous and more comparable measure of material aspirations by using the response to the minimum-income question. This contrasts with the experimental study of Hyll and Schneider (2013) which relies on broad survey questions to measure material aspirations. ${ }^{7}$ Finally, we address some of the endogeneity concerns present in previous cross-sectional studies by controlling for time-invariant unobserved heterogeneity in our measure of reference income in the panel analysis of European households.

The remainder of this paper is structured as follows: To illuminate the mechanism behind ICT-driven relative concerns in subjective well-being, we lay out a simple theoretical argument in section 2.2. We derive the testable implications that more ICT-driven information flows in society lead to an increase in material aspirations and indirectly to a lower satisfaction with actual income. Section 2.3.1 provides the results from an empirical model of reference incomes that is estimated with the data from the EU-SILC. Section 2.3.2 describes the WVS data, explains the choice of control variables in light of identification problems in the simple cross-section, and presents results from an empirical model of subjective well-being with heterogeneous income effects dependent on the usage of different information technologies. Section 2.4 concludes.

\subsection{Theoretical considerations}

Recent work on the economics of well-being shows that subjective well-being and economic decision-making are affected by how individuals see themselves within their social environment. Brosnan and De Waal (2003) report that such so-called relative concerns might have been formed in an evolutionary process. One core finding of their study is that, in an experimental setup, monkeys reject formerly acceptable food deals after observing that other monkeys got a better deal. Brosnan and de Waal conjecture that "during the evolution of cooperation it may have become critical for individuals to compare their own efforts and pay-offs with those of others" (Brosnan and De Waal 2003, p. 297).

\footnotetext{
${ }^{7}$ Specifically, Hyll and Schneider (2013) use responses from the following questions to measure aspirations: "To what extent do you attach importance to acquiring valuable personal possessions (real estate, expensive cars, etc.)?", "To what extent do you attach importance to making use of all opportunities offered to earn money?", and "To what extent do you attach importance to living a comfortable and pleasant life without much effort?".
} 
Obviously, concerns about other people's incomes require sufficient information about their living conditions. The income comparison process should therefore be crucially affected by the availability of information and social transparency (Diener and Fujita 1997; van Praag 2011). Scarce empirical evidence confirms the vital role of information. In a study on rural China, Knight et al. (2009) find strong evidence for the importance of individual information sets for the formation of reference groups. Most rural people have rather narrow scopes of comparison, often limited to their local village. Having lived outside of the community for more than a year in turn leads to a negative effect on subjective well-being, potentially via increasing material aspirations. The findings are in line with an early study by van Praag et al. (1979) who find that people in less urbanised regions attach more weight to their own income than to incomes of others in terms of subjective well-being.

If information would indeed be central to evaluate one's own living conditions, one evident question evolves around the potential impact of modern information technologies, most importantly the internet. Ex ante, the literature points to two main theoretical channels through which increasing exposure to ICTs can impact subjective well-being. First, firms market their new products through modern information technologies, meaning that people with access to ICTs are increasingly confronted with material temptations. Second, modern information technologies can create new reference points since, following the distinction by Castronova and Wagner (2011), "virtual" reference groups (rather than "literal" ones) might gain importance. Individuals that used to have relative concerns vis-à-vis their closest environment may be inclined to compare their living conditions with individuals in other regions, countries, continents, or even in the virtual world (Bruni and Stanca 2006; Layard 2003; Castronova and Wagner 2011). Compared to more conventional information technologies, such as the television or the radio, the internet is distinct for at least two reasons. First, the internet by its very nature is not a local, but a global medium that connects people separated by national and continental borders, particularly when common platforms or news websites are used in different countries. Second, the internet is potentially a much more interactive technology than, e.g., television, that gives users the ability to easily, frequently and instantaneously exchange information with one another. This has been particularly reflected in the emergence of social networks and instant messaging services. In both cases, the internet can function as a vehicle to deliver information about the living conditions and consumption patterns of others - and therefore trigger new material aspirations. Accordingly, one of the hypotheses that will be tested in the following empirical analysis can be formulated as: 
Hypothesis on the level of aspired reference income: The aspired income level rises with increased access to modern ICTs.

If existing material possessions do not grow in line with these aspirations, the gap between aspirations and actual income can have a detrimental effect on subjective well-being. This phenomenon is commonly referred to as the "satisfaction treadmill". Arguably, the more information people have about other people's living conditions, the more relevant status concerns will be for subjective well-being. To illustrate this point, we refer to a stylized composite subjective well-being (SWB) function commonly used in empirical analyses of well-being (e.g., Stutzer 2004; Ferrer-i-Carbonell 2005). Individuals derive well-being from own income $(Y)$ and from comparing their own income to their aspired income $\left(Y^{*}\right)$. To accommodate for the fact that available information matters for the formation of aspired incomes, we model it to endogeneously depend on the availability of information $(\pi)$, where $\frac{\partial Y^{*}(\pi)}{\partial \pi}>0$ :

$$
\mathrm{SWB}=\alpha+\beta Y+\gamma \frac{Y}{Y^{*}(\pi)}
$$

where $\beta>0$ captures the well-being component from one's own income and $\gamma$ from relative income. Assuming that people suffer deprivation when falling short of their aspired income (and, conversely, enjoy happiness when being above), we suggest that $\gamma>0$. Increasing social transparency then has an additional effect on subjective well-being over and above own income concerns by changing the ratio of actual and aspired income. Against this framework, we pose the following testable hypothesis about differential income effects in the well-being function:

Hypothesis on differential income effects: If material aspirations increase with the availability of information about others, this will lower the positive effect of income on subjective well-being.

\subsection{Empirical Analysis}

The empirical analysis builds on the presumption that the access to modern ICTs, especially the internet, is crucially linked to the availability of information about other people's living conditions. It comes in two parts and makes use of two different micro-datasets at the household level. First, we directly investigate the relationship between ICT possession and a measure of reference income using panel data from the European Union Statistics on Income and Living Conditions. Subsequently, we explore the implications of access to information technologies for subjective well-being using a broader set of countries in the World Values Survey. 


\subsubsection{The effect of ICT possession on material aspirations}

\subsubsection{Empirical strategy and data}

This part of the empirical analysis directly tests whether ICT access has an impact on the level of aspired reference income in a sample of European countries. As the measure of material aspirations, we use the response to the minimum-income question, i.e., how much a household states it needs to "make ends meet" at the end of the month. The precise wording is: "In your opinion, what is the very lowest net monthly income that your household would have to have in order to make ends meet, that is to pay its usual necessary expenses?".

There are two concerns with using the minimum-income question as an empirical proxy of aspirations. First, it might just be a noisy measure of actual income, especially given that households were asked how much it needs to "make ends meet, that is to pay its usual necessary expenses [emphasis added]." In figure 2.A.1 in the appendix, we plot country averages of the response to the minimum-income question against actual household income. As can be seen, the estimated quadratic fit is significantly different from the 45-degree line, such that we do not have a strong reason to believe that the minimum-income question was misunderstood to reflect current expenses, but that households indeed stated what they considered as some kind of subsistence level of income. The pattern resembles typical pictures from development economics where households are asked about subjective minimum incomes (e.g., Vos and Garner 1991; Pradhan and Ravallion 2000). Households in poorer countries locate themselves around their actual income levels while in richer countries households' actual incomes are well above subsistence. With higher incomes, the response to the minimum-income question rises, but at a diminishing rate.

Second, it remains uncertain to what extent the minimum-income question in fact contains information about the standard of living against which people actually evaluate their actual income, i.e., whether it is meaningful in the context of well-being analyses. There is no dataset available that allows us to investigate the relationship between the answer to the minimumincome question and life satisfaction for a broad set of countries and years. However, we can use selected waves of the German Socio-Economic Panel to address part of this concern. The GSOEP covers information on life satisfaction, income, and internet access for the years 2002-2011. The minimum-income question is not asked in every year - which prevents a comprehensive test of the relationship between internet usage, material aspirations, and subjective well-being in one dataset. For those years where the minimum-income question is available (2002, 2007, 2012), however, table 2.A.1 in the appendix shows that the response to the minimum-income question is found to have a robust negative association with life satisfaction, controlling for actual 
income and a range of socio-economic and demographic characteristics. It therefore behaves like standard measures of reference income based on exogenously given demographic or geographic characteristics (see, e.g., Ferrer-i-Carbonell (2005) who uses the same dataset and similar control variables). Similar conclusions follow when life satisfaction is regressed on the difference between actual and minimum income. We take this as an indication that the minimum-income question serves as one reasonable reference point against which households evaluate their actual income position and thus reflects different levels of material aspirations that we seek to identify in this paper.

In the empirical model, this measure of material aspirations is related to ICT access in the household. As is commonly done in literature using minimum-income questions (e.g., van Praag et al. 1980; Pradhan and Ravallion 2000; Stutzer 2004), we transform the minimum-income response into logs. With subscript $i$ denoting households, $c$ countries, and $t$ denoting the time dimension, our basic estimation equation with household fixed effects reads:

$$
\log (\text { MinIncome })_{i t}=\alpha+\beta_{1} \mathrm{ICT}_{i t}+\beta_{2} \log (\text { Income })_{i t}+\mathbf{\Phi} \mathbf{Z}_{i t}+\boldsymbol{\delta}_{i}+\boldsymbol{\delta}_{c t}+\epsilon_{i t},
$$

where the variable ICT reflects whether a household has access to a specific ICT. We define binary variables taking the value 1 if the household possesses a computer, a television set, or a phone, respectively. The simplifying assumption that computer possession is an imperfect proxy for internet access seems reasonable, given that our data span the second half of the first decade of the 2000s. ${ }^{8}$ We furthermore analyse if the effect of computer possession depends on the availability of modern internet infrastructure below. We expect $\beta_{1}$ to be positive and significant if possession of ICTs increases material aspirations.

The vector $\mathbf{Z}$ includes various time-variant demographic and socio-economic control variables at the household level. $\boldsymbol{\delta}_{c t}$ represents a full set of country-year fixed effects which are required to capture all unobservable factors that are constant within a country and a given year, most importantly a country's general economic environment. As we have multiple observations per household over time, we can also include unobserved household fixed effects $\boldsymbol{\delta}_{i}$ in the model and absorb all time-invariant determinants of material aspirations. This is essential to our analysis as there are various unobserved reasons why some households typically report to need higher incomes than others - and these are possibly related to the possession of information technologies. Some of these influences might be on the country-level, e.g., some countries might generally be more or less modest (in answering these questions). Other factors might be on the

\footnotetext{
${ }^{8}$ Also, the World Values Survey, analysed in detail below, reveals that almost $80 \%$ of those respondents who stated that they used personal computers "frequently" also said that they used the internet as a source of information.
} 
individual-level, such as cultural or religious values that we cannot observe.

As it seems likely that the household fixed effects are correlated with the values of the other regressors in equation (2.2), we use the within-transformation to estimate the coefficients. That is, the estimate of $\beta_{1}$ reflects the variation in computer possession in one household over time. Consistency of the estimate depends on the assumption that there are no time-variant unobserved factors that determine both the possession of computers and the response to the minimum-income question. As we detail below, we employ the most important time-varying determinants of ICT access.

We furthermore estimate equation (2.2) with the $I C T$ variable interacted with a measure of broadband internet infrastructure to make a step towards establishing a causal interpretation linked to internet access. In all specifications, standard errors are clustered at the country level. Model (2.2) is estimated using the EU-SILC dataset, a household survey carried out in 29 European countries (27 EU member states plus Norway and Iceland) for the purpose of studying monetary and non-monetary aspects of living conditions and social inclusion throughout Europe. $^{9}$ Typically, the survey is conducted annually in 3,000 to 5,000 households within each country as a rotating panel. ${ }^{10}$ For our analysis, we use data from the waves of 2004 to 2009 for all available households, such that the resulting panel is unbalanced. Including all control variables used in the main specification, the dataset for the analysis comprises 367,264 households that are observed over an average period of 2.2 years up to a maximum of seven years. ${ }^{11}$

In the sample, we find that $56 \%$ of the households in our sample stated that they possess a personal computer in the year of the survey. Television and (mobile) phones are much more diffused and coverage extends to almost the whole sample. Figure 2.A.3 in the appendix depicts how computer possession changed within countries throughout our sample period. Almost all countries feature a notable increase in the diffusion of personal computers. Less developed and transition countries, e.g., Estonia, saw computer ownership rates growing by about 20 percentage points between 2005 and 2009. Countries that already had high ownership rates at the beginning of the sample period, e.g., Luxembourg or Finland, still experienced a moderate increase of around ten percentage points. We find that $13 \%$ of all households acquired a personal computer within the sample period.

\footnotetext{
${ }^{9}$ The countries are: Austria (AUT), Belgium (BEL), Bulgaria (BUL), Cyprus (CYP), the Czech Republic (CZE), Germany (GER), Denmark (DEN), Estonia (EST), Spain (ESP), Finland (FIN), France (FRA), Greece (GRE), Hungary (HUN), Ireland (IRE), Iceland (ICE), Italy (ITA), Lithuania (LTH), Luxembourg (LUX), Latvia (LAT), Malta (MAL), Norway (NOR), Poland (POL), Portugal (POR), Romania (ROM), Sweden (SWE), the Slovak Republic (SVK), and the United Kingdom (UK).

${ }^{10}$ Since the EU-SILC survey harmonises different national household surveys, the sampling procedure is not uniform, but rotating periods vary between four years for most of the countries and eight years in Norway. The survey in Luxembourg is implemented without rotation as a pure panel.

${ }^{11}$ All income variables in the dataset are denominated in Euros.
} 
As for control variables, we use disposable household income, being the sum of all gross personal income components among the household members after taxes and transfers, as the main measure of the actual income position of a household. We allow for different measures of wealth when testing for robustness. At the household level, we furthermore control for the degree of urbanisation (rural, mid-urban, and high-urban areas), and household size. Additional controls are the respondent's age, gender, marital status, educational attainment, and labour market status.

\subsubsection{Results}

As a starting point, figure 2.A.2 in the appendix presents the average response to the minimumincome question for all countries in our sample differentiated by whether or not the household has access to a personal computer. The figure reveals that on average in all countries households in possession of a computer report that they need a higher income to make ends meet. In many countries, the difference between owners and non-owners is stark, going up to about $50 \%$ in Latvia, for instance. The simple comparison of averages is, of course, only descriptive. There are various reasons why households with computers report to need more money, foremost since both variables are jointly determined by actual household income.

To disentangle the determinants of the response to the minimum-income question, table 2.1 reports the regression results for equation (2.2) when we pool all countries in our sample. In column (1), logged minimum income is regressed solely on the binary computer indicator, household fixed effects, and country-year fixed effects. We find that for the respondents in our sample, the possession of a computer is associated with a significant increase of about $7.2 \%$ in the reported minimum income needed. In column (2), we add the television and phone indicators. The coefficient for computer possession drops slightly to 0.069 , but stays highly significant. TV possession features a smaller, but also significant effect with 0.054 . Phone possession is not associated with a significant increase in the response to the minimum-income question. In column (3), we add the log of actual household income. In this specification, a $10 \%$ increase in household income is associated with an increase in the minimum income needed of $1.4 \%$. As the computer and TV variables are positively related to household income, their estimates drop, but stay significantly different from zero.

In column (4), we finally include demographic and socio-economic characteristics as control variables. The control variables have the expected signs. Higher household income is linked to higher material aspirations, with an estimated elasticity of about 0.12 . Material aspirations increase with age, but at a declining rate. An increase in household size is associated with a higher minimum income needed, as does being married. Male respondents are found to have 
Table 2.1: Determinants of subjective minimum-income

\begin{tabular}{|c|c|c|c|c|c|}
\hline & (1) & $(2)$ & (3) & (4) & $(5)$ \\
\hline Computer & $\begin{array}{c}0.0699^{* * *} \\
(0.0171)\end{array}$ & $\begin{array}{c}0.0694^{* * *} \\
(0.0169)\end{array}$ & $\begin{array}{c}0.0558^{* * *} \\
(0.0130)\end{array}$ & $\begin{array}{c}0.0410^{* * *} \\
(0.0077)\end{array}$ & $\begin{array}{c}0.0005 \\
(0.0087)\end{array}$ \\
\hline Broadband coverage & & & & & $\begin{array}{l}-0.0002 \\
(0.0007)\end{array}$ \\
\hline Computer $\times$ Broadband & & & & & $\begin{array}{c}0.0005^{* *} \\
(0.0002)\end{array}$ \\
\hline $\mathrm{TV}$ & & $\begin{array}{c}0.0535^{* * *} \\
(0.0104)\end{array}$ & $\begin{array}{c}0.0446^{* * *} \\
(0.0091)\end{array}$ & $\begin{array}{c}0.0422^{* * *} \\
(0.0091)\end{array}$ & $\begin{array}{c}0.0281^{* * *} \\
(0.0070)\end{array}$ \\
\hline Phone & & $\begin{array}{c}0.0075 \\
(0.0348)\end{array}$ & $\begin{array}{l}-0.0009 \\
(0.0326)\end{array}$ & $\begin{array}{l}-0.0144 \\
(0.0306)\end{array}$ & $\begin{array}{c}0.0190 \\
(0.0199)\end{array}$ \\
\hline $\log ($ Income $)$ & & & $\begin{array}{c}0.1345^{* * *} \\
(0.0216)\end{array}$ & $\begin{array}{c}0.1162^{* * *} \\
(0.0170)\end{array}$ & $\begin{array}{c}0.0890^{* * *} \\
(0.0202)\end{array}$ \\
\hline Age & & & & $\begin{array}{c}0.0202^{* * *} \\
(0.0040)\end{array}$ & $\begin{array}{c}0.0354^{* * *} \\
(0.0079)\end{array}$ \\
\hline Age-squared & & & & $\begin{array}{c}-0.0003^{* * *} \\
(0.0000)\end{array}$ & $\begin{array}{c}-0.0002^{* * *} \\
(0.0000)\end{array}$ \\
\hline Household size & & & & $\begin{array}{c}0.0068^{* * *} \\
(0.0007)\end{array}$ & $\begin{array}{c}0.0033^{* * *} \\
(0.0009)\end{array}$ \\
\hline Male & & & & $\begin{array}{c}0.0776^{* * *} \\
(0.0169)\end{array}$ & \\
\hline Married & & & & $\begin{array}{c}0.1114^{* * *} \\
(0.0138)\end{array}$ & $\begin{array}{c}0.1005^{* * *} \\
(0.0184)\end{array}$ \\
\hline Mid-education & & & & $\begin{array}{c}0.0256 \\
(0.0205)\end{array}$ & $\begin{array}{l}-0.0037 \\
(0.0030)\end{array}$ \\
\hline High-education & & & & $\begin{array}{c}0.0529 \\
(0.0314)\end{array}$ & $\begin{array}{c}0.0047 \\
(0.0146)\end{array}$ \\
\hline Employee & & & & $\begin{array}{c}0.0393^{* * *} \\
(0.0053)\end{array}$ & $\begin{array}{c}0.0184^{* *} \\
(0.0066)\end{array}$ \\
\hline Self-employed & & & & $\begin{array}{c}0.0044 \\
(0.0042)\end{array}$ & $\begin{array}{c}0.0049 \\
(0.0050)\end{array}$ \\
\hline Unemployed & & & & $\begin{array}{l}-0.0024 \\
(0.0084)\end{array}$ & $\begin{array}{c}-0.0138^{*} \\
(0.0064)\end{array}$ \\
\hline In-training & & & & $\begin{array}{l}-0.0028 \\
(0.0050)\end{array}$ & $\begin{array}{c}0.0094 \\
(0.0102)\end{array}$ \\
\hline Retired & & & & $\begin{array}{c}0.0108 \\
(0.0084)\end{array}$ & $\begin{array}{l}-0.0012 \\
(0.0063)\end{array}$ \\
\hline Mid-urban & & & & $\begin{array}{c}0.0108 \\
(0.0146)\end{array}$ & $\begin{array}{c}0.0046 \\
(0.0347)\end{array}$ \\
\hline High-urban & & & & $\begin{array}{c}0.0509 \\
(0.0322)\end{array}$ & $\begin{array}{l}-0.0478 \\
(0.0291)\end{array}$ \\
\hline Household-FE & Yes & Yes & Yes & Yes & Yes \\
\hline Country-Year-FE & Yes & Yes & Yes & Yes & Yes \\
\hline Observations & 881,668 & 881,564 & 881,564 & 791,551 & 218,006 \\
\hline
\end{tabular}

Dependent variable: Logged minimum income to make ends meet. Fixed-effects within panel regression.

Standard errors, clustered at the country level, in parentheses. ${ }^{* * *} / * * / *$ : significant at $1 \% / 5 \% / 10 \%$

Source: EU-SILC (2004-2009) and EUROSTAT (2012)

higher aspirations. Being employed (as compared to being economically inactive) significantly raises the response to the minimum-income question.

Turning to the interpretation of the ICT variables, we see that the possession of a computer as well as a TV is related to an increase in the response to the minimum-income question of roughly 4.2 to $4.3 \%$. Compared to column (1), the coefficient of computer ownership decreased notably which points to omitted individual characteristics having biased the estimate upwards in the univariate analysis. ${ }^{12}$

\footnotetext{
${ }^{12}$ Note that the sample size differs across the columns as the panel is unbalanced. The results do not change significantly if we restrict our sample in column (1) to the same 791,551 observations as with including all covariates.
} 
Given the finding that computer possession and material aspirations are highly correlated, we next test more systematically for the role of the internet. To this end, we estimate a model that tests for heterogenous effects by regions with differently developed broadband internet infrastructure. Recalling that the argument of ICT-driven material aspirations due to increased social transparency rests in the usage of highly interactive technologies such as the internet, we would expect stronger effects in regions with better internet infrastructure. Regional statistics on broadband usage of internet are obtained from EUROSTAT (2012) for eleven countries in our sample for the 2006-2009 period. In column (5), we estimate equation (2.2) adding an interaction between computer possession and the regional share of household with access to broadband internet with the reduced sample. ${ }^{13}$ Although our statistical analysis loses some power due to a much lower number of observations, we find the estimated effect of computer possession in fact to be non-linear. The computer indicator gains statistical significance when it is interacted with the measure of the penetration of the broadband internet technology. With the average value of the broadband coverage variable in the sample around $40 \%$ and a maximum share of around $80 \%$ in all households, the combined effect is of a similar magnitude as in the original specification in column (4) for the average household in the sample. In sum, households with computer acccess in areas with advanced internet infrastructure report to need significantly more income "to make ends meet". ${ }^{14}$

\subsubsection{Does internet access affect life satisfaction through material aspirations?}

\subsubsection{Empirical strategy and data}

If access to ICTs increases the level of material aspirations, this potentially has repercussions on subjective well-being if material possessions do not grow in line with these aspirations. The results from table 2.A.1 in the appendix revealed that material aspirations are robustly negatively linked to life satisfaction for the case of Germany. Using cross-sectional data from the World Values Survey, we aim at testing the relation between internet access and life satisfaction for a broader set of countries in what follows. The testable hypothesis is whether individuals who use different ICTs, particularly the internet, differ systematically in how their income translates

\footnotetext{
${ }^{13}$ As our sample size decreases significantly, we no longer have intra-household variation for the respondent's gender and thus drop this variable from the analysis. We also checked that the results from column (4) hold qualitatively when using the same estimation sample as in column (5).

${ }^{14}$ We checked that the estimated relationship between computer possession and aspired incomes is robust to a number of alternative specifications of household income and wealth. These checks include (i) using the unlogged income variable as well as its square, (ii) using year- and country-specific income deciles in lieu of the continuous income measure, (iii) adding indicator variables for other assets (cars, washing machines) to the model, and (iv) additionally including ten occupational variables capturing the different sectors of the labour market in which the respondent operates. Throughout all specifications, the estimated effect for computer possession remains significant at around 3-4\%. We also check that our results for computer and television ownership hold in subsamples of different degrees of urbanisation. Regression results are presented in table 2.A.3 in the appendix.
} 
into life satisfaction.

In the empirical model, subjective well-being is related to a measure of own income and the usage of information technologies. The crucial element of the estimation equation is an interaction term between information sources and income, which reflects how well-being effects from income differ between users and non-users of information technologies. This approach resembles the work by Bruni and Stanca (2006), but is less restrictive. We allow for varying coefficients of the interaction term and estimate interaction effects for different income groups separately. In this way, the effect of income on well-being does not need to be linear and we can test whether differential income effects matter when going up or down the income ladder. Given that we perform a cross-sectional analysis, this essentially serves to identify in which group (the relatively rich, the relatively poor, or both) such indirect well-being effects matter. If we separate income into deciles, the estimation equation reads:

$$
\mathrm{SWB}_{i}=\alpha+\sum_{k=1}^{10} \beta_{k} I\left(Y_{i}=k\right)+\sum_{j \in S} \gamma_{j} \operatorname{info}_{i j}+\sum_{k=1}^{10} \sum_{j \in S} \delta_{k j}\left(\operatorname{info}_{i j} \cdot I\left(Y_{i}=k\right)\right)+\mathbf{\Phi} \mathbf{Z}_{i}+\epsilon_{i}
$$

where subjective well-being (SWB) is regressed on indicator variables for ten income deciles $\left(I\left(Y_{i}=k\right)\right)$, binary variables for each source of information from the set $S$ used (info), an interaction term of income and the different sources of information for all income groups, and a set of control variables $(\mathbf{Z})$. The effect of ICTs on the relationship between income and subjective well-being is therefore identified through comparing self-reported well-being of individuals who are similar in terms of basic socio-economic and demographic variables, but differ only in incomes and their usage of information technologies. If $\beta_{k}>0$ and $\delta_{k j}<0$, for instance, the positive effect of additional income on well-being would be reduced by the negative effect of ICT-driven material aspirations driven by technology $k$.

The WVS (2009) provides individual-level data on subjective well-being as well as values and beliefs towards economic, political, religious, social, and ethical topics. We use data from the fifth wave which, for the first time, included questions on the usage of different technologies used to acquire information in everyday life. The survey for the fifth wave was conducted from 2005 to 2007. It covers six continents and 57 countries.

Self-reported life satisfaction scores serve as a proxy for subjective well-being. Respondents were asked "All things considered, how satisfied are you with your life as a whole these days?" which 
they answered on a scale from 1 (completely dissatisfied) to 10 (completely satisfied). ${ }^{15}$ As the dependent variable is discrete and measured on an ordinal scale from 1 to 10, the analysis will focus on ordered probit estimation in addition to Ordinary Least Squares (OLS). As for the variables included in the interaction term, it is taken into account that in non-linear models, the calculation of the interaction effect is not straightforward (Ai and Norton 2003). We finally assume observations to be independent across countries, but account for the possibility of correlated error terms within countries by clustering standard errors at the country level in all specifications.

The main explanatory variables of interest include a measure of income and a measure of ICT usage. Regarding the measure of income, we refer to self-reported deciles in the national income distribution. While these do not provide perfectly comparable and objective income measures across countries, they still serve as a comparable indicator of income within countries. ${ }^{16}$ As for a measure of usage of information technologies, respondents were asked the following question: "People use different sources to learn what is going on in their country and the world. For each of the following sources, please indicate whether you used it last week or did not use it last week to obtain information: daily newspaper, news broadcasts on radio or TV, printed magazines, in-depth reports on radio or TV, books, internet and e-mail, talk with friends or colleagues." We define binary variables that take the value of 1 if the respondent used the sources of information, and a value of 0 otherwise. Arguably, those people who report using the internet as a source of information are also those people who use the internet very often and those respondents who do not use the internet as source of information are also less frequent users of the internet in general. Using the internet as a source of information thus seems to provide an adequate proxy for the usage of the internet in general.

Around $30 \%$ of the respondents in the sample stated that they had used the internet or e-mail as sources of information. Thus, in comparison, the internet is still the least often used source of information. $59 \%$ of the people used the daily newspaper, $35 \%$ used magazines, $31 \%$ used books. $90 \%$ of the respondents followed daily news broadcasts on radio or TV and $66 \%$ followed in-depth reports on these media. Finally, $77 \%$ of all individuals in the sample reported that they had stayed informed through friends and work colleagues. Multiple answers were possible

\footnotetext{
${ }^{15}$ We thus build on the presumption that reported satisfaction scores convey some information about utility, an assumption commonly made in both the theoretical and empirical happiness literature on the grounds that life satisfaction statements and economic decision-making are highly correlated (e.g., van Praag 2011; Clark et al. 2008; Frey and Stutzer 2002; Kahneman et al. 2004; Ferrer-i-Carbonell 2012; Clark and Oswald 1996; van Praag 2011; Benjamin et al. 2012).

${ }^{16}$ To verify that our results are not driven by the imperfect measure of income, we also replicate the results from the WVS with the longitudinal GSOEP dataset that has precise information on income at the household-level. Estimating within-household regressions, we find that the estimated relationship between life satisfaction, income, and ICT usage from the WVS is not sensitive to this proxy measure of income. Results are provided in table 2 .A.2 in the appendix.
} 
Table 2.2: Internet access by income groups

\begin{tabular}{lcccccccccc}
\hline \hline Income Decile & 1 & 2 & 3 & 4 & 5 & 6 & 7 & 8 & 9 & 10 \\
\hline Internet / E-Mail & 12.0 & 14.3 & 19.3 & 24.7 & 27.9 & 35.2 & 41.4 & 43.7 & 55.2 & 62.1 \\
Low-income countries & 7.5 & 5.3 & 8.3 & 14.2 & 16.8 & 19.4 & 21.2 & 28.3 & 36.9 & 27.5 \\
Lower middle-income countries & 3.3 & 6.1 & 8.6 & 10.9 & 15.3 & 19.4 & 24.8 & 25.8 & 24.9 & 21.4 \\
Upper middle-income countries & 6.1 & 9.6 & 13.1 & 18.7 & 22.7 & 29.8 & 31.3 & 35.7 & 40.9 & 48.6 \\
High-income countries & 31.6 & 30.3 & 37.4 & 44.2 & 46.4 & 55.1 & 64.6 & 66.5 & 76.8 & 77.8 \\
\hline \hline Source: World Values Survey, Wave 5 (2005-2007)
\end{tabular}

and the responses are positively correlated. ${ }^{17}$ As for those respondents using the internet, $79 \%$ used newspapers, $94 \%$ watched daily news and $75 \%$ followed in depth-reports on TV, and roughly every second person also used books or magazines.

Table 2.2 shows that there is large variation in internet access across income groups within a country as well as across countries in different stages of development when the countries are grouped into four categories according to the World Bank (2012a) classification. Internet access is found to be most diffused in high-income countries and higher parts of individual countries' income distributions. While only $12 \%$ of all respondents in the lowest income decile said that they used the internet at least once a week, of those in the highest income bracket $62 \%$ reported doing so. This pattern points to the fact that internet is, in many countries, still one of the more expensive sources of information. ${ }^{18}$ The share of users almost quadruples from the lowest to higher income deciles in low-income countries ( $7.5 \%$ to around $27.5 \%)$. In high-income countries, $32 \%$ of those people at the bottom of the income distribution use the internet regularly.

The choice of control variables is motivated by the existing literature on subjective well-being and the usage of information technologies. According to existing studies on the micro-level determinants of internet use, e.g., Chaudhuri et al. (2005), socio-demographics, income and education are among the major predictors. As for socio-demographic control variables, we employ standard regressors from well-being regressions (e.g., McBride 2001; Stutzer 2004; Dolan et al. 2008; Bjørnskov et al. 2008; Di Tella et al. 2003), namely the respondent's age, marital status, labour market status, educational attainment, and subjective health status. Additionally, we consider a number of softer attitudinal characteristics - trust, honesty, and perception of freedom - that could potentially also affect the propensity to buy access to ICTs. As for their precise definition, we stay in line with Bruni and Stanca (2006). On the macro side, the diffusion of ICTs is likely to be highly dependent on the general economic performance of a country. For this reason, and to capture economic, societal and cultural differences in reported

\footnotetext{
${ }^{17}$ All pairwise correlation coefficients are significantly different from zero.

${ }^{18}$ Other sources of information, not shown here, are used more extensively across all income brackets.
} 
life satisfaction that are common within countries, we also include country fixed effects in all the regressions. This also accounts for the empirical fact that measures of subjective well-being are hardly comparable across different countries (Diener and Oishi 2004). Including all control variables, we are left with 53,325 observations from 49 countries.

\subsubsection{Results}

As a starting point, we only look at the internet as the ICT of interest. Table 2.3 provides regression results from both OLS and ordered probit estimations. The partial correlations of the control variables are in line with the existing literature (e.g., McBride 2001; Stutzer 2004; Dolan et al. 2008; Bjørnskov et al. 2008; Di Tella et al. 2003; Bruni and Stanca 2006). As expected, we find income to be strongly and positively correlated with life satisfaction in the least squares specification. The results also show that the usage of the internet as a source of information is associated with a highly significant increase in life satisfaction. This is consistent with the hypothesis that people derive satisfaction from using the internet, possibly because it serves as a source of information or because it allows them to engage in other happiness-giving activities.

Scrutinising the nexus between ICTs, income, and subjective well-being, the interaction term between income and internet in the OLS specification is found to be significantly negative. In fact, the positive satisfaction effect of additional income in the form of being in a higher income decile is reduced by more than $40 \%{ }^{19}$

By construction, the negative interaction effect would also imply that going down one rung on the income ladder is associated with a smaller loss of satisfaction for those who use the internet. To allow for asymmetric effects, we relax the restrictive assumption that the income and interaction effects are homogeneous across all income groups but turn to the more flexible estimation given by equation (2.3) in what follows. This also addresses concerns of potential functional form misspecification for the relationship between income and life satisfaction, which might have driven the results in table 2.3. Due to the ordinal dimension of our dependent variable, we focus on the results of the more adequate ordered probit model in the remaining analyses.

To test our hypothesis of different income effects by usage of the internet and by different income groups, we calculate the marginal effects of income on the probability of reporting the highest

\footnotetext{
${ }^{19}$ We also allow for less restrictive specifications where the effect of income as well as the income differential by internet usage may vary with age. Using OLS regressions, we find the effect of income on life satisfaction to be marginally decreasing in age. The estimated interaction effect between internet usage, however, does not change in terms of magnitude or statistical significance (the estimated coefficient is -0.09 with a p-value of 0.003). Furthermore, there is no evidence that the interaction varies with the age of the respondents (the p-value of the triple interaction is 0.785 ).
} 
Table 2.3: Determinants of life satisfaction - Least squares and ordered probit

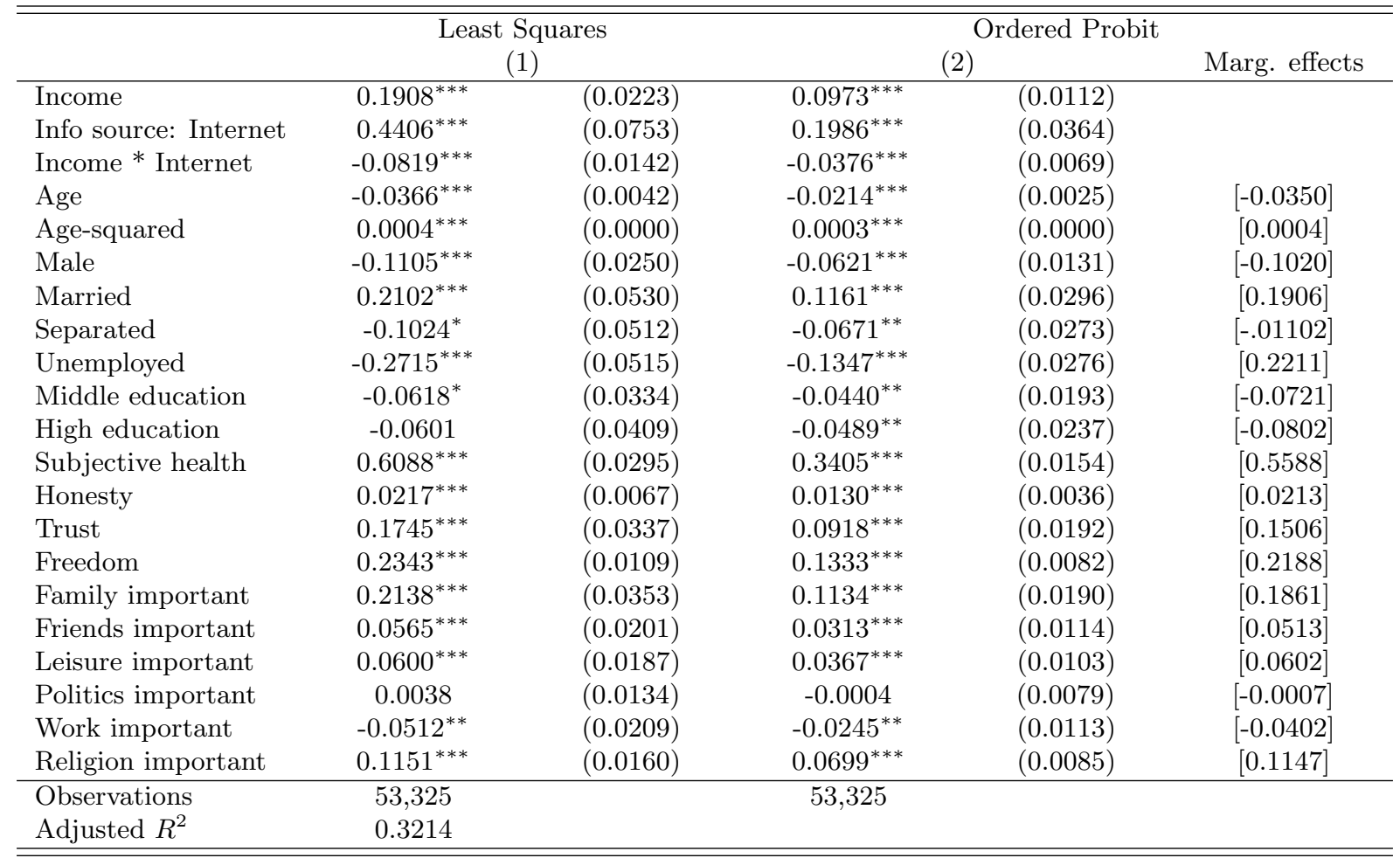

Dependent variable: Life Satisfaction (1-10)

Standard errors, clustered at the country level, in parentheses. $* * * / * * *$ : significant at $1 \% / 5 \% / 10 \%$.

49 country dummies are included as additional controls.

Source: World Values Survey, Wave 5 (2005-2007)

category of life satisfaction differentiating by users and non-users of the internet. As table 2.4 shows, we find all the estimated marginal effects for income to be positive and significant for the group of non-users. A rise in income up to the eighth income decile is associated with a higher probability to report high life satisfaction. For people who use the internet regularly, it is only from the fifth income decile onwards that there are significantly positive income effects on life satisfaction.

More importantly, the last column of table 2.4 gives the contrast in marginal effects of income between internet users and non-users. ${ }^{20}$ Given a confidence level of $95 \%$, we find the increase in life satisfaction associated with a higher income to be significantly lower for internet users than for non-users from the sixth income decile on. The difference in marginal effects rises from slightly above two percentage points in the sixth income decile to almost five percentage points in higher income deciles. For the fifth income decile, for instance, the marginal effect of income on life satisfaction is reduced by roughly $35 \%$. The highest relative difference occurs for the eighth income decile with a reduction of more than $42 \%$ - a similar magnitude as for the interaction

\footnotetext{
${ }^{20}$ The difference is the percentage points that the marginal effect of income on the likelihood to report the highest category of life satisfaction is larger for internet users than for non-users.
} 
Table 2.4: Marginal effects of income on life satisfaction by internet users

\begin{tabular}{|c|c|c|c|c|c|c|}
\hline & \multicolumn{2}{|c|}{ Without internet } & \multicolumn{2}{|c|}{ With internet } & \multicolumn{2}{|c|}{ Difference } \\
\hline 1st decile & \multicolumn{6}{|c|}{ (omitted) } \\
\hline 2nd decile & $0.01037^{* *}$ & $(0.0047)$ & -.00150 & $(.0078)$ & -0.0119 & $(0.0096)$ \\
\hline 3rd decile & $0.0158^{* * *}$ & $(.0057)$ & 0.0103 & $(0.0094)$ & -0.0055 & $(0.0100)$ \\
\hline 4th decile & $0.0289^{* * *}$ & $(0.0067)$ & 0.0115 & $(0.0088)$ & $-0.0174^{*}$ & $(0.0089)$ \\
\hline 5 th decile & $0.0539^{* * *}$ & $(0.0111)$ & $0.0352^{* * *}$ & $(0.0090)$ & $-0.0187^{*}$ & $(0.0109)$ \\
\hline 6 th decile & $0.0676^{* * *}$ & $(0.0108)$ & $0.0427^{* * *}$ & $(0.0103)$ & $-0.0248^{* *}$ & $(0.0105)$ \\
\hline 7th decile & $0.0922^{* * *}$ & $(0.0118)$ & $0.0583^{* * *}$ & $(0.0125)$ & $-0.0339^{* * *}$ & $(0.0093)$ \\
\hline 8th decile & $0.1175^{* * *}$ & $(0.0144)$ & $0.0680^{* * *}$ & $(0.0157)$ & $-0.0495^{* * *}$ & $(0.0123)$ \\
\hline 9th decile & $0.1079^{* * *}$ & $(0.0192)$ & $0.0730^{* * *}$ & $(0.0152)$ & $-0.0348^{* *}$ & $(0.0157)$ \\
\hline 10th decile & $0.1129^{* * *}$ & $(0.0227)$ & $0.0680^{* * *}$ & $(0.0179)$ & $-0.0449^{* *}$ & $(0.0137)$ \\
\hline Observations & \multicolumn{6}{|c|}{53,325} \\
\hline
\end{tabular}

Ordered probit estimation of (2.3).

Marginal effects are calculated for the probability to report the highest level of life satisfaction.

Standard errors, clustered at the country level, in parentheses. $* * * / * * *$ : significant at $1 \% / 5 \% / 10 \%$.

Source: World Values Survey, Wave 5 (2005-2007)

effect in the OLS analysis in table 2.3. For lower income groups, we do not find a statistically significant difference in the marginal effects of income. Against the background that we are performing a cross-sectional analysis and identification comes from comparing incomes and ICT possession between individuals, these results imply that higher incomes yield less life satisfaction for internet users than for non-users. This is consistent with the rationale that internet access increases material aspirations which in turn are negatively linked to subjective well-being.

So far, we considered the internet as the only technology in our regression. Arguably, the internet is qualitatively different from other sources of information, for the scope of information that can be acquired is typically much wider and it allows for much more interpersonal interaction than, for example, radio or TV. Also, processing of information from the internet might happen more consciously and actively than if information would be passively acquired through TV programmes. We therefore might expect material aspiration effects to be stronger when the internet is used as a source of information. For a formal test, we include all the information technologies that were covered by the WVS in the empirical model. We find the differences in marginal effects of income between users of the respective sources of information and non-users to be statistically insignificant for most sources of information. The internet is the only technology for which income effects are systematically different for middle- to high-income groups. Respective distributions of the marginal effects for each information source are provided in figure 2.A.4 in the appendix. Of course, the usage of different sources of information is positively correlated in most cases. People who watch TV are also more likely to use the internet. Finding different patterns for different sources of information thus puts high demands on variation in the WVS dataset. 
Finally, our results are potentially challenged by a number of endogeneity concerns which might prevent the identification of the causal effect of ICTs on the satisfaction effect of income. We choose to analyse the WVS since it reflects a broad set of countries. One obvious limitation of the WVS dataset is that we can only control for individual heterogeneity based on observable characteristics. Using single-country longitudinal data from the GSOEP, however, we find that the central results on differential income effects hold when controlling for unobserved time-invariant characteristics. More specifically, the positive effect of income on life satisfaction is found to be reduced by about one fifth if a household has internet access, even after introducing household fixed effects. Table 2.A.2 in the appendix provides the corresponding regressions results. The results from the WVS therefore are unlikely to be biased by unobserved time-invariant heterogeneity. ${ }^{21}$

\subsection{Conclusion}

There is now robust evidence from the emerging literature on the economics of happiness that individual subjective well-being is influenced by relative concerns with respect to the social environment. What has only attained limited attention in previous research is the role of information in shaping these relative concerns. Using two micro-datasets with information on life satisfaction, a level of reference income, and usage of modern media, we empirically test whether access to the internet (i) raises material aspirations and (ii) explains differences in the effects of income on reported life satisfaction. Our results show that households in possession of a computer report higher material aspirations than those without in areas with an advanced degree of internet infrastructure. Cross-sectional evidence from the fifth wave of the World Values Survey (2005-2007) suggests that individuals who regularly use the internet as a source of information derive less life satisfaction from higher incomes. In summary, the empirical results suggest that internet access lowers the satisfaction that people derive from their income position and that one explanation for this pattern lies in the positive link between internet access and aspired incomes against which actual incomes are evaluated.

The findings on the role of ICTs for material aspirations in this paper provide new insights on the relationship between globalisation and subjective well-being. While the literature has so far mostly focused on the impact of economic globalisation, we contribute to the burgeoning literature on the microeconomic implications of social globalisation on well-being. Investigating the determinants of material aspirations is particularly intriguing for the discussion in the

\footnotetext{
${ }^{21}$ The results are furthermore robust to using a different measure of computer and internet usage. In the WVS, respondents were also asked how often they made private use of a personal computer. In a sensitivity analysis we separated the sample into two groups with different frequencies of usage: "frequent/occasional usage" and "no usage". Regression results are available upon request.
} 
happiness literature on how income translates into well-being. In line with Easterlin (1995), our findings underscore the notion of external and internal norms to evaluate well-being and suggest a vital role for information technologies. Furthermore, material aspirations and positionality concerns matter if we want to understand how individuals make economic decisions within their social environment. Banerjee and Duflo (2011), for instance, document the consumption of status goods despite low levels of income while Hill and Buss (2010) report that increasing positional concerns can alter the certainty effect in decisions under risk. Finally, our results augment the literature on the determinants of reference groups for interpersonal (income) comparisons. Clark and Senik (2010b), for instance, conjecture that in the future ICT-driven material aspiration effects might be particularly relevant for less developed countries which currently experience drastic advancements in information technology infrastructure. As a result, cross-national standard of living comparisons might gain in importance (see also James 1987).

There are some limitations to our observational study. Most importantly, we are not able to specify an exact channel through which material aspirations enter the well-being function. We do have some indication that ICT access raises the level of reference income, but we cannot identify whether this is driven by internal or external norms. ICTs might allow for stronger comparisons vis-à-vis a given reference group (potentially including the individual themselves), but are also likely to change the entire scope of reference. Such detailed analyses of how informational globalisation changes the nature of reference group formation provide interesting scope for further research. 


\section{A Appendix}

Table 2.A.1: The minimum-income question and life satisfaction

\begin{tabular}{|c|c|c|c|c|}
\hline (Log) Income & $\begin{array}{c}(1) \\
0.3956^{* * *} \\
(0.0382)\end{array}$ & $(2)$ & $\begin{array}{c}(3) \\
0.4412^{* * *} \\
(0.0392)\end{array}$ & $(4)$ \\
\hline (Log) Minimum income & & $\begin{array}{c}-0.0712^{* *} \\
(0.0284)\end{array}$ & $\begin{array}{c}-0.1475^{* * *} \\
(0.0291)\end{array}$ & \\
\hline Log (Actual income) - Log (Min. income) & & & & $\begin{array}{c}0.2409^{* * *} \\
(0.0258)\end{array}$ \\
\hline Age & $\begin{array}{l}0.0894^{*} \\
(0.0477)\end{array}$ & $\begin{array}{c}0.1035^{* *} \\
(0.0467)\end{array}$ & $\begin{array}{l}0.0923^{*} \\
(0.0471)\end{array}$ & $\begin{array}{c}0.1011^{* *} \\
(0.0463)\end{array}$ \\
\hline Age-squared & $\begin{array}{c}-0.0002^{* * *} \\
(0.0001)\end{array}$ & $\begin{array}{c}-0.0003^{* * *} \\
(0.0001)\end{array}$ & $\begin{array}{c}-0.0002^{* * *} \\
(0.0001)\end{array}$ & $\begin{array}{c}-0.0003^{* * *} \\
(0.0001)\end{array}$ \\
\hline (Log) Years of education & $\begin{array}{l}-0.3768 \\
(0.3118)\end{array}$ & $\begin{array}{c}-0.2829 \\
(0.3119)\end{array}$ & $\begin{array}{l}-0.3064 \\
(0.3138)\end{array}$ & $\begin{array}{c}-0.2290 \\
(0.3139)\end{array}$ \\
\hline$(\log +1)$ Number of children & $\begin{array}{l}-0.0498 \\
(0.0413)\end{array}$ & $\begin{array}{c}-0.1028^{* *} \\
(0.0412)\end{array}$ & $\begin{array}{l}-0.0395 \\
(0.0413)\end{array}$ & $\begin{array}{c}-0.0648 \\
(0.0412)\end{array}$ \\
\hline (Log) Household size & $\begin{array}{l}-0.0752 \\
(0.0539)\end{array}$ & $\begin{array}{c}0.1873^{* * *} \\
(0.0502)\end{array}$ & $\begin{array}{l}-0.0628 \\
(0.0539)\end{array}$ & $\begin{array}{l}0.0858^{*} \\
(0.0495)\end{array}$ \\
\hline Married & $\begin{array}{c}0.0728 \\
(0.0451)\end{array}$ & $\begin{array}{c}0.1015^{* *} \\
(0.0452)\end{array}$ & $\begin{array}{l}0.0832^{*} \\
(0.0450)\end{array}$ & $\begin{array}{c}0.1028^{* *} \\
(0.0450)\end{array}$ \\
\hline Unemployed & $\begin{array}{c}0.0240 \\
(0.0397)\end{array}$ & $\begin{array}{c}-0.0760^{*} \\
(0.0389)\end{array}$ & $\begin{array}{c}0.0159 \\
(0.0396)\end{array}$ & $\begin{array}{c}-0.0419 \\
(0.0389)\end{array}$ \\
\hline Employed part-time & $\begin{array}{c}-0.0067 \\
(0.0339)\end{array}$ & $\begin{array}{c}-0.0667^{* *} \\
(0.0339)\end{array}$ & $\begin{array}{l}-0.0122 \\
(0.0339)\end{array}$ & $\begin{array}{c}-0.0472 \\
(0.0336)\end{array}$ \\
\hline Household-FE & Yes & Yes & Yes & Yes \\
\hline Year-State-FE & Yes & Yes & Yes & Yes \\
\hline Observations & 46011 & 46011 & 46011 & 46011 \\
\hline$R^{2}$ & 0.024 & 0.018 & 0.025 & 0.023 \\
\hline Mean of dependent variable & 7.03 & 7.03 & 7.03 & 7.03 \\
\hline
\end{tabular}

Linear within-panel regressions. Dependent variable: General life satisfaction (0-10).

Standard errors, clustered at the respondent level, in parentheses. ${ }^{*} p<0.1,{ }^{* *} p<0.05,{ }^{* * *} p<0.01$.

Source: German Socio-Economic Panel (GSOEP). Years 2002, 2007, and 2012. 
Table 2.A.2: The differential in satisfaction derived from income by internet access

\begin{tabular}{|c|c|c|c|c|}
\hline & \multicolumn{2}{|c|}{ (1) } & \multicolumn{2}{|c|}{ (2) } \\
\hline (Log) Income & $0.3848^{* * *}$ & $(0.0322)$ & $0.3702^{* * *}$ & $(0.0359)$ \\
\hline Internet & $0.8216^{* * *}$ & $(0.2423)$ & $0.6331^{* *}$ & $(0.2509)$ \\
\hline Internet $*(\log )$ Income & $-0.1075^{* * *}$ & $(0.0315)$ & $-0.0763^{* *}$ & $(0.0327)$ \\
\hline Age & & & 0.0220 & $(0.0357)$ \\
\hline Age-squared & & & $-0.0004^{* * *}$ & $(0.0001)$ \\
\hline (Log) Years of education & & & $-1.0433^{* * *}$ & $(0.2036)$ \\
\hline$(\log +1)$ Number of children & & & $-0.0783^{* *}$ & $(0.0327)$ \\
\hline (Log) Household size & & & -0.0314 & $(0.0398)$ \\
\hline Married & & & $0.1325^{* * *}$ & $(0.0378)$ \\
\hline Unemployed & & & $-0.0914^{* * *}$ & $(0.0290)$ \\
\hline Employed part-time & & & $-0.0750^{* * *}$ & $(0.0228)$ \\
\hline Household-FE & Yes & & Yes & \\
\hline Year-State-FE & No & & Yes & \\
\hline Observations & 91694 & & 87673 & \\
\hline$R^{2}$ & 0.005 & & 0.018 & \\
\hline Mean of dependent variable & 6.90 & & 6.89 & \\
\hline
\end{tabular}




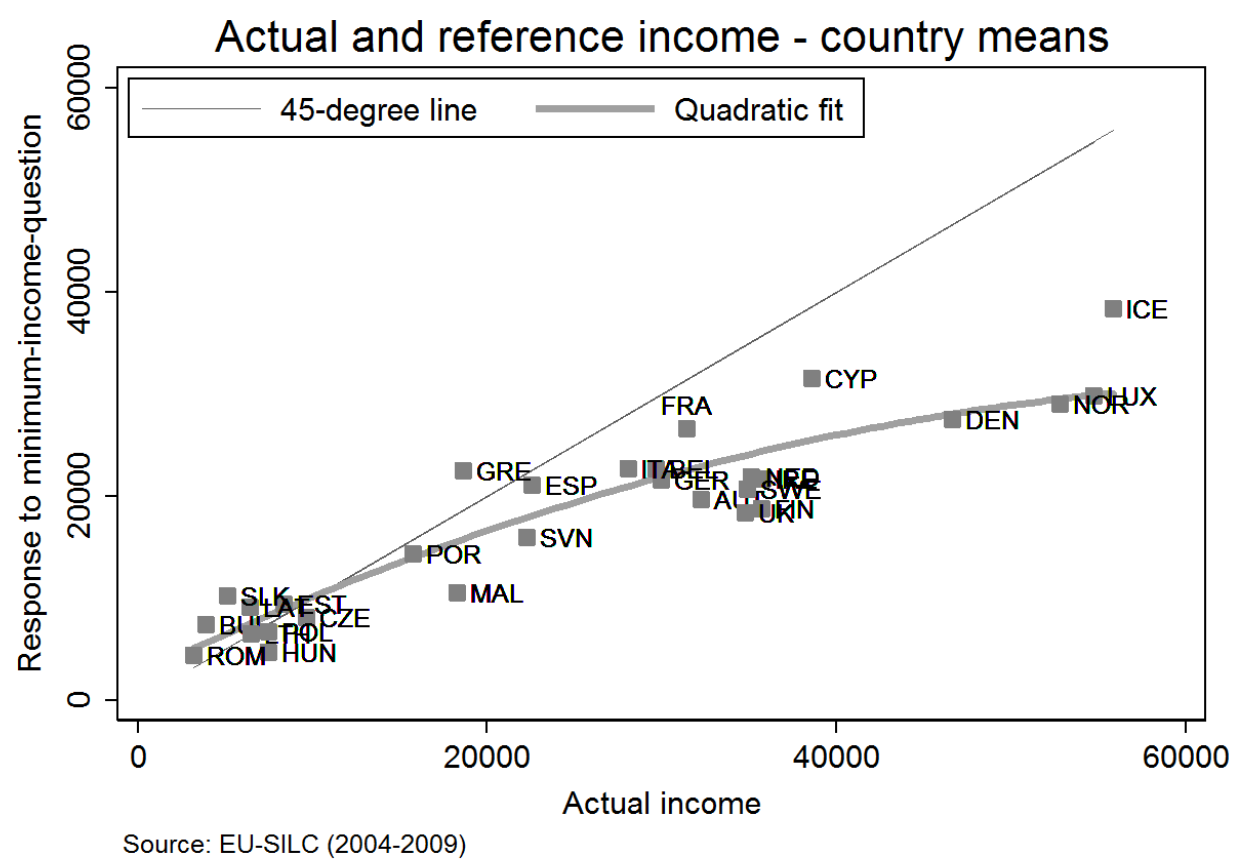

Figure 2.A.1: Response to minimum-income question and actual household income, in USD

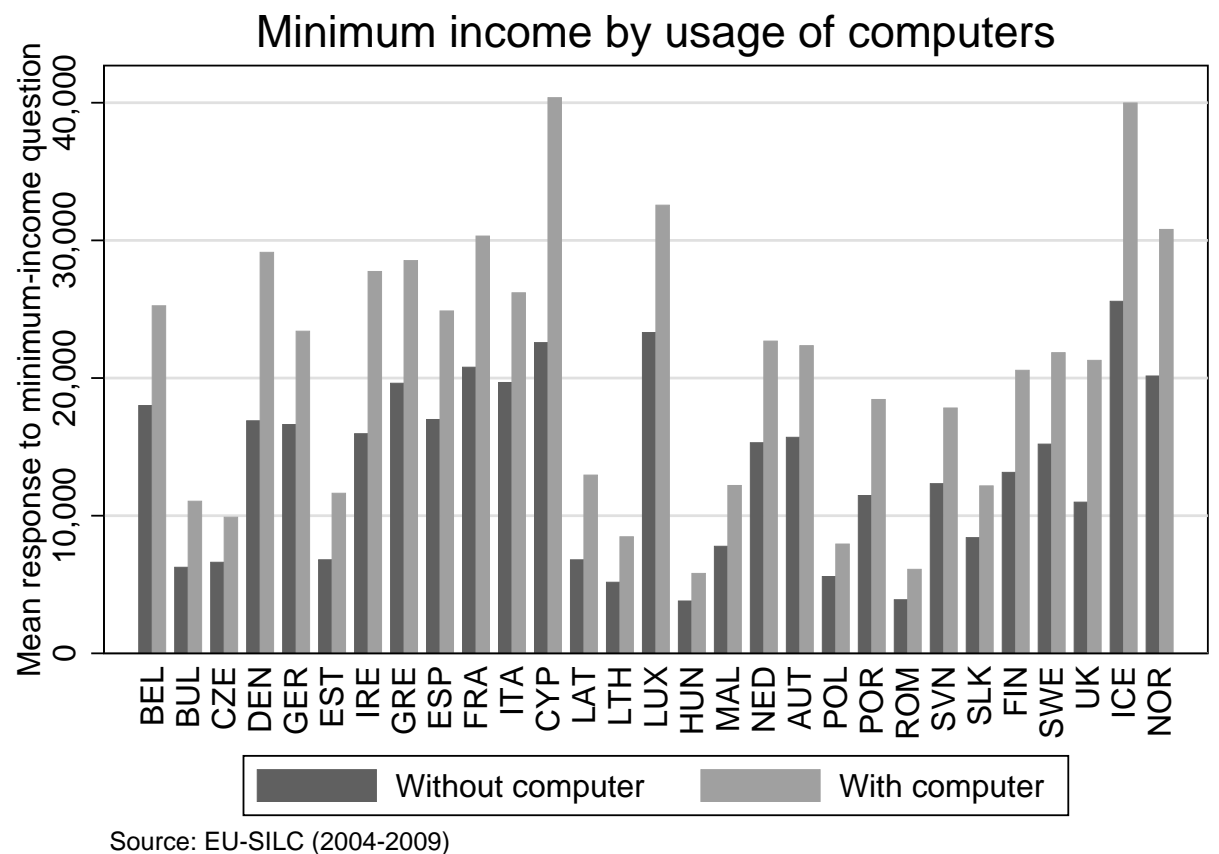

Figure 2.A.2: Difference in response to minimum-income question by computer possession 


\section{Share of households with a computer over time}
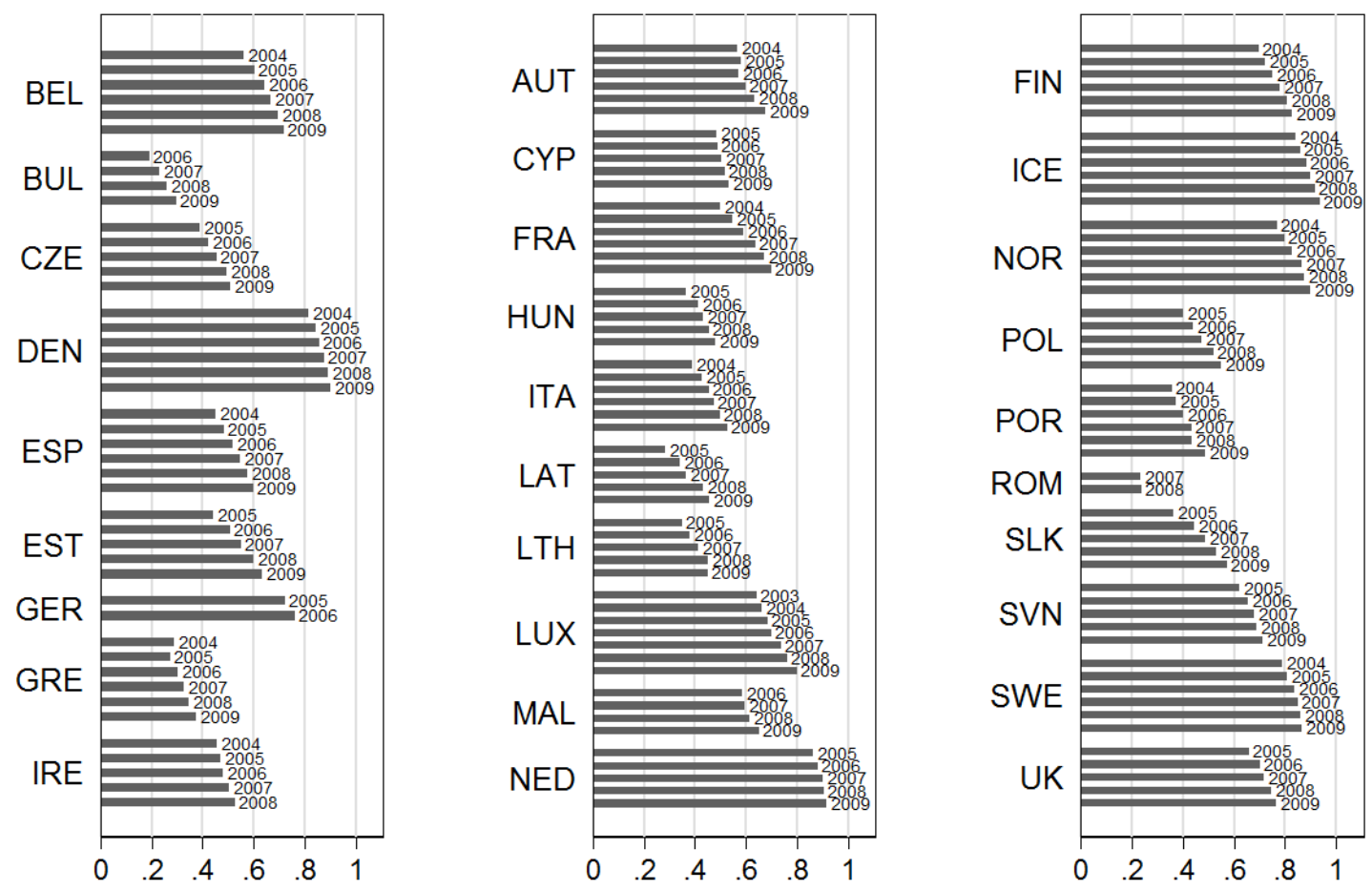

Source: EU-SILC (2004-2009)

Figure 2.A.3: Computer possession over the sample period

Table 2.A.3: Determinants of subjective minimum-income, Robustness checks

\begin{tabular}{|c|c|c|c|c|c|c|c|c|}
\hline & \multicolumn{2}{|c|}{ (1) } & \multicolumn{2}{|c|}{$(2)$} & \multicolumn{2}{|c|}{$(3)$} & \multicolumn{2}{|c|}{ (4) } \\
\hline Computer & $0.0425^{* * *}$ & $(0.0081)$ & $0.0403^{* * *}$ & $(0.0076)$ & $0.0362^{* * *}$ & $(0.0067)$ & $0.0409^{* * *}$ & $(0.0077)$ \\
\hline TV & $0.0432^{* * *}$ & $(0.0090)$ & $0.0423^{* * *}$ & $(0.0091)$ & $0.0293^{* * *}$ & $(0.0063)$ & $0.0422^{* * *}$ & $(0.0091)$ \\
\hline Phone & -0.0108 & $(0.0312)$ & -0.0136 & $(0.0309)$ & -0.0221 & $(0.0332)$ & -0.0144 & $(0.0307)$ \\
\hline Income & $0.0000^{* * *}$ & $(0.0000)$ & & & & & & \\
\hline Income-squared & $-0.0000^{* * *}$ & $(0.0000)$ & & & & & & \\
\hline Wage decile & & & $0.0286^{* * *}$ & $(0.0028)$ & & & & \\
\hline Log(Income) & & & & & $0.1118^{* * *}$ & $(0.0160)$ & $0.1160^{* * *}$ & $(0.0169)$ \\
\hline Observations & 791,551 & & 791,551 & & 791,174 & & 791,551 & \\
\hline Controls as in table 2.1 & Yes & & Yes & & Yes & & Yes & \\
\hline Year-FE & Yes & & Yes & & Yes & & Yes & \\
\hline Country-Year-FE & Yes & & Yes & & Yes & & Yes & \\
\hline Other assets & No & & No & & Yes & & No & \\
\hline Occupation-FE & No & & No & & No & & Yes & \\
\hline
\end{tabular}

Dependent variable: Logged minimum income to make ends meet. Fixed-effects within panel regressions.

Standard errors, clustered at the country level, in parentheses. ${ }^{* * *} /{ }^{* *} / *$ : significant at $1 \% / 5 \% / 10 \%$

Source: EU-SILC (2004-2009) 

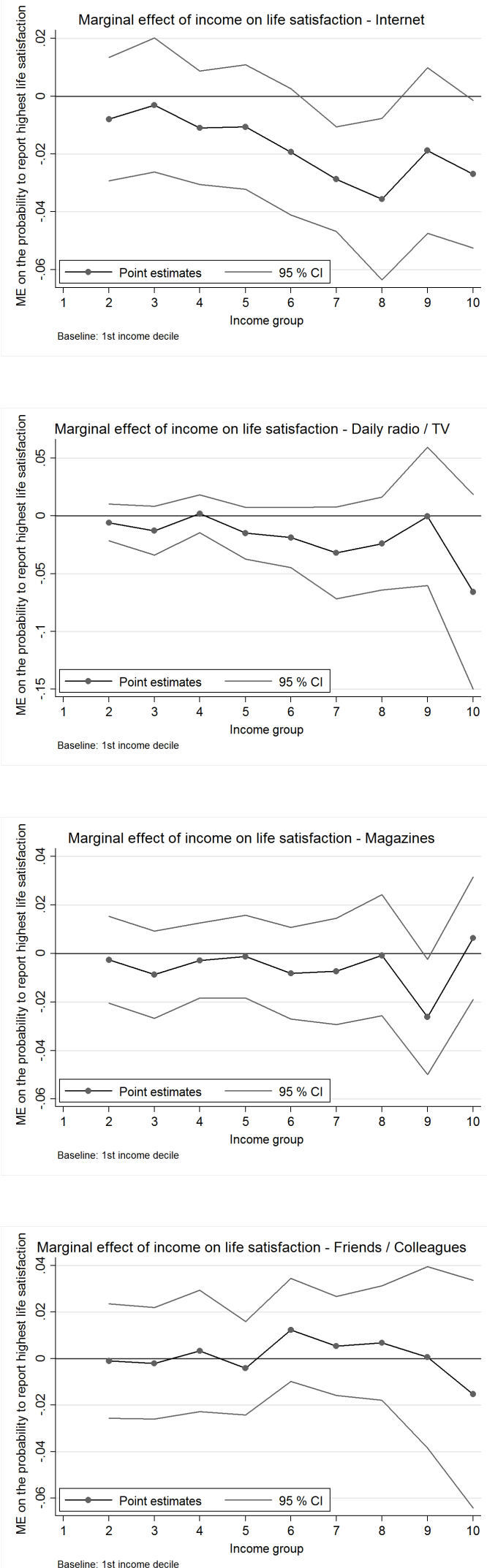

Figure 2.A.4: Contrast in marginal effects of income by sources of information
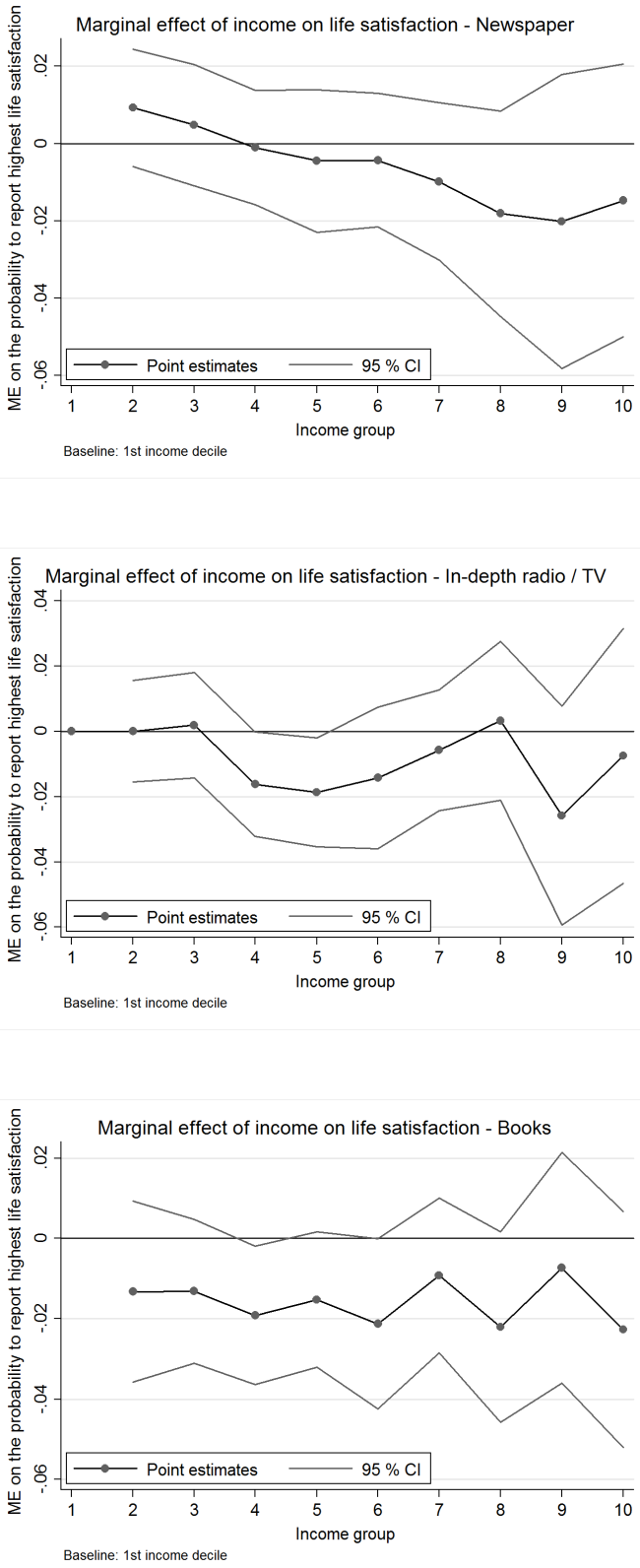


\title{
3 The Effect of Drought on Health Outcomes and Health Ex- penditures in Rural Vietnam
}

This essay has been published in World Development.

\begin{abstract}
This paper quantifies the short-term impact of drought on health conditions and health expenditures. Using panel data from rural Vietnam and rainfall data in an Instrumental Variable approach, the results suggest that populations face an increased risk of illness in the year they are exposed to drought. Households with reduced agricultural incomes and limited access to coping mechanisms seem particularly affected. Drought-related health shocks also cause financial burden for many households, with health expenditures increasing by 9-17\% of total consumption. This paper contributes to a literature which so far has mostly focused on the long-term consequences of climate shocks.
\end{abstract}

This essay is joint work with Tobias Lechtenfeld. We would like to thank Axel Dreher, Stephan Klasen, Sebastian Vollmer as well as participants of the DIW Berlin Workshop "Climate shocks and household behavior", the "Spring Meeting of Young Economists 2014" in Vienna, and the "Annual Conference of the German Development Economics Association 2014" in Passau for helpful comments. Theres Kluehs and Jennifer Phillips provided excellent research assistance. Financial support from the German Research Foundation within the project "DFG-FOR 756: Vulnerability to Poverty in Southeast Asia" is gratefully acknowledged. 
"Extreme weather linked to climate change is increasing and will likely cause more disasters. Such disasters, especially those linked to drought, can be the most important cause of impoverishment, cancelling progress on poverty reduction."

(Overseas Development Institute, 2013, p. vii))

\subsection{Introduction}

As the frequency of climate shocks increases rapidly across the world, researchers and policy makers alike recognize the enormous cost developing countries face from the damage done to infrastructure, crop production, and most importantly, human development and human lives (IPCC, 2012). In fact, for most countries weather shocks are the single most important cause that pushes households below the poverty line and keeps them there (World Bank, 2013). The second most important cause relates to health shocks, which are highly correlated with weather shocks such as floods and droughts. Given that climate shocks affect a wide range of socio-economic outcomes, understanding their precise effects is at the core of designing effective policies and institutions to mitigate their consequences (Skoufias, 2003).

Vietnam is among the countries most frequently affected by extreme weather. With a very long coastline in tropical South-East Asia, the country is prone to strong typhoons during the monsoon season. Rainfall patterns are very volatile and in 40 of the past 50 years, droughts have occurred in different extents and locations across Vietnam. Particularly in rural areas dependent on agriculture, sufficient rainfall is crucial for subsistence and income generation (Nguyen, 2011). In fact, despite Vietnam's impressive record on economic growth and poverty reduction, one out of five Vietnamese continues to live on less than 1.25 USD a day. In addition, many households earn barely more than the poverty line (World Bank, 2012c). Weather shocks frequently affect poor and vulnerable households and push families into poverty, especially in rural parts of the country (Klasen et al., 2014; Arouri et al., 2015).

Most of the existing epidemiology and economics literature estimates the long-term effects of drought on health outcomes during adult-life, i.e., after a decade and more. ${ }^{22}$ While very different methods are used to identify droughts in historic data, it has been well established that lack of rainfall can have substantial health effects on children and adults later in life. Hoddinott and Kinsey (2001), for instance, find that children aged 12 to 24 months lose 1.5 to $2 \mathrm{~cm}$ of growth in the aftermath of a drought where annual rainfall decreased by 20-30 \% compared to long-term average rainfall. Their evidence shows that poor households and girls are especially vulnerable. The catch-up growth of these children is limited causing this growth faltering to

\footnotetext{
${ }^{22}$ See, e.g., Dell et al. (2014) for a recent review of the climate-economy literature.
} 
have a permanent effect. Yamano et al. (2005) reach similar conclusions in a study from Ethiopia conditional on the absence of food aid. Looking at child mortality in the aftermath of drought, Rose (1999) reports that during years with significantly more rainfall than the historic average the survival rates of girls increase relative to boys.

A second, related strand of literature examines to what extent early-life rainfall has lasting effects on health, education, and socioeconomic outcomes during adulthood. Maccini and Yang (2009) find that higher rainfall (compared to a district's long-term average) during birth years has large positive effects on the adult outcomes of women, but not of men: Women born in years with higher rainfall (relative to the local norm) are taller, complete more schooling grades, and live in households scoring higher on an asset index. Schooling attainment appears to mediate the impact on adult women's socioeconomic status. Using longitudinal datasets from Zimbabwe and Tanzania, Alderman et al. (2006) and Alderman et al. (2009) document that prolonged periods of drought during the pre-school age have adverse effects on nutritional status and subsequent child growth as well as on lifetime earning capacity due to both delays in schooling and declines in total schooling, including years of education and delay in enrollment. In sum, children growing up during an extended drought episode can suffer from under-investments in schooling and earn lower incomes throughout their lives. With about $85 \%$ of rural households in Vietnam being farms and about two thirds growing rice, droughts can create intense pressure on rural livelihoods.

The short-term health impacts of drought on health outcomes within one year are not as well established. In addition, the health-related economic costs of drought are largely unknown at the micro level. The literature from developing countries points to three primary channels through which drought can affect health outcomes and expenditures, namely food shortages, price effects, and scarcity of potable water (for a comprehensive literature review see Kovats et al. (2003)). First, droughts tend to have detrimental effects on the quality and quantity of agricultural output. As a consequence, food shortages and lower income from agricultural sources can cause a substantial deterioration of nutritional intake among children and adults, leading to malnutrition and an impaired immune system (Vu and Glewwe, 2011). Second, spikes in local food prices due to reductions in aggregate food production can further precipitate this effect, in particular when markets are fragmented (CDC, 2010; World Bank, 2010, 2012b; Warner and van der Geest, 2013). Third, drought conditions can lead to increased infectious diseases due to scarcity of potable water (CDC, 2010; World Bank, 2010). The breeding and survival of disease vectors also increases the risk of infections (Kovats et al., 2003). In addition, for the case of Vietnam, degraded soil conditions can increase the physical burden from on-farm labor 
in rural households who engage in cropping (Burgess et al., 2011).

This paper provides new estimates on the short-term effects of drought on health outcomes and health-related expenditures for households in rural Vietnam. Using data on local rainfall, this study identifies episodes of drought by comparing current precipitation patterns with historic trends. By following households over four panel waves between 2007 and 2013, the analysis exploits variation over time and space. Methodologically, the empirical analysis comes in two parts. In a first part, variations in local rainfall are related to individual indicators of health conditions in order to estimate the direct impact of drought on health outcomes. To unravel potential transmission channels, the analysis also assesses the relationship of drought-related health shocks with regard to the performance of the agricultural sector and specifies which economic characteristics drive a household's vulnerability to drought. The second part quantifies the effect of drought on health expenditures, using an Instrumental Variable (IV) approach in which the incidence of health shocks is estimated using varying degrees of drought intensity.

The results reveal the immediate burden of drought in terms of human health and contribute to closing a gap in the development literature on the short-term health effects of drought. Specifically, the empirical results suggest that drought negatively affects agricultural production as well as revenues from crop sales for the surveyed households in rural Vietnam. Comparing the most with the least drought-affected households in the sample, the estimated effects amount to reductions of more than $40 \%$. As for the impact on health conditions, there is evidence that drought increases the probability of being affected by disease, particularly when households experience significant reductions in agricultural production. Given a mean incidence of diseases around $16 \%$ in the sample, a one standard deviation increase in drought severity raises the likelihood of diseases by two percentage points, on average. The adverse effect is found to be more pronounced among households with limited access to coping mechanisms such as selling assets or tapping off-farm income sources. Access to public and private health insurance schemes is not found to robustly reduce the adverse effects of drought on health. In terms of the financial burden on the household budget, the IV estimates suggest that drought-related health shocks cause substantial financial cost. The additional expenditures sum up to around 9 to $17 \%$ of what the median household in the sample spends in terms of total consumption throughout the year. Against the background that the major share of health expenditures is financed out-ofpocket, these findings do not only reveal the direct microeconomic costs of drought events in the short-term, but also show that drought may pose a non-negligible burden for many households vulnerable to poverty in rural Vietnam. These results have important policy implications for risk management, including insurance against adverse weather shocks, and health care financing. 
The remainder of the paper is structured as follows. Section 3.2 briefly discusses the droughthealth nexus in light of recent developments in Vietnam. Section 3.3 details the empirical strategy and section 3.4 introduces the panel dataset and the central variables for the empirical analysis, including the measure of drought. Section 3.5 presents the results with implications on health outcomes and household finances. Section 3.6 offers concluding remarks.

\subsection{Rural Vietnam's vulnerability to drought and health shocks}

Vietnam has an extensive record of climate shocks including drought, commonly defined as prolonged periods of abnormally low rainfall. ${ }^{23}$ In fact, Vietnam ranks thirteenth on an index of the vulnerability to the impacts of climate change. ${ }^{24}$ Over the past decade, episodes of drought have increased both in terms of severity and duration - and so have the associated economic costs (UNISDR, 2011). For a single drought in 2005, for instance, the estimated economic damage was 110 million USD, or roughly $0.2 \%$ of the country's Gross Domestic Product (GDP) (UNISDR, 2011). In the search of explanations for the increasing prevalence of drought-like conditions in Vietnam, external factors (such as poor and unequally distributed rainfall) and internal factors matter. The most important internal causes include ongoing deforestation, the cultivation of water-intensive crops, and increased unregulated industrial activity (NCHMF, 2013). In the widespread absence of large-scale irrigation systems in rural areas, climate shocks will likely continue to affect poor households in the years to come. ${ }^{25}$

Given the distinct features of Vietnam's agrarian economy, several pathways between drought and health outcomes and health expenditures are pertinent. First, poor rainfall conditions likely lead to reduced agricultural output through lower yields, reduced availability of fodder for livestock, and possibly the increase of rice-eating insects (Toulmin, 1987; CDC, 2010; World Bank, 2010, 2012b; Warner and van der Geest, 2013; Gaurav, 2015). In the face of the high dependency on income from crops and livestock that many households in rural Vietnam have, slumps in agricultural income might not only directly lead to the degradation of the supply of food and basic nutrients from subsistence agriculture, but might also lower the ability to secure a sufficient nutritional intake through purchases at local markets. The effect is particularly strong when episodes of drought trigger food price surges, such as for rice, and when consumption

\footnotetext{
${ }^{23}$ In this paper, drought is defined as the annual shortfall in precipitation with regard to historical monthly means.

${ }^{24}$ The country's share of rural population was $71.2 \%$ in 2010 according to the World Bank.

${ }^{25}$ While on a national level almost half of Vietnam's farms use some form of irrigation according to World Bank data, these systems are largely owned by larger farm businesses. Arouri et al. (2015) do not find evidence that the presence of irrigation systems significantly alleviates adverse effects of droughts on household welfare in Vietnam. In the survey sample used for this analysis only $12 \%$ of the farmland does not depend on rainfall for cultivation.
} 
smoothing is limited. ${ }^{26}$ Using data from the 2010 round of the Vietnam Living Standards Survey, Gibson and Kim (2013) provide evidence that increases in food prices are considerably compensated by downgrading the quality of food consumed, i.e., substituting nutrient-rich for staple food. A deterioration in the quality of food consumed can in turn be expected to adversely affect physical conditions and immunity which increases the vulnerability towards both communicable and non-communicable diseases. Higher expenditures for food also reduce the scope for preventative health care. Apart from these purely nutritional considerations, there are likely to be direct effects on physical health as agricultural labor becomes more strenuous due to deteriorated soil conditions (Burgess et al., 2011). This is particularly relevant for households whose incomes are based on labor intensive farm work, which can lead to increased musculo-skeletal illness (Rabassa et al., 2012).

Second, besides the effects to the agricultural sector, poor rainfall might also be directly linked to the incidence of certain infectious diseases linked to a deterioration in potable drinking water (CDC, 2010; World Bank, 2010). In addition, insect larvae have been found to be more resistant to drought conditions than their natural predators (Chase and Knight, 2003). Indeed, a higher number of dengue fever cases has been reported following longer drought spells in neighboring Laos (IRIN, 2013). Finally, part of the literature also raises concerns that the economic consequences of drought can cause deteriorated mental and behavioral health conditions (CDC, 2010). ${ }^{27}$

Access to health care can potentially reduce the health-related burden of drought. In the early 1990s, Vietnam launched a social health insurance program that initially focused on civil servants and formal sector workers. To improve health care access for lower-income households, the government decided to introduce the Health Care Fund for the Poor (HCFP) in 2003 which was designed to reach out especially to poor households and ethnic minorities. The program covers inpatient and outpatient health care costs - initially only at public providers, but recently private providers have increasingly been included in the scheme as well. Being partly financed by central government revenues and partly by the provincial governments, the HCFP essentially functions as a cross-subsidization from better-off to poorer parts of the population (Ekman et al., 2008). However, while delivering some promising results in terms of health care utilization and

\footnotetext{
${ }^{26}$ Fichera and Savage (2015) document a causal relation between rainfall-induced income changes and health outcomes in Tanzania while Del Ninno et al. (2003) report significant reductions in calorie consumption following a natural disaster in Bangladesh. Relatedly, Kazianga and Udry (2006) find little evidence for consumption smoothing during episodes of drought for rural Burkina Faso.

${ }^{27}$ In addition, when health outcomes are negatively affected by drought, these rather short-term effects might eventually spur second-round effects on household welfare, such as reduced working capacity or negative productivity shocks, depending on the ability of households to cope with the immediate consequences (Jayachandran, 2006; Loayza et al., 2012). Since the focus of this paper is on short-term impacts, such secondary effects are omitted from further discussion in this paper.
} 
reductions in out-of-pocket health care expenditures (Axelson et al., 2009; Wagstaff, 2007), coverage remains far from universal with average rates of around $60 \%$ and scope for improved targeting (Palmer, 2014). ${ }^{28}$ In fact, a substantial number of Vietnamese households remain uncovered by either public or private health insurance scheme. Economic disparities between rural and urban regions in Vietnam have furthermore implied disproportionately bad health conditions in many rural areas of the country (World Bank, 2012c). Most rural Vietnamese households still heavily depend on out-of-pocket health expenditures to finance health care due to the limited coverage of the national health insurance scheme (Lieberman and Wagstaff, 2009). ${ }^{29}$ In a global comparison, health expenditures linked to catastrophic events have traditionally affected a relatively large share of Vietnam's population (Wagstaff and van Doorslaer, 2003; Wagstaff, 2007; Ekman et al., 2008; Xu et al., 2003). ${ }^{30}$ Against this background, major parts of Vietnam's population, with farmers and self-employed individuals being the most vulnerable groups, are exposed to the risk of impoverishment in the aftermath of health shocks.

\subsection{Empirical strategy}

In order to assess the effects of drought on health outcomes and household expenditures, the empirical analysis comes in two parts. In the first step, the effect of drought incidence on individual health conditions is analyzed. The estimation equation for health shocks includes a measure of drought incidence, individual socio-demographic determinants of illness, and - in subsequent analyses - the interactions of both. This first part of the empirical investigation therefore also bears insight into which parts of the population are most vulnerable to drought shocks - which serves to identify those most in need of protection by economic and social policy. In the second step, the costs of drought incidence at the household level are analyzed using drought as a source of exogenous variation to health conditions in the household.

The role of drought for health outcomes is analyzed in a reduced-form regression that relates a measure of health conditions on drought incidence and other determinants of health:

$$
\text { health }_{\text {ihdt }}=\beta_{0}+\beta_{1} \text { drought }_{d t}+\beta_{2} X_{i h d t}+\delta_{t}+\delta_{p}+\epsilon_{i h d t},
$$

where health $h_{i h d t}$ denotes the health status indicator of individual $i$ in household $h$ and district $d$ at time $t$. The variable drought is the continuous measure of drought severity, collected at

\footnotetext{
${ }^{28}$ Using data from Living Standards Measurement Studies, Kemper and Lechtenfeld (2012) find substantial targeting error, which leaves nearly half of all poor households without access to health care financing.

${ }^{29}$ For the rural sample analyzed in this study, we find that HCFP coverage varies between 51 and $60 \%$ depending on the province while only 5 to $11 \%$ of the population has some type of private health insurance.

${ }^{30}$ Some authors also argue that Vietnam's economic transition to a more market-oriented economy was accompanied by weaker institutional structures of collective action on the consequences of extreme (weather) events (Adger, 1999).
} 
the district level. The vector $X$ includes socio-demographic and economic characteristics at the household or member level, such as age, gender, and household assets. $\delta_{t}$ is a set of wave fixed-effects to account for covariate changes in living conditions in between the four survey waves and $\delta_{p}$ denote province fixed-effects to account for time-invariant province-specific factors in the drought-health nexus. Finally, $\epsilon$ is a standard error term whose structure allows for interdependent observations within one household. ${ }^{31}$ To exploit variation in drought conditions both between spatially dispersed households and over time, household fixed-effects are not included in the regressions.

Whereas equation (3.1) assumes that all households in the sample have a homogeneous health response towards drought shocks, demographic and socio-economic characteristics might be important factors that determine how drought channels through on health outcomes. As a consequence, the ex-ante vulnerability to the drought shock as well as the mechanisms available to cope with it ex post may crucially alter the extent to which households suffer from droughtrelated health shocks (see, e.g., Thiede, 2014). The identification of heterogeneous impacts by observable individual characteristics therefore sheds light on possible transmission channels. At the same time it yields implications for economic and social policy aimed at mitigating the vulnerability to adverse weather shocks. To subject these theoretical considerations to an empirical test, equation (3.1) is augmented with interaction terms of illness and a number of household and individual characteristics, such that the estimated interaction effects reflect any differentials in the effect of drought on health outcomes based on these characteristics.

To gauge the financial costs that drought exerts on household budgets, health expenditures are related to the incidence of drought-related health shocks at the household level. Specifically, a binary variable household illness is constructed from the incidence of diseases in the household:

$$
\text { health expenditures }{ }_{h t}=\gamma_{0}+\gamma_{1} \text { household illness } s_{h t}+\gamma_{2} X_{h t}+\sigma_{t}+\sigma_{p}+u_{h t} .
$$

Other control variables in the vector $X$ in equation (3.2) include household-level determinants of health expenditures, mostly time-variant, such as the household's age and gender composition, the total household size, and the household's dependency ratio. As before, $\sigma_{t}$ and $\sigma_{p}$ capture wave and province fixed-effects, respectively. $u$ is a residual term which allows for heteroskedasticity, such that robust standard errors are reported.

In the reduced form, reported health conditions in the household are potentially endogenous to unobserved household behavior and prone to measurement error. First and foremost, whether

\footnotetext{
${ }^{31}$ The main results are robust to using more conservative clustering of standard errors at the district and province level.
} 
a household actually suffers a health shock is likely to be systematically related with both its preparedness towards such a shock ex ante - that is, its shock prevention strategies - as well as its ability to cope with the shock ex post. For instance, household members that are aware of their adverse health status might seek formal or informal insurance mechanisms, e.g., through buying health insurance or investing into a reciprocal social network. If health shocks are systematically anticipated, households might also decide for higher preventative health care spending or households members in bad health might also have a higher propensity to build up savings beforehand in order to bear the anticipated costs of treatment. In these cases, sicker individuals would be better prepared and insured against health shocks, such that the simple difference in health expenditures between households differently affected by health shocks would not capture the true financial impact of the shocks. More precisely, the true costs would be underestimated when the endogenous household behavior remained unobservable. Second, measurement error due to over- and underreporting is a major concern when dealing with subjective information on health shocks, particularly if responses might be subject to moral hazard. Ordinary Least Squares (OLS) estimates of $\gamma_{1}$ in equation (3.2) are therefore expected to be downward biased.

The incidence of drought serves as an exogenous source of variation in health shocks. To be an adequate instrument, it should be sufficiently relevant for health outcomes within the household and must not have a direct effect on health expenditures that does not work through the incidence of illness and is not controlled for given the other regressors in equation (3.2). The relevance of the instrument will be benchmarked by the explanatory power of the first stage regression. As for the exclusion restriction, the identifying assumption that drought affects health expenditures only through a change in the incidence of illness within the households is made. To exclude anticipatory changes in household behavior as with conventional health shocks, rainfall shortages need to be unexpected. As the following analysis benchmarks actual precipitation against a long-term multi-decade average, it takes into account the differences between regions that have historically had different amounts of exposure to rainfall. Drought therefore results from short-term variations in rainfall, which are by their very nature difficult to anticipate. Based on survey information from rural Vietnam (see section 3.4 for details on the survey), only a few households in the sample indicated employing some type of individual or collective drought prevention strategies. ${ }^{32}$ Under these circumstances, the bias from systematic anticipation of drought and active prevention strategies on the estimated health costs should be

\footnotetext{
${ }^{32}$ Unfortunately, the information is not available for the whole period of analysis, such that an inclusion would substantially reduce the sample. Also, there is no reliable information on these strategies' effectiveness and whether the take-up of drought prevention strategies is in fact related to actual occurrence of drought.
} 
limited and, if at all existent, induce a downward bias. As a robustness check, we verify that omitting those households that reported taking up prevention strategies from the sample does not change the empirical results significantly.

Econometrically, to isolate the drought-related component of health shocks in the household, we instrument the illness incidence by varying exposure to drought. The first-stage resembles the setting of equation (3.1), but is aggregated at the household level. In the second stage, a measure of health expenditures of the household is regressed on this instrumented illness variable. The analysis focuses on the IV coefficient which captures the Local Average Treatment Effect (LATE) of changes in illness incidence solely due to variation in exposure to drought.

\subsection{Data}

\subsubsection{Survey data}

The empirical analysis builds on a rich panel dataset collected as part of the "Vulnerability to Poverty in Southeast Asia" research project. Funded by the German Research Foundation, the survey work was carried out in four waves between 2007 and $2013 .{ }^{33}$ The dataset covers more than 2,000 households in 200 villages in the rural provinces of Ha Tinh, Thua Thien Hue (also referred to as Hue), and Dak Lak. ${ }^{34}$ All three survey provinces can be found within the poorest income quintile of Vietnam, with Ha Tinh province being the poorest of Vietnam's 58 provinces in 2007. Provinces are approximately the same size which allows calculating province-specific rainfall anomalies. Households in all three provinces are predominantly engaging in small-scale agriculture and informal self-employment and off-farm employment. Households were selected through a three-stage sampling procedure which paid special attention to including densely and less-densely populated districts into the survey. ${ }^{35}$ While temporary migration to urban centers has been observed in some households, attrition in the panel is very low, with attrition rates between two to three percent in each wave. ${ }^{36}$ In the main specifications, we work with a total sample of 10,844 individuals and 1,954 households.

For the study of how adverse drought shocks impact on the households in our sample, information on health outcomes and socio-demographic characteristics for each household member

\footnotetext{
${ }^{33}$ The survey was deliberately timed to take place in April during each survey wave: 2007 (Wave 1), 2008 (Wave 2), 2010 (Wave 3), and 2013 (Wave 4). April coincides with the end of the dry season in Vietnam and before the wet monsoon season begins in May.

${ }^{34}$ Figure 3.A.1 in the appendix shows a map of the study area. A detailed description of the survey instrument can be found in Klasen and Waibel (2010).

${ }^{35}$ First, districts were selected through probability proportional to size (PPS) sampling. Second, within each district two villages were selected by PPS. Finally, within each village, ten households were randomly selected. The survey then included all individuals of the selected households. For further details of the sampling procedure, see Hardeweg et al. (2007).

${ }^{36}$ For this reason, and because drought is arguably difficult to anticipate, we assume that selective migration does not affect the sample in a meaningful way.
} 
are analyzed in conjunction with household-level information on annual health expenditures. The principal measure of health conditions is constructed from the survey's health module documenting physical well-being at the time of the survey as well as the suffering from diseases in the twelve months preceding the survey. Specifically, a binary disease variable takes a value of one if the household member reports having suffered a "severe illness" in the year before the survey. ${ }^{37}$ Next to this simple measure of general illness, we further subdivide diseases into infectious diseases, non-communicable diseases that can be acquired in the short-term, and non-communicable diseases of a more long-run nature. Diseases not falling into one of these categories together with those for which the specific type of disease is unknown constitute a residual category. The classification is detailed in table 3.A.2 in the appendix. Against the theory of impact and the potential key role of the agricultural sector, outlined in section 3.2, this will allow some broad insights into potential transmission channels in the drought-health nexus.

To assess the impact of drought on household welfare, health expenditures are recorded at the household level. Drawing on an expenditure module, the survey provides detailed information on annual household expenditures on health, education, food and other items. ${ }^{38}$ The variable health expenditures is the aggregate of all health-related expenditures, including doctor fees and medicine per household member. ${ }^{39}$

\subsubsection{Data on drought incidence}

Drought can be defined as "a period of abnormally dry weather long enough to cause serious hydrological imbalance" (IPCC, 2012, p. 167). A large part of academic literature focusing on the micro-level consequences of health shocks relies on the survey respondents' subjective perception of what they consider an adverse weather shock and when this shock is "severe" enough to have a significant impact on the household. These subjective measures certainly have the distinct advantage of being theoretically more precise at the local level than information from spatially aggregated data. Subjectivity, however, is boon and bane at the same time and the subjective measures suffer from both practical and methodological shortcomings (Thomas et al., 2010). Self-reported measures can hardly assess varying severities of weather shocks precisely and are subject to over- and underreporting as well as recall biases which might further be related to the vulnerability of the household in question. Specifically, for this analysis, the subjective

\footnotetext{
${ }^{37}$ This includes every illness that the respondent considers severe, but the empirical results are robust to excluding very light diseases.

${ }^{38}$ That is, health expenditures are recorded after coping and mitigation behavior of the household.

${ }^{39}$ All financial amounts have been converted to constant 2005 USD for the analysis to allow comparability across waves.
} 
perception of weather shocks and indicators of morbidity might be systematically related. Two households experiencing the very same objective rainfall conditions might differ in their shock perception because they took different ex ante strategies to limit their shock exposure. Similarly, the availability of formal and informal insurance networks can influence people's perception of shocks. It is easily imaginable, for instance, that households whose economic costs were partly shared with third parties are less likely to report the shock in a survey setting. Finally, being asked for subjective shock assessments during an externally-commissioned survey might induce a problem of moral hazard. For these reasons, this paper uses external data on local rainfall conditions obtained from satellite observations to measure drought. As Thomas et al. (2010) point out, this method has the advantage that empirical findings have higher external validity in that variations in climatic conditions are more easily available outside of the sample.

Shortfall in rain is arguably the key driving factor behind drought which is useful for its objective measurement, by which observed rainfall is compared against long-term historic mean rainfall, and significant shortages of rainfall can then be defined as episodes of drought (IPCC, 2012). The subsequent analysis combines rainfall data with survey data. Specifically, district-level rainfall data is merged to the household data for each district. ${ }^{40}$ The historic rainfall distribution can be estimated using monthly weather data from the Global Precipitation Climatology Centre (GPCC) Product in the 50-year period from 1960 to 2010 (DWD, 2013), recorded at a resolution of 0.25 degrees (about 28 kilometers at the equator). Data on current rainfall is obtained from the National Oceanic and Atmospheric Administration (NOAA) which provides daily precipitation estimates for all years covered by the household survey, recorded at a resolution of 0.1 degrees (about 11 kilometers at the equator). ${ }^{41}$ To combine current and historic rainfall, daily precipitation data is aggregated to monthly rainfall aggregates for every district between 2006 and mid-2013 by taking the mean value of all rainfall estimates within the district boundaries. ${ }^{42}$ Given actual and historic average precipitation, the preferred indicator for the empirical analysis builds on absolute deviations of rainfall from the historic mean. Three-months rolling averages of actual and historic precipitation are calculated and a month is then defined to be dry, for the purpose of this paper, whenever the average rainfall in this three-month window negatively differs from the historic average. Using rolling averages, this measure therefore allows for some

\footnotetext{
${ }^{40}$ Districts are the administrative tier below provinces and constitute the smallest feasible unit of aggregation given the resolution of the precipitation estimates.

${ }^{41}$ The NOAA dataset contains precipitation estimates based on records from weather stations and precipitation estimates from geostationary satellites. The estimate provides reliable reflections of spatial and temporal distribution of rainfall and is particularly valuable in countries with few weather stations. The NOAA rainfall data displays the same short-term trends than weather station data and it has undergone sensitivity analysis. The raw data are available at http://www.cpc.ncep.noaa.gov/products/fews/SASIA/rfe.shtml.

${ }^{42}$ We refrain from a within-district analysis given the resolution of the NOAA dataset and since drought is a less local weather event than, for instance, flooding.
} 
inter-annual compensation, when shortages of rain are immediately preceded or followed by excess rain. The three-month window is commonly regarded as being most suitable to build agricultural drought indices as it reflects the moisture conditions of the soil (McKee et al., 1995; Sims et al., 2002; Vicente-Serrano, 2006). To obtain a drought severity indicator that can be matched to the reference period of the household survey, the absolute differences between normal and actual rainfall are added up for all the dry periods throughout each year. The resulting annual total then reflects the shortfall in rain (in milimetres) in the identified dry periods. $^{43}$ By exploiting only variations in rain shortfall and thus only considering when rainfall deviates negatively from the historic mean, this drought severity indicator has more variation than existing rainfall measures, including binary indicators for drought, that have been used in earlier studies on the effects of drought (e.g., Arouri et al., 2015). The empirical analysis furthermore uses province fixed-effects to model the relationship between drought and health. Province-specific differences in absolute rainfall, which might invalidate the comparison of absolute rather than relative drought measures, are hence accounted for. For the empirical analysis, this indicator is normalized between zero and one. In table 3.A.3 in the appendix, the preferred drought indicator is benchmarked against an indicator based on relative deviations (in terms of standard deviations of the long-term rainfall distribution), and two indicators based on the length of drought spells within the year. The central result from the empirical analysis is not sensitive to different choices of drought indicators while the preferred indicator is found to have the largest explanatory power.

\subsubsection{Descriptive statistics of the sample}

Table 3.1 provides the summary statistics of the central variables used in the respondent-level empirical analysis if the sample is pooled across all four waves. ${ }^{44}$ The average age of the respondents is slightly below 30. Roughly every third person is younger than 20 years old and the group of people older than 60 make up some $8 \%$ of the sample. ${ }^{45}$ Furthermore, the sample is equally split between male and female household members.

Regarding health outcomes, the incidence of illness in the year before the survey among all individuals in the sample is around $15 \%$. This average is quite stable over the first waves while

\footnotetext{
${ }^{43}$ Another possibility would be to consider drought-like conditions only in agriculturally relevant growing seasons. Due to mixed cropping being common in rural Vietnam - many households grow both summer and winter rice -, it is, however, difficult to unambigously specify these periods. Also, some farmers plant different types of crops at varying times of the year. Any bias that might nevertheless result from the year-based method of aggregation is furthermore partially addressed through the inclusion of province fixed-effects in the estimation. Within provinces, cropping patterns are more homogeneous.

${ }^{44}$ In table 3.A.1 in the appendix we provide province-specific descriptive statistics of health outcomes and insurance coverage.

${ }^{45}$ The sample is restricted to people below the age of 80 .
} 
Table 3.1: Descriptive Statistics, pooled sample

\begin{tabular}{|c|c|c|c|c|c|}
\hline & Mean & Median & $\mathrm{SD}$ & Min. & Max. \\
\hline$(1 / 0)$ Serious disease & 0.15 & 0.00 & 0.36 & 0.00 & 1.00 \\
\hline$(1 / 0)$ Infections & 0.05 & 0.00 & 0.21 & 0.00 & 1.00 \\
\hline (1/0) Long-term diseases & 0.04 & 0.00 & 0.19 & 0.00 & 1.00 \\
\hline$(1 / 0)$ Non-communicable diseases & 0.05 & 0.00 & 0.21 & 0.00 & 1.00 \\
\hline$(1 / 0)$ Other diseases & 0.02 & 0.00 & 0.14 & 0.00 & 1.00 \\
\hline Age & 29.43 & 25.00 & 18.94 & 0.00 & 80.00 \\
\hline$(1 / 0)$ Male & 0.50 & 0.00 & 0.50 & 0.00 & 1.00 \\
\hline Dependency ratio & 1.67 & 1.50 & 0.70 & 0.00 & 6.00 \\
\hline Total consumption per capita & 1199.93 & 1008.74 & 773.73 & 114.37 & 6361.66 \\
\hline Health consumption per capita & 44.66 & 14.71 & 83.96 & 0.00 & 832.50 \\
\hline Food consumption per capita & 604.08 & 521.77 & 341.20 & 17.03 & 2662.33 \\
\hline Asset index & 0.33 & 0.34 & 0.15 & 0.00 & 1.00 \\
\hline Gross income from crops, per-capita & 393.04 & 135.00 & 629.78 & 0.00 & 4091.96 \\
\hline Share of rainfed agricultural land & 0.88 & 1.00 & 0.25 & 0.01 & 1.00 \\
\hline Off-farm cash income, per-capita & 55.73 & 4.53 & 98.68 & 0.00 & 659.34 \\
\hline$(1 / 0)$ Free health card & 0.57 & 1.00 & 0.50 & 0.00 & 1.00 \\
\hline (1/0) Private health insurance & 0.07 & 0.00 & 0.26 & 0.00 & 1.00 \\
\hline (1/0) Social network for coping & 0.57 & 1.00 & 0.50 & 0.00 & 1.00 \\
\hline Drought severity $(\mathrm{mm}), 3$-months average & 482.59 & 494.01 & 195.41 & 74.64 & 1022.05 \\
\hline Observations & 39863 & & & & \\
\hline
\end{tabular}

in the fourth wave the incidence rises to some $17 \%$. Ha Tinh, being the poorest province, features a mean rate of close to $17.2 \%$ while in Hue as the relatively wealthiest province only $13.9 \%$ reported being ill. Health expenditures per capita vary between 0 and 833 USD. Their distribution naturally is highly right-skewed with median expenditures being even lower. In comparison, the average respondent in the sample spends around $4 \%$ of its total consumption budget on health items whereas out-of-pocket food consumption ranges between 17 and 2662 USD. There are varying degrees of agricultural activity which we measure by the per-capita gross income that is generated from the production of crops. ${ }^{46}$ Almost all households in the sample report relying on sufficient rainfall to water the agricultural land which is reflected in the high average share of rainfed land.

Looking at the prevalence of formal insurance mechanisms among the rural population in the three provinces, about two thirds of the people have access to some kind of health insurance, i.e., either the free health insurance program for the poor $(57 \%)$ or some form of private health insurance scheme $(7 \%)$. Off-farm income opportunities are approximated by the per-capita value of cash income from off-farm labor which varies between 0 and 660 USD. Many households in the rural parts of Vietnam also build up an informal social network in order to be better prepared for and be better able to cope with adverse economic shocks in times of need (Carter and Maluccio, 2003; Fafchamps and Lund, 2003). These informal networks consisting of relatives, friends, or neighbors are hard to capture without using well-designed economic experiments or in-depth

\footnotetext{
${ }^{46}$ The gross incomes distinguish themselves from net incomes through not considering production costs. Since we are interested in a proxy for agricultural activity and these costs are self-reported and prone to serious reporting error, we refrain from calculating net incomes.
} 


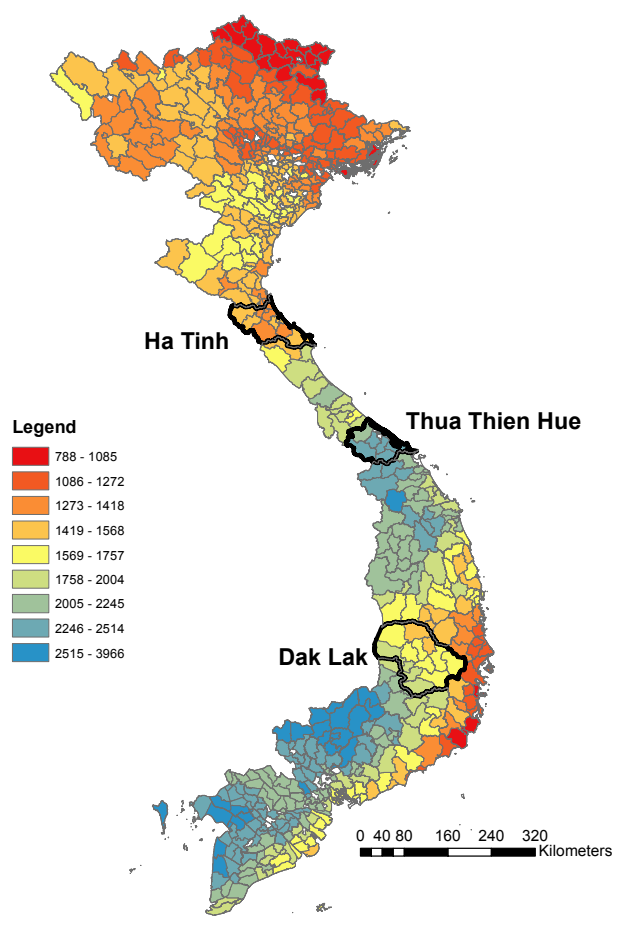

(a) Precipitation (mm)

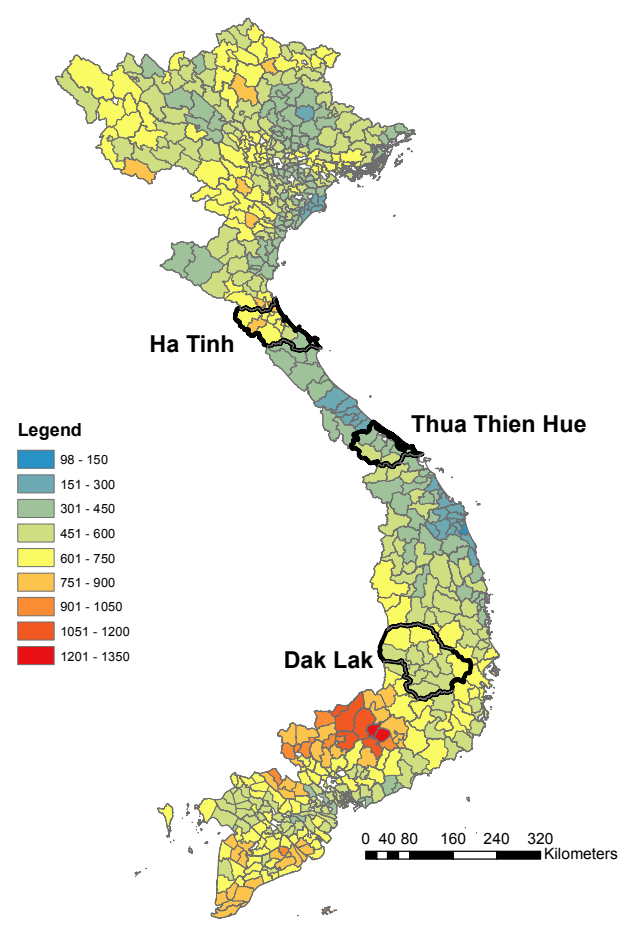

(b) Drought severity, 3-months average (mm)

Figure 3.1: Rainfall and drought in Vietnam in the year before the third survey wave

social network analysis. As an approximation, the household survey features a hypothetical lending question: "Suppose you would suddenly need 15 million Vietnamese Dong (VND). ${ }^{47}$ Would you do any of the following things?", followed by a list of strategies including employment diversification, taking children out of school, or using help from friends and relatives. The social network variable takes a value of one whenever a household states that it would take any strategy that involves help from friends, relatives, or neighbors as an empirical proxy for the existence of an informal insurance network. Based on this hypothetical lending scenario, more than half of the respondents indicate turning to informal assistance from their social network in cases of hardship.

The final row of table 3.1 gives information on the prevalence of rainfall shortage in the sample regions. Drought severity - the cumulated rainfall shortage over "dry" periods throughout the year - varies between 75 and $1022 \mathrm{~mm}$. Figure 3.1 shows the exemplary distribution of rainfall and the resulting drought severity indicator for the third survey wave. The survey regions are outlined in bold.

\footnotetext{
${ }^{47} 15 \mathrm{mn} \mathrm{VND} \approx 700 \mathrm{USD}$ using exchange rates from March, 16th, 2015.
} 
In panel 3.1a, the annual rainfall estimate is mapped for each district in Vietnam. Almost all districts exceed the cumulative total of $1000 \mathrm{~mm}$. The southern regions as well as the region around the province of Hue can be seen as having had more rainfall than the northern part or the southern coastal regions of the country. However, this picture neither reflects subannual developments nor accounts for how particular periods within the year compared to longterm climatic averages and normal provincial rainfall. Therefore, panel $3.1 \mathrm{~b}$ depicts how the normalized drought severity indicator varies across the country. As in the empirical analysis, the indicators are calculated net of time-invariant province-specific level differences. Together with the variation in rainfall conditions over time, these differences in drought severity will be exploited to explain the variation in agricultural and health outcomes in the survey data. Figure 3.A.2 in the appendix contrasts the drought indicator and the rainfall data by province and survey wave.

\subsection{Results}

\subsubsection{Drought and the agricultural sector}

The agricultural sector constitutes the principal channel through which drought can impact health outcomes. In fact, based on the most recent survey data, the majority of households are engaged in cropping activities $(82 \%)$ and, albeit to a lesser extent, some form of animal husbandry (74\%). Paddy rice, whose cultivation requires sufficient precipitation, is the main staple crop for the rural households in the sample. If drought exerts a significant impact on agricultural production, we consequently would expect this to be reflected in key indicators of paddy rice production.

Before turning to the detailed analysis of the determinants of health conditions, table 3.2 therefore presents reduced-form estimates of the relationship between the severity of drought and rice production, rice yields and rice prices. ${ }^{48}$ While the data is self-reported and arguably a subjective indication of the effects of drought, it provides a detailed description of agricultural activity at the household level. Regarding the main variables, rice production is calculated as the aggregate output of paddy rice cropping at the household level. Rice yields relates this measure to the size of agricultural land available. Rice prices are based on survey data in which the household head reports at what price agricultural output has been sold. Province fixed-effects account for heterogeneities in rice prices across different regions due to unobserved determinants of rice quality. Year fixed-effects control for countrywide developments in the rice price over time. To reduce the effect of any measurement error prices are included as reported

\footnotetext{
${ }^{48}$ These results are based on information from the second, third, and fourth wave of the household survey. Unfortunately, this information is absent from the first wave.
} 
Table 3.2: The effect of drought on rice cropping

\begin{tabular}{lcccc}
\hline \hline & $\begin{array}{c}(1) \\
\text { Rice production }\end{array}$ & $\begin{array}{c}(2) \\
\text { Rice yield }\end{array}$ & $\begin{array}{c}(3) \\
\text { Rice price }\end{array}$ & $\begin{array}{c}(4) \\
\text { Crop revenue }\end{array}$ \\
\hline Drought severity & $\begin{array}{c}-0.5727^{* * *} \\
(0.0918)\end{array}$ & $\begin{array}{c}-0.5010^{* * *} \\
(0.0934)\end{array}$ & $\begin{array}{c}0.1858^{* * *} \\
(0.0316)\end{array}$ & $\begin{array}{c}-0.5309^{* * *} \\
(0.1294)\end{array}$ \\
Wave-FE & Yes & Yes & Yes & Yes \\
Province-FE & Yes & Yes & Yes & Yes \\
\hline Observations & 3636 & 3575 & 637 & 2418 \\
Adjusted $R^{2}$ & 0.023 & 0.148 & 0.470 & 0.141 \\
\hline \hline \multicolumn{2}{l}{ OLS regressions. Dependent variables (see first row) in natural logarithm. } \\
Robust standard errors in parentheses. ${ }^{*} p<0.1,{ }^{* *} p<0.05,{ }^{* * *} p<0.01$
\end{tabular}

median values of each community.

The results from table 3.2 show that drought can have a negative impact on rice production. Living in the most drought-affected district compared to living in the least drought-affected district is associated with a more than $40 \%$ drop in rice production. Rice yields are estimated as dropping by similar magnitudes. Rice prices in turn react positively to drought-like conditions, i.e., if households sold rice to local or regional markets, the price at which they reported doing so was significantly higher in times of drought, around $20 \%$ when comparing the extremes of the drought distribution. Clearly, for net sellers of agricultural produce, quantity and price effects counteract. The estimated elasticity of crop revenues is estimated as being slightly below the one for crop production, such that the production effect seems to dominate. A precise estimation of household welfare effects would need to take into account its net selling or buying position for many agricultural crops, which is beyond the scope of this analysis. ${ }^{49}$ The results from column 4, however, provide some indication that the gross revenue achieved through selling agricultural output is negatively associated with drought severity. For the average household in the rural sample, the incidence of drought therefore seems to have adverse effects on paddy rice cultivation, and likely the agricultural sector in general should other crops be similarly affected.

\subsubsection{The impact of drought on the incidence of diseases}

Table 3.3 provides a picture of how the severity of drought is related to the health conditions at the level of individual household members. All specifications include basic socio-demographic control variables at the individual level, province and survey wave fixed effects. Standard errors are clustered at the household level. As for the basic control variables, the results show intuitive patterns in the relationship to the health indicators. Younger people have a lower propensity to

\footnotetext{
${ }^{49}$ Given that most households in the sample also grow crops for subsistence, one can probably expect, however, that the net effect of drought is negative, such that drought conditions are detrimental to household welfare in the vast majority of cases. $\mathrm{Vu}$ and Glewwe (2011) study the welfare implications of rising food prices for Vietnam, albeit not for exceptional events such as drought. They find that higher food prices decrease household welfare for most households while a smaller amount of households benefits.
} 
Table 3.3: The relationship between drought and health conditions at the individual level

\begin{tabular}{|c|c|c|c|c|c|c|}
\hline & $\begin{array}{c}(1) \\
\text { All diseases }\end{array}$ & $\begin{array}{c}(2) \\
\text { All diseases }\end{array}$ & $\begin{array}{c}(3) \\
\text { Infection }\end{array}$ & $\begin{array}{c}(4) \\
\text { Non-communicable }\end{array}$ & $\begin{array}{c}(5) \\
\text { Long-term }\end{array}$ & $\begin{array}{c}(6) \\
\text { Other }\end{array}$ \\
\hline Drought severity & $\begin{array}{c}0.0971^{* * *} \\
(0.0156)\end{array}$ & $\begin{array}{c}0.1004^{* * *} \\
(0.0177)\end{array}$ & $\begin{array}{c}0.0328^{* * *} \\
(0.0102)\end{array}$ & $\begin{array}{c}0.0275^{* * *} \\
(0.0087)\end{array}$ & $\begin{array}{c}0.0207^{* * *} \\
(0.0068)\end{array}$ & $\begin{array}{c}0.0141^{* * *} \\
(0.0054)\end{array}$ \\
\hline$(1 / 0)$ Male & $\begin{array}{r}-0.0077^{*} \\
(0.0042)\end{array}$ & $\begin{array}{l}-0.0048 \\
(0.0080)\end{array}$ & $\begin{array}{l}-0.0016 \\
(0.0026)\end{array}$ & $\begin{array}{l}0.0053^{* *} \\
(0.0025)\end{array}$ & $\begin{array}{c}-0.0071^{* * *} \\
(0.0025)\end{array}$ & $\begin{array}{r}-0.0040^{* *} \\
(0.0016)\end{array}$ \\
\hline Drought $*$ Male & & $\begin{array}{l}-0.0065 \\
(0.0160)\end{array}$ & & & & \\
\hline Age $0-10$ & $\begin{array}{c}-0.0973^{* * *} \\
(0.0078)\end{array}$ & $\begin{array}{c}-0.0973^{* * *} \\
(0.0078)\end{array}$ & $\begin{array}{l}-0.0022 \\
(0.0052)\end{array}$ & $\begin{array}{c}-0.0399^{* * *} \\
(0.0038)\end{array}$ & $\begin{array}{c}-0.0345^{* * *} \\
(0.0040)\end{array}$ & $\begin{array}{c}-0.0205^{* * *} \\
(0.0029)\end{array}$ \\
\hline Age $10-20$ & $\begin{array}{c}-0.0976^{* * *} \\
(0.0072)\end{array}$ & $\begin{array}{c}-0.0976^{* * *} \\
(0.0072)\end{array}$ & $\begin{array}{c}-0.0197^{* * *} \\
(0.0043)\end{array}$ & $\begin{array}{c}-0.0317^{* * *} \\
(0.0039)\end{array}$ & $\begin{array}{c}-0.0288^{* * *} \\
(0.0039)\end{array}$ & $\begin{array}{c}-0.0172^{* * *} \\
(0.0027)\end{array}$ \\
\hline Age $20-30$ & $\begin{array}{c}-0.0802^{* * *} \\
(0.0081)\end{array}$ & $\begin{array}{c}-0.0802^{* * *} \\
(0.0081)\end{array}$ & $\begin{array}{c}-0.0228^{* * *} \\
(0.0047)\end{array}$ & $\begin{array}{c}-0.0265^{* * *} \\
(0.0042)\end{array}$ & $\begin{array}{c}-0.0223^{* * *} \\
(0.0043)\end{array}$ & $\begin{array}{c}-0.0081^{* * *} \\
(0.0030)\end{array}$ \\
\hline Age $40-50$ & $\begin{array}{c}0.0677^{* * *} \\
(0.0099)\end{array}$ & $\begin{array}{c}0.0677^{* * *} \\
(0.0099)\end{array}$ & $\begin{array}{c}0.0049 \\
(0.0054)\end{array}$ & $\begin{array}{c}0.0313^{* * *} \\
(0.0056)\end{array}$ & $\begin{array}{c}0.0198^{* * *} \\
(0.0054)\end{array}$ & $\begin{array}{c}0.0115^{* * *} \\
(0.0039)\end{array}$ \\
\hline Age $50-60$ & $\begin{array}{c}0.1593^{* * *} \\
(0.0116)\end{array}$ & $\begin{array}{c}0.1592^{* * *} \\
(0.0116)\end{array}$ & $\begin{array}{c}0.0242^{* * *} \\
(0.0064)\end{array}$ & $\begin{array}{c}0.0702^{* * *} \\
(0.0071)\end{array}$ & $\begin{array}{c}0.0454^{* * *} \\
(0.0070)\end{array}$ & $\begin{array}{c}0.0199^{* * *} \\
(0.0047)\end{array}$ \\
\hline Age $60+$ & $\begin{array}{c}0.2542^{* * *} \\
(0.0135)\end{array}$ & $\begin{array}{c}0.2542^{* * *} \\
(0.0135)\end{array}$ & $\begin{array}{c}0.0350^{* * *} \\
(0.0073)\end{array}$ & $\begin{array}{c}0.0999^{* * *} \\
(0.0084)\end{array}$ & $\begin{array}{c}0.1031^{* * *} \\
(0.0091)\end{array}$ & $\begin{array}{c}0.0166^{* * *} \\
(0.0050)\end{array}$ \\
\hline Asset index & $\begin{array}{c}-0.2573^{* * *} \\
(0.0214)\end{array}$ & $\begin{array}{c}-0.2573^{* * *} \\
(0.0214)\end{array}$ & $\begin{array}{c}-0.1142^{* * *} \\
(0.0134)\end{array}$ & $\begin{array}{c}-0.0738^{* * *} \\
(0.0101)\end{array}$ & $\begin{array}{c}-0.0508^{* * *} \\
(0.0096)\end{array}$ & $\begin{array}{c}-0.0201^{* * *} \\
(0.0068)\end{array}$ \\
\hline Wave-FE & Yes & Yes & Yes & Yes & Yes & Yes \\
\hline Province-FE & Yes & Yes & Yes & Yes & Yes & Yes \\
\hline Observations & 34593 & 34593 & 34593 & 34593 & 34593 & 34593 \\
\hline Adjusted $R^{2}$ & 0.110 & 0.110 & 0.016 & 0.049 & 0.044 & 0.028 \\
\hline Mean of dependent variable & 0.1647 & 0.1647 & 0.0525 & 0.0507 & 0.0400 & 0.0208 \\
\hline
\end{tabular}

OLS regressions. Binary dependent variables are indicated in the first row.

Standard errors, clustered at the household level, in parentheses. ${ }^{*} p<0.1,{ }^{* *} p<0.05,{ }^{* * *} p<0.01$

suffer from a health shock than adults while there is some evidence for differential gender effects in health with male respondents suffering less. As can be expected, household wealth, measured by a cumulative asset index is associated with lower illness rates throughout all specifications.

Overall, the results suggest that individuals who live in a district that was more affected by drought on average show a significantly higher likelihood of suffering from a health shock. Column 1 in the table first looks at the relationship of drought and the incidence of general diseases. When comparing across individuals and across all four survey waves, living in the most drought-affected district compared to living in the least drought-affected district increases the probability of illness by about 10 percentage points. While this figure constitutes the largest effect possible in the data, i.e., going to the extremes of the drought distribution, a change of one standard deviation in the severity of drought (0.21) causes the propensity of illness to rise by two percentage points. This effect is about one eighth of the average sickness rate of the sample population. The results in column 2 do not suggest a differential effect by gender.

In columns 3 to 6 , the general disease indicator is disaggregated into four disease types. We find drought severity to be significantly linked to all four types for the average individual in the sample. Infectious and non-communicable diseases feature the largest coefficients in absolute magnitudes. In relative terms, an increase of one standard deviation in drought severity raises the incidence of infectious and non-communicable diseases by about one eighth and one ninth 
of the average rates, respectively. ${ }^{50}$

The theoretical considerations from section 3.2 as well as the evidence presented in section 3.5.1 highlight the crucial role of the agricultural sector when studying the consequences of drought. In the following specifications, we test whether reduced agricultural activity also constitutes a major transmission channel in the nexus between drought and the adverse effects on health identified above. For this to be the case, indicators of agricultural activity and vulnerability to drought should be negatively related since households with greater agricultural activity even in times of drought evidently have been able to cope better with the drought conditions. Households where agricultural output is low are therefore likely to be disproportionately vulnerable, while households with relatively high agricultural activity are less likely to suffer from drought-related health shocks. For a systematic test, figure 3.2 depicts the marginal effects of drought severity on the incidence of diseases, estimated from a regression where the drought indicator is interacted with a proxy measure of agricultural activity. For this measure, we again take the logged gross revenue per capita that the household achieved through cropping activities. In the figure, the distribution of logged revenues is provided by a histogram. To control for inter-household differences in crop revenues even in "normal" times, a household's average crop revenues across all survey waves is added as an additional covariate. The underlying regression results are detailed in table 3.A.4 in the appendix.

Focusing on those households who report any positive revenues, higher revenues are likely to reflect a larger degree of agricultural activity. The results indeed suggest that there is a greater difference in the size of the adverse effect between households with low and high agricultural activity. In fact, drought is estimated as having a statistically significant effect (at the $10 \%$ level) on health up until third quartile of the revenue distribution. In the upper end of the revenue distribution, this effect loses statistical significance. These findings constitute indicative evidence that households with a slump in agricultural revenue are disproportionately affected by drought conditions. As shown in figure 3.A.3 in the appendix, the incidence of infectious diseases during periods of drought affects the entire sample more evenly with the interaction between drought and agricultural revenue not being statistically significant. While the data does not allow a causal interpretation, these results are consistent with an increase of infectious diseases due to deteriorating sanitation and hygiene conditions. ${ }^{51}$

\footnotetext{
${ }^{50}$ We treat headache as an infectious diseases. If it is classified as non-infectious, the estimated coefficient of infectious is reduced (0.0155) while non-communicable diseases display a stronger response to drought (0.0449). Both associations remain statistically significant.

${ }^{51}$ Non-communicable diseases seem to be significantly determined by agricultural revenues. The results show larger effects for households with affected agricultural activities.
} 


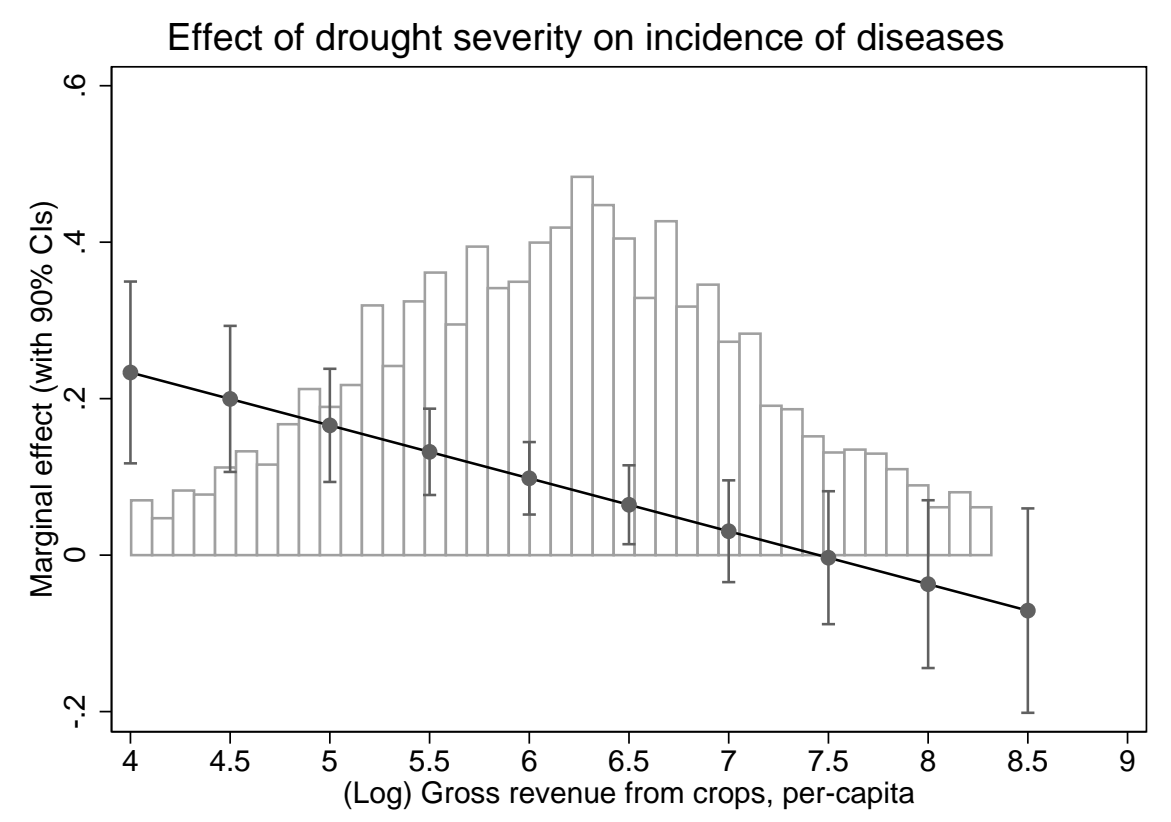

Figure 3.2: The effect of drought on health for varying crop revenues

\subsubsection{Coping through formal and informal insurance mechanisms}

From a policy perspective it will be useful to identify which coping mechanisms are best suited to reduce drought-related vulnerability. Table 3.4 presents regression results for coping strategies, modeled by interacting the drought severity indicator with variables reflecting various coping strategies available in the household survey. Negative coefficients on the interaction terms would indicate that a coping strategy reduces vulnerability to drought.

First, we investigate whether the vulnerability to drought depends on the economic position of a household. As Morduch (1995) and Thomas et al. (2010) point out, one might expect wealthier households to be better able to smooth out negative consumption effects of drought if coping strategies involve the selling of assets. This is tested through the interaction with the asset index, which is lagged by one survey wave to avoid capturing direct asset effects of drought. In addition, we analyze whether the effect of drought prevails in households that have limited access to off-farm income sources, measured by current cash income through off-farm employment. These could provide an intra-household insurance mechanism in times of drought. The results from columns (1) and (2) suggest that both coping strategies are effective in alleviating the adverse effects on health. Ownership of more assets is found to lower the incidence of health shocks. Members of asset-rich households also show significantly lower effects of drought on general diseases. In fact, the adverse effect vanishes for the highest deciles of the asset distribution. Similarly, the availability of sufficiently high off-farm income within the household is found to 
Table 3.4: Formal and informal insurance schemes as coping strategies

\begin{tabular}{|c|c|c|c|c|c|}
\hline & $\begin{array}{c}(1) \\
\text { Assets }\end{array}$ & $\begin{array}{c}(2) \\
\text { Off-farm income }\end{array}$ & $\begin{array}{c}(3) \\
\text { HCFP }\end{array}$ & $\begin{array}{c}(4) \\
\text { Priv. insurance }\end{array}$ & $\begin{array}{c}(5) \\
\text { Social network }\end{array}$ \\
\hline Drought severity & $\begin{array}{c}0.2272^{* * *} \\
(0.0433)\end{array}$ & $\begin{array}{c}0.1070^{* * *} \\
(0.0172)\end{array}$ & $\begin{array}{c}0.1082^{* * *} \\
(0.0188)\end{array}$ & $\begin{array}{c}0.0928^{* * *} \\
(0.0163)\end{array}$ & $\begin{array}{c}0.0995^{* * *} \\
(0.0204)\end{array}$ \\
\hline Asset index, lagged & $\begin{array}{c}-0.0484 \\
(0.0520)\end{array}$ & & & & \\
\hline Off-farm cash income (1000 USD) & & $\begin{array}{c}0.0271 \\
(0.0565)\end{array}$ & & & \\
\hline Household part of HCFP & & & $\begin{array}{c}0.0387^{* * *} \\
(0.0104)\end{array}$ & & \\
\hline Private health insurance & & & & $\begin{array}{l}-0.0158 \\
(0.0144)\end{array}$ & \\
\hline Social network for coping & & & & & $\begin{array}{c}0.0088 \\
(0.0110)\end{array}$ \\
\hline Drought $*$ Asset index, lagged & $\begin{array}{c}-0.4386^{* * *} \\
(0.1190)\end{array}$ & & & & \\
\hline Drought $*$ Off-farm cash income & & $\begin{array}{l}-0.2152^{*} \\
(0.1225)\end{array}$ & & & \\
\hline Drought $* \mathrm{HCFP}$ & & & $\begin{array}{l}-0.0269 \\
(0.0217)\end{array}$ & & \\
\hline Drought $*$ Private health insurance & & & & $\begin{array}{c}0.0367 \\
(0.0268)\end{array}$ & \\
\hline Drought $*$ Social network & & & & & $\begin{array}{l}-0.0039 \\
(0.0227)\end{array}$ \\
\hline Wave-FE & Yes & Yes & Yes & Yes & Yes \\
\hline Province-FE & Yes & Yes & Yes & Yes & Yes \\
\hline Other control variables & Yes & Yes & Yes & Yes & Yes \\
\hline Observations & 25143 & 34267 & 34561 & 34593 & 34467 \\
\hline Adjusted $R^{2}$ & 0.119 & 0.110 & 0.111 & 0.110 & 0.110 \\
\hline Mean of dependent variable & & 0.1644 & 0.1647 & & \\
\hline
\end{tabular}

lower the vulnerability to drought-related diseases. The overall effect, however, remains positive and significant for the average household.

Second, apart from these economic coping strategies, the households in the sample have limited access to public and private health insurance schemes. Column 3 disaggregates the effect of drought by whether a household is part of the HCFP health insurance scheme. Since the HCFP mainly targets households vulnerable to poverty and economic shocks, it is reasonable that members of those households generally display higher illness rates. Being part of the program, however, does not lead to a significantly lower vulnerability to drought-related diseases. Similar results emerge for private health insurance (column 4). However, these results should be seen as indicative, rather than causal. Self-selection effects might play a major role here since people with worse health conditions are more likely to acquire insurance in the first place.

Finally, we investigate the role of informal social networks. As a proxy measure, we take the self-reported information on whether the household could refer to a network of friends, relatives, or neighbors in times of need. Column 5 does not reveal statistically significant evidence for differential drought-related health effects by the availability of social networks within the village. This could point to the fact that the amount of damage done by drought is too large to be coped 
with through social networks. Recall that droughts are covariate shocks which could limit the ability of community members to provide assistance to each other in cases of hardship.

\subsubsection{The impact of drought on the household budget}

Given the drought related deterioration of health outcomes, it will be important to establish the costs associated with drought-related health shocks. This section estimates how much additional per-capita health expenditures are spent in households that suffer one or more drought-related health shocks. The main explanatory variable of interest is the incidence of illness within one household. The socio-demographic characteristics are aggregated at the household level by calculating the share of male household members as well as the shares that specific age groups make up in the household. Household sizes and household dependency ratios are added to the model as control variables to account for economies of scale in the household health budget. All specifications to follow include time and province fixed-effects to capture changes in Vietnam's health sector over time and province-specific differences in household (health) budgets. As the dependent variable is inflated at zero, left-censored Tobit and IV-Tobit models are estimated. The main results are summarized in table 3.5.

In terms of the demographic structure of the household, the results generally suggest that households with a higher share of elderly have higher per-capita health expenditures while households with younger members have relatively lower per-capita health expenditures. Larger households are found to have less per-capita health expenditures on average, which illustrates the existence of economies of scale in health care expenditures.

Before turning to the analysis of the causal drought-health-expenditure nexus, column 1 presents reduced-form estimates of the relationship between health conditions and health expenditures as a benchmark. As can be expected, a rising incidence in ill household members is associated with more expenditures allocated for health purposes. The response of the budget is relatively weak, estimated at about 35 USD only. Columns (2) to (4) of table 3.5 report the results from IV-Tobit estimation when the share of ill household members is instrumented by the severity of drought. The first subcolumn reports the second stage while the last subcolumn provides the results from the first stage.

Similar to the analysis at the household member level, the results show a strong association between the severity of drought and the share of sick people in the household in the first stage. In the pooled analysis with all income groups (column 2), going from the least drought-affected to the most drought-affected district in the sample is estimated to lead to a roughly 24 percentage 
Table 3.5: The effect of drought-related health shocks on health expenditures

\begin{tabular}{|c|c|c|c|c|c|c|c|}
\hline \multirow[b]{2}{*}{ Illness in household } & \multirow{2}{*}{$\begin{array}{c}(1) \\
\text { Tobit } \\
34.8054^{* * *} \\
(2.1050)\end{array}$} & \multicolumn{2}{|c|}{$\begin{array}{c}(2) \\
\text { IV-Tobit }\end{array}$} & \multicolumn{2}{|c|}{$\begin{array}{c}(3) \\
\text { Income oroup } 1\end{array}$} & \multicolumn{2}{|c|}{$\begin{array}{c}(4) \\
\text { Income group } 2\end{array}$} \\
\hline & & $\begin{array}{c}115.3417^{* * *} \\
(34.1056)\end{array}$ & & $\begin{array}{l}70.4695^{* *} \\
(35.5459)\end{array}$ & & $\begin{array}{l}220.0652^{* *} \\
(97.1881)\end{array}$ & \\
\hline Drought severity & & & $\begin{array}{c}0.2417^{* * *} \\
(0.0393)\end{array}$ & & $\begin{array}{c}0.3146^{* * *} \\
(0.0556)\end{array}$ & & $\begin{array}{c}0.1462^{* * *} \\
(0.0555)\end{array}$ \\
\hline Share Age 0 - 10 & $\begin{array}{c}-43.4163^{* * *} \\
(9.3336)\end{array}$ & $\begin{array}{c}0.0558 \\
(21.0093)\end{array}$ & $\begin{array}{c}-0.5382^{* * *} \\
(0.0506)\end{array}$ & $\begin{array}{l}-23.2406 \\
(22.4504)\end{array}$ & $\begin{array}{c}-0.4987^{* * *} \\
(0.0668)\end{array}$ & $\begin{array}{c}98.8563 \\
(67.3744)\end{array}$ & $\begin{array}{c}-0.6747^{* * *} \\
(0.0792)\end{array}$ \\
\hline Share Age 10 - 20 & $\begin{array}{c}-35.0901^{* * *} \\
(8.5762)\end{array}$ & $\begin{array}{c}-5.6859 \\
(15.2111)\end{array}$ & $\begin{array}{l}-0.3694^{* * *} \\
(0.0454)\end{array}$ & $\begin{array}{l}-26.5807^{*} \\
(14.9590)\end{array}$ & $\begin{array}{c}-0.2711^{* * *} \\
(0.0604)\end{array}$ & $\begin{array}{c}78.5573 \\
(55.3837)\end{array}$ & $\begin{array}{c}-0.5535^{* * *} \\
(0.0706)\end{array}$ \\
\hline Share Age 20 - 30 & $\begin{array}{c}-19.0360^{* *} \\
(8.9554)\end{array}$ & $\begin{array}{c}4.2331 \\
(13.4741)\end{array}$ & $\begin{array}{l}-0.2891^{* * *} \\
(0.0471)\end{array}$ & $\begin{array}{l}-16.0146 \\
(13.1408)\end{array}$ & $\begin{array}{c}-0.1837^{* * *} \\
(0.0613)\end{array}$ & $\begin{array}{c}55.0099 \\
(42.8767)\end{array}$ & $\begin{array}{c}-0.4029^{* * *} \\
(0.0770)\end{array}$ \\
\hline Share Age $30-40$ & $\begin{array}{l}-7.0742 \\
(9.9769)\end{array}$ & $\begin{array}{c}29.5111 \\
(18.4486)\end{array}$ & $\begin{array}{l}-0.4544^{* * *} \\
(0.0547)\end{array}$ & $\begin{array}{c}1.0900 \\
(16.5919)\end{array}$ & $\begin{array}{c}-0.2948^{* * *} \\
(0.0721)\end{array}$ & $\begin{array}{c}93.5385 \\
(61.7669)\end{array}$ & $\begin{array}{c}-0.6031^{* * *} \\
(0.0871)\end{array}$ \\
\hline Share Age 40 - 50 & $\begin{array}{c}4.8590 \\
(10.1210)\end{array}$ & $\begin{array}{l}41.5497^{* *} \\
(18.7035)\end{array}$ & $\begin{array}{c}-0.4489^{* * *} \\
(0.0520)\end{array}$ & $\begin{array}{c}6.2097 \\
(16.3266)\end{array}$ & $\begin{array}{c}-0.3052^{* * *} \\
(0.0692)\end{array}$ & $\begin{array}{l}96.4479^{*} \\
(55.9197)\end{array}$ & $\begin{array}{c}-0.5285^{* * *} \\
(0.0845)\end{array}$ \\
\hline Share Age 50 - 60 & $\begin{array}{l}20.3070^{* *} \\
(10.0613)\end{array}$ & $\begin{array}{c}37.5833^{* * *} \\
(12.6676)\end{array}$ & $\begin{array}{l}-0.2072^{* * *} \\
(0.0498)\end{array}$ & $\begin{array}{c}6.3584 \\
(13.8939)\end{array}$ & $\begin{array}{l}-0.1194^{*} \\
(0.0648)\end{array}$ & $\begin{array}{c}87.6066^{* * *} \\
(33.9481)\end{array}$ & $\begin{array}{c}-0.2807^{* * *} \\
(0.0813)\end{array}$ \\
\hline Share Male & $\begin{array}{l}-0.5728 \\
(5.4866)\end{array}$ & $\begin{array}{c}6.6251 \\
(6.6038)\end{array}$ & $\begin{array}{c}-0.0906^{* * *} \\
(0.0302)\end{array}$ & $\begin{array}{c}0.0253 \\
(8.0446)\end{array}$ & $\begin{array}{c}-0.1161^{* * *} \\
(0.0409)\end{array}$ & $\begin{array}{c}6.9923 \\
(12.3879)\end{array}$ & $\begin{array}{l}-0.0475 \\
(0.0447)\end{array}$ \\
\hline Household size & $\begin{array}{l}-4.7911^{* * *} \\
(0.7125)\end{array}$ & $\begin{array}{c}-7.1753^{* * *} \\
(1.2725)\end{array}$ & $\begin{array}{c}0.0297^{* * *} \\
(0.0040)\end{array}$ & $\begin{array}{l}-4.7971^{* * *} \\
(1.4475)\end{array}$ & $\begin{array}{c}0.0286^{* * *} \\
(0.0058)\end{array}$ & $\begin{array}{c}-13.0780^{* * *} \\
(3.5971)\end{array}$ & $\begin{array}{c}0.0351^{* * *} \\
(0.0057)\end{array}$ \\
\hline Dependency ratio & $\begin{array}{l}-1.0240 \\
(1.8384)\end{array}$ & $\begin{array}{l}-3.4740 \\
(2.3134)\end{array}$ & $\begin{array}{c}0.0310^{* * *} \\
(0.0105)\end{array}$ & $\begin{array}{c}-4.1733^{*} \\
(2.4909)\end{array}$ & $\begin{array}{l}0.0260^{*} \\
(0.0136)\end{array}$ & $\begin{array}{l}-2.6088 \\
(5.2777)\end{array}$ & $\begin{array}{l}0.0294^{*} \\
(0.0168)\end{array}$ \\
\hline Wave-FE & Yes & Yes & Yes & Yes & Yes & Yes & Yes \\
\hline Province-FE & Yes & Yes & Yes & Yes & Yes & Yes & Yes \\
\hline Observations & 7355 & 7355 & & 3633 & & 3705 & \\
\hline Mean of dep. var. & 45.1250 & & & 37.4926 & & 52.6904 & \\
\hline Median of dep. var. & 14.9850 & & & 12.6061 & & 18.9091 & \\
\hline
\end{tabular}

Tobit regressions. Dependent variable: Health expenditures (constant 2005 USD).

Robust standard errors in parentheses. ${ }^{*} p<0.1,{ }^{* *} p<0.05,{ }^{* * *} p<0.01$

points increase in the likelihood of illness in the household..$^{52}$

Turning to the effect of drought-related health shocks on the household budget, the results in column 2 suggest that drought-related diseases have a non-negligible impact on the health component of household consumption. If all income groups are pooled, the drought-related illness incidence is estimated to increase per-capita health expenditures by roughly 115 USD. ${ }^{53}$ This is about $11 \%$ of the total annual per-capita consumption of the median household in the sample.

To get a better understanding of what the additional drought-related health costs imply for a typical rural household in Vietnam, columns 3 and 4 provide separate regressions for the

\footnotetext{
${ }^{52}$ Regarding the power of the instrument, we find the p-value on the excluded drought variable in the first stage below 0.000 corresponding to an F-statistics of well above 10 .

${ }^{53}$ The corresponding $95 \%$ confidence interval ranges from 48 to 192 USD.
} 
lower and the upper part of the sample's wealth distribution. ${ }^{54}$ The results show that in both income groups, there is evidence for a positive and significant effect of drought-related illness on the household budget - with an increasing response in asset wealth. For the lower part of the distribution, the estimated response of the health budget is around $9 \%$ of median total per-capita consumption and some $16 \%$ of what the median household member in that wealth group consumes in food throughout the entire year. The analysis for the upper wealth group leads to similar conclusions with the response being $17 \%$ of median total per-capita consumption and $35 \%$ of median per-capita food consumption. Consequently, the additional expenditures due to drought-related illness are non-negligible for many households vulnerable to poverty, especially for the poorest households in the rural provinces and arguably more so when multiple health shocks occur within the same household. ${ }^{55}$

\subsection{Conclusion}

Climate shocks are common in many countries across the world. Many developing countries are particularly prone to droughts and rainfall patterns that have started to deviate from their traditional seasonal patterns. Countries throughout Asia are experiencing climate variability and many regularly face delayed rainfall which can cause damaging episodes of drought. In rural Vietnam, whose economy continues to depend on rice production and other water-intensive crops, a lack of timely rainfall can have significant impacts on incomes, nutrition, health and health expenditures.

The long-term impacts of drought on adult outcomes have been well established by the literature. Surviving children are frequently affected by lower height-for-age, often in combination with reduced cognitive abilities and lower income trajectories during their adult-life. The short-term health implications of drought for health conditions are less well established, and especially the direct economic costs are largely unknown at the micro level. This paper contributes to the existing literature by providing new estimates on the immediate effects of drought on health outcomes and health-related expenditures for rural households in Vietnam. Combining household panel data with local rainfall data, it is possible to establish a direct link between periods of low rainfall, drought-related illness, and associated health care expenditures. In the econometric

\footnotetext{
${ }^{54}$ The quartiles are assigned by the values of the cumulative asset index in the first wave. The asset index shows a high correlation with total household consumption, but is less prone to being affected by the direct effects of drought exposure in the first survey wave.

${ }^{55}$ The estimated figures should be understood as gross additional expenditures in response to drought-related health shocks. While this serves to quantify the monetary costs from drought to the household, this does not directly reveal whether the household substitutes other components of consumption, i.e., non-health consumption, or whether these are extra expenditures. If the log of total household consumption is added as a control variable, the estimated numbers would reflect net additional expenditures since total consumption is kept constant. We find the estimates in the pooled sample to drop from 153 to 118 USD when total consumption is included as a regressor. It therefore seems that the major part of drought-related health costs indeed causes extra expenditures.
} 
domain, the paper employs the established IV approach based on an estimation strategy where the incidence of self-reported health shocks is estimated using objectively measured rainfall events.

The results suggest that rural households affected by drought experience a deterioration in health conditions and face significantly higher health expenditures. The evidence presented here shows that drought increases the likelihood of illness, particularly among households whose agricultural revenues are negatively affected. The ability to tap into durable assets as well as the availability of diverse income sources, particularly off-farm income, is shown to alleviate some of the drought-related effects on health. In terms of the health expenditures, the IV estimates suggest that drought-related health shocks can pose significant financial challenge for households vulnerable to poverty in rural Vietnam. The overall impact of climate shocks on health outcomes and related expenditures is substantial.

Several policy conclusions emerge from this study. While it highlights the potential short-term impacts climate shocks such as drought can have on health outcomes and health expenditures, it emphasizes the need for mitigation as well as ex-ante risk reduction. Households with diversified income sources tend to be less affected by malnutrition and impaired immune systems during drought. Insuring agricultural output against climate shocks is another potential mechanism farm households can pursue. Vietnam's efforts to extend free basic health care to the poor may, if effectively targeted, help reduce the health expenditures associated with drought. Future research might benefit from piloting interventions aimed at reducing the health effects from climate shocks, while preventing families from falling (deeper) into poverty. 


\section{A Appendix}

Table 3.A.1: Average disease incidence and insurance coverage by province

\begin{tabular}{lccc}
\hline \hline & Ha Tinh & Hue & Dak Lak \\
\hline$(1 / 0)$ Serious disease & 0.17 & 0.14 & 0.14 \\
$(1 / 0)$ Infections & 0.06 & 0.05 & 0.04 \\
$(1 / 0)$ Long-term diseases & 0.04 & 0.03 & 0.03 \\
$(1 / 0)$ Non-communicable diseases & 0.05 & 0.04 & 0.04 \\
$(1 / 0)$ Other diseases & 0.02 & 0.01 & 0.02 \\
$(1 / 0)$ Free health card & 0.60 & 0.51 & 0.58 \\
$(1 / 0)$ Private health insurance & 0.05 & 0.11 & 0.06 \\
\hline Observations & 12358 & 12507 & 14998 \\
\hline \hline
\end{tabular}

Table 3.A.2: Classification of diseases

\begin{tabular}{|c|c|c|c|}
\hline Infection in blood circle & I & Absent minded & $\mathrm{N}$ \\
\hline Pneumonia & I & Other accident-related injuries & $\mathrm{N}$ \\
\hline Dengue Hemorrhagic Fever & I & Coronary heart disease & $\mathrm{L}$ \\
\hline Headache & I & Cerebral infarction & $\mathrm{L}$ \\
\hline Diarrhoea, gastroenteritis & I & Asthenia & $\mathrm{L}$ \\
\hline Tuberculosis & $\mathrm{I}$ & Hypertension & $\mathrm{L}$ \\
\hline Encephalitis & I & Valvular heart disease & $\mathrm{L}$ \\
\hline Bronchitis & I & Calculus of kidney & $\mathrm{L}$ \\
\hline Tetanus & I & Artificial kidney & $\mathrm{L}$ \\
\hline Hepatitis B & $\mathrm{I}$ & Osteoporosis & $\mathrm{L}$ \\
\hline Influenza & $\mathrm{I}$ & Blindness & $\mathrm{L}$ \\
\hline Bellyache & I & Deaf & $\mathrm{L}$ \\
\hline Diphtheria & I & Malignant neoplasms & $\mathrm{L}$ \\
\hline Mumps & I & AIDS & $\mathrm{L}$ \\
\hline Pertussis & I & Cervical Cancer & $\mathrm{L}$ \\
\hline Measles & I & Lung cancer & $\mathrm{L}$ \\
\hline Poliomyelitis & I & Down-Syndrom & $\mathrm{L}$ \\
\hline Arthralgia & $\mathrm{N}$ & Breast cancer & $\mathrm{L}$ \\
\hline Fractures of other limb bones & $\mathrm{N}$ & Leukemia & $\mathrm{L}$ \\
\hline Backache & $\mathrm{N}$ & Rubella & $\mathrm{L}$ \\
\hline Cataract and other disorders of lens & $\mathrm{N}$ & Epilepsy & $\mathrm{L}$ \\
\hline Bleeding per rectum & $\mathrm{N}$ & Diabetes mellitus & $\mathrm{O}$ \\
\hline Ischaemic heart diseases & $\mathrm{N}$ & Alcoholism & $\mathrm{O}$ \\
\hline Diseases of appendix & $\mathrm{N}$ & Lymph nodes of the neck & $\mathrm{O}$ \\
\hline Asthma & $\mathrm{N}$ & Agent-orange related disease & $\mathrm{O}$ \\
\hline \multicolumn{4}{|c|}{ I: Infections } \\
\hline \multicolumn{4}{|c|}{$\mathrm{N}$ : short-term non-communicable diseases } \\
\hline \multicolumn{4}{|c|}{ L: long-term non-communicable diseases } \\
\hline O: Other diseases & & & \\
\hline
\end{tabular}


Table 3.A.3: Different measures of drought, standardized coefficients

\begin{tabular}{|c|c|c|c|c|}
\hline & $\begin{array}{c}(1) \\
\text { Disease }\end{array}$ & $\begin{array}{c}(2) \\
\text { Disease }\end{array}$ & $\begin{array}{c}(3) \\
\text { Disease }\end{array}$ & $\begin{array}{c}(4) \\
\text { Disease }\end{array}$ \\
\hline Drought severity $(\mathrm{mm}), 3$-months average & $\begin{array}{c}0.0540^{* * *} \\
(0.0000)\end{array}$ & & & \\
\hline Drought severity $(\mathrm{mm}), 3$-months average, SPI & & $\begin{array}{c}0.0544^{* * *} \\
(0.0019)\end{array}$ & & \\
\hline \# Drought months & & & $\begin{array}{c}0.0365^{* * *} \\
(0.0030)\end{array}$ & \\
\hline \# Drought months, 3-months avg. & & & & $\begin{array}{c}0.0227^{* * *} \\
(0.0021)\end{array}$ \\
\hline Wave-FE & Yes & Yes & Yes & Yes \\
\hline Province-FE & Yes & Yes & Yes & Yes \\
\hline Other control variables & Yes & Yes & Yes & Yes \\
\hline Observations & 34593 & 34593 & 34593 & 34593 \\
\hline Adjusted $R^{2}$ & 0.110 & 0.110 & 0.109 & 0.109 \\
\hline$A I C$ & 25535.28 & 25527.15 & 25563.30 & 25580.76 \\
\hline $\mathrm{F}$ & 146.03 & 145.52 & 145.04 & 144.96 \\
\hline
\end{tabular}

Table 3.A.3 presents the relationship of drought incidence and health outcomes on the individual level when using alternative measures of drought. Standardized coefficients are reported. Column 1 reproduces the results from the main empirical section using the three-months time scale and absolute deviations from the climatic average. In column 2, these deviations are scaled in terms of standard deviations of the long-term climatic rainfall distribution, as is commonly done in computing Standard Precipitation Indices (SPI). The association is found to be slightly weaker, but still highly statistically significant. Columns 3 and 4 finally report a positive relationship between the length of dry spells and illness incidence. Apart from hydrological considerations, the three-month measure from column 1, as used in the main part of this paper, also yields the highest explanatory power - as reflected in the adjusted $R^{2}$ or the Akaike Information Criteria (AIC). 
Table 3.A.4: The effect of drought on health for varying crop revenues

\begin{tabular}{|c|c|c|c|c|c|c|}
\hline & $\begin{array}{l}\text { (1) } \\
\text { All } \\
\end{array}$ & $\begin{array}{l}(2) \\
\text { All } \\
\end{array}$ & $\begin{array}{c}(3) \\
\text { Infections }\end{array}$ & $\begin{array}{c}(4) \\
\text { Infections }\end{array}$ & $\begin{array}{c}(5) \\
\text { N-c. }\end{array}$ & $\begin{array}{c}(6) \\
\text { N-c. }\end{array}$ \\
\hline Drought & $\begin{array}{c}0.1024^{* * *} \\
(0.0286)\end{array}$ & $\begin{array}{c}0.5041^{* * *} \\
(0.1906)\end{array}$ & $\begin{array}{c}0.0643^{* * *} \\
(0.0203)\end{array}$ & $\begin{array}{c}0.1354 \\
(0.1361)\end{array}$ & $\begin{array}{c}0.0194 \\
(0.0146)\end{array}$ & $\begin{array}{c}0.2443^{* * *} \\
(0.0933)\end{array}$ \\
\hline Crop revenue & $\begin{array}{c}-0.0184^{* * *} \\
(0.0070)\end{array}$ & $\begin{array}{c}0.0106 \\
(0.0145)\end{array}$ & $\begin{array}{l}-0.0063 \\
(0.0051)\end{array}$ & $\begin{array}{l}-0.0012 \\
(0.0101)\end{array}$ & $\begin{array}{l}-0.0016 \\
(0.0035)\end{array}$ & $\begin{array}{c}0.0146^{* *} \\
(0.0074)\end{array}$ \\
\hline Drought $*$ Crop revenue & & $\begin{array}{c}-0.0676^{* *} \\
(0.0309)\end{array}$ & & $\begin{array}{l}-0.0120 \\
(0.0217)\end{array}$ & & $\begin{array}{c}-0.0379^{* *} \\
(0.0154)\end{array}$ \\
\hline Avg. crop revenue (all years) & $\begin{array}{l}-0.0130 \\
(0.0083)\end{array}$ & $\begin{array}{l}-0.0126 \\
(0.0083)\end{array}$ & $\begin{array}{c}-0.0124^{* *} \\
(0.0061)\end{array}$ & $\begin{array}{c}-0.0123^{* *} \\
(0.0062)\end{array}$ & $\begin{array}{l}-0.0052 \\
(0.0047)\end{array}$ & $\begin{array}{l}-0.0049 \\
(0.0047)\end{array}$ \\
\hline Wave-FE & Yes & Yes & Yes & Yes & Yes & Yes \\
\hline Province-FE & Yes & Yes & Yes & Yes & Yes & Yes \\
\hline Control variables & Yes & Yes & Yes & Yes & Yes & Yes \\
\hline $\begin{array}{l}\text { Observations } \\
\text { Pseudo } R^{2}\end{array}$ & 11573 & 11573 & 11573 & 11573 & 11573 & 11573 \\
\hline
\end{tabular}

OLS regressions. Binary dependent variables are indicated in the first row.

Control variables include binary variables for gender and age brackets as well as an asset index.

Standard errors, clustered at the household level, in parentheses. ${ }^{*} p<0.1,{ }^{* *} p<0.05,{ }^{* * *} p<0.01$. 


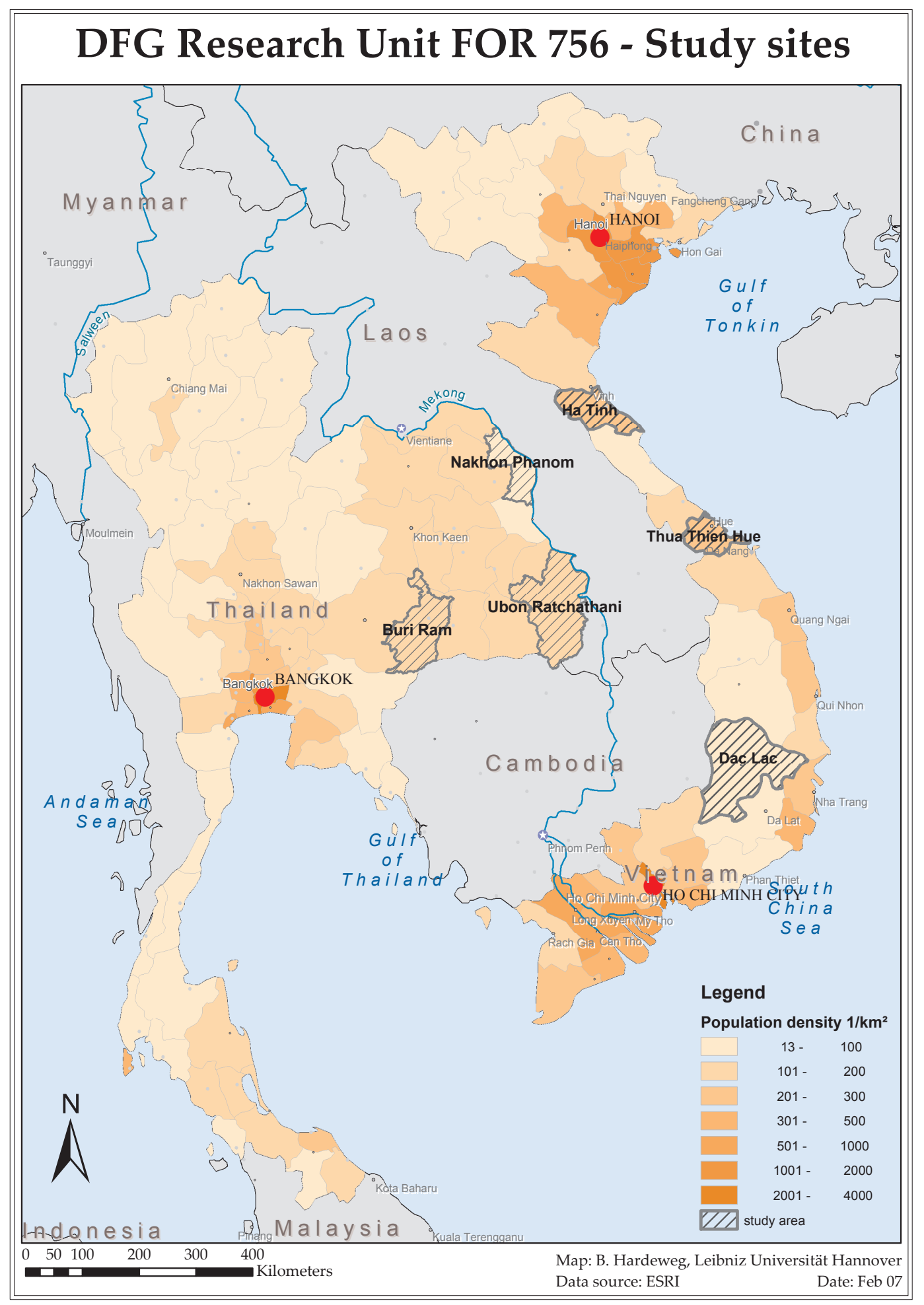

Figure 3.A.1: Study area of the "Vulnerability to poverty in Southeast Asia" survey 

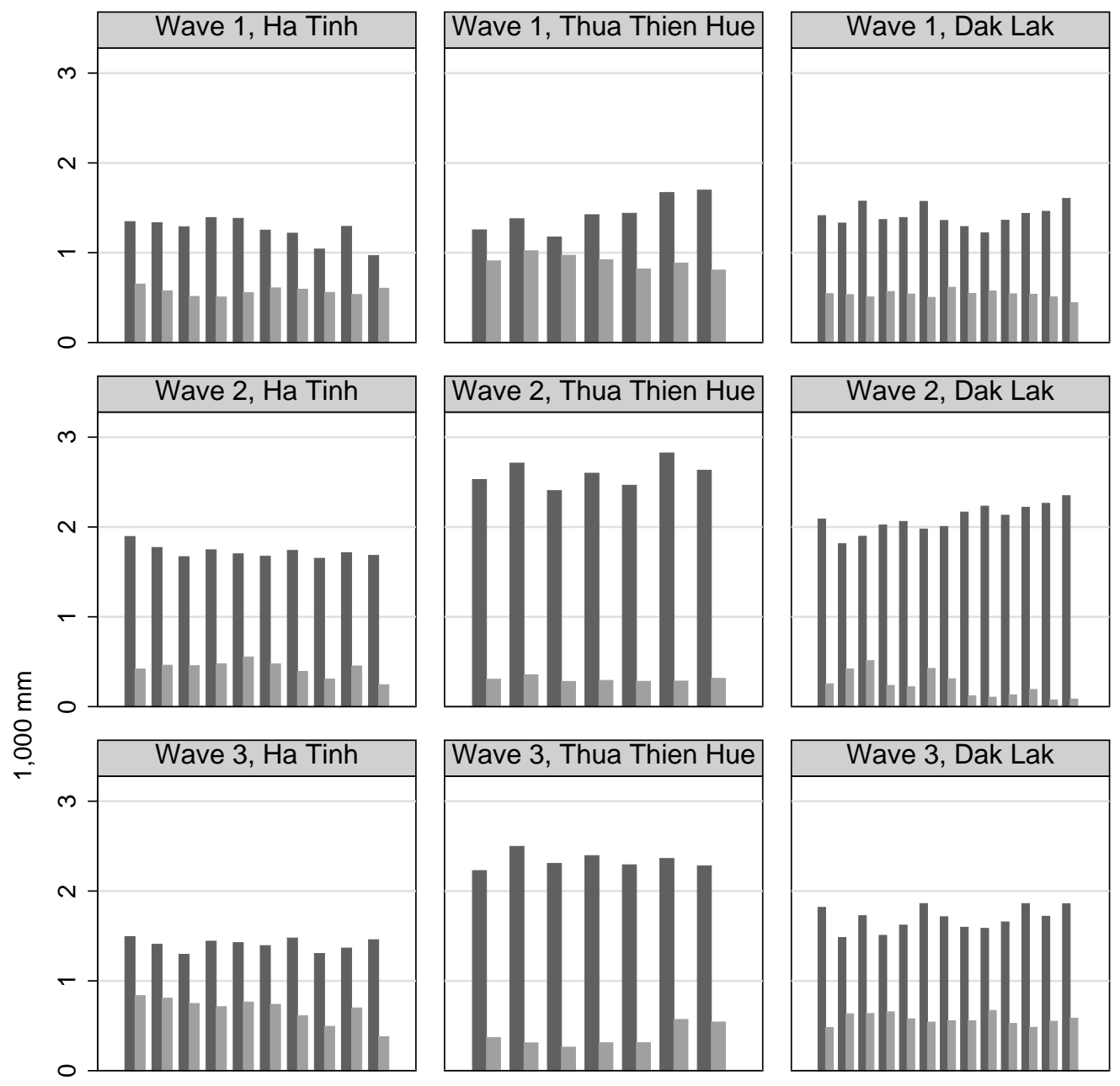

Wave 2, Thua Thien Hue
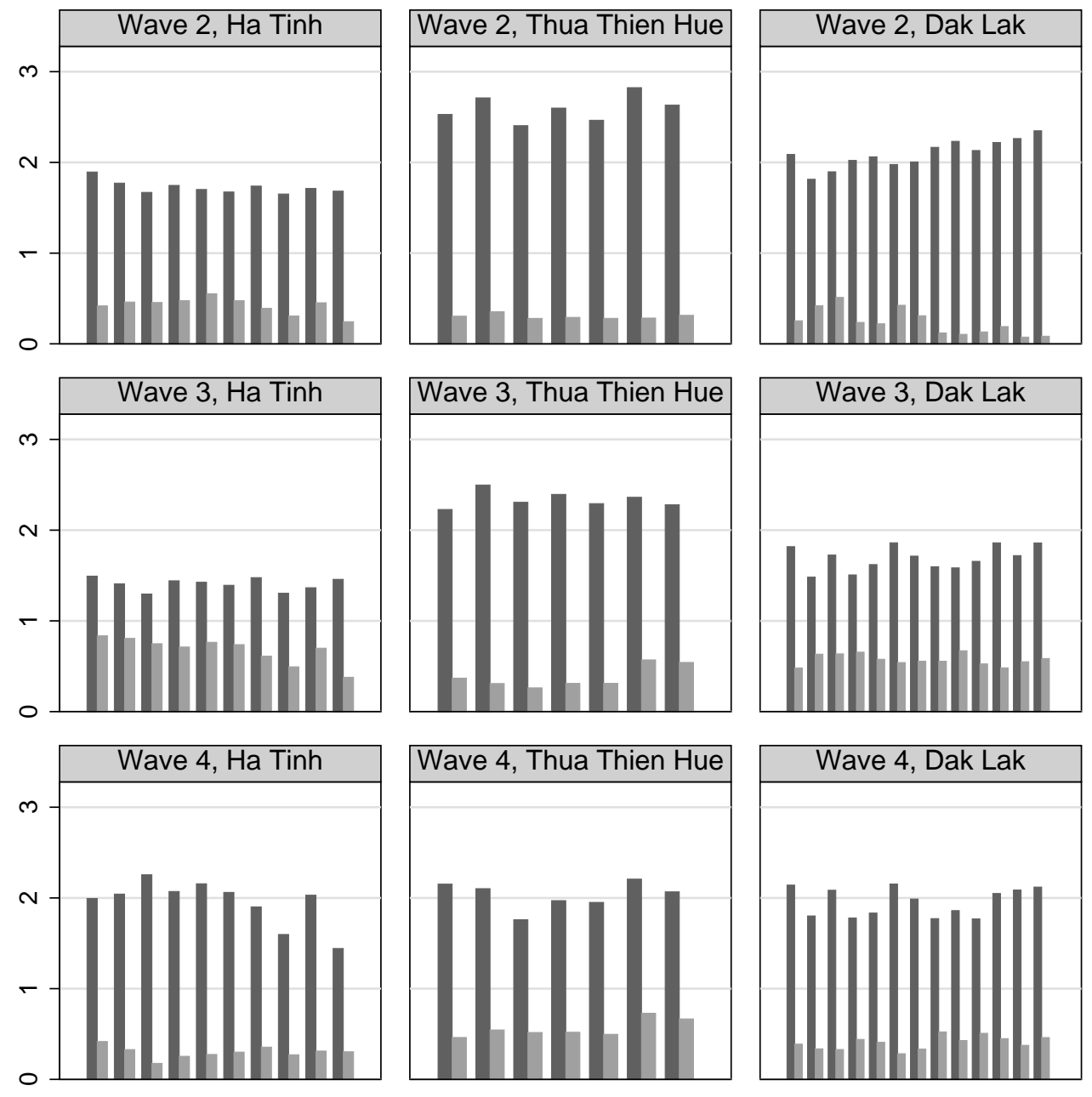

Actual precipitation

Drought severity

Source: own calculations

Figure 3.A.2: Drought severity at the district level, by province and wave 


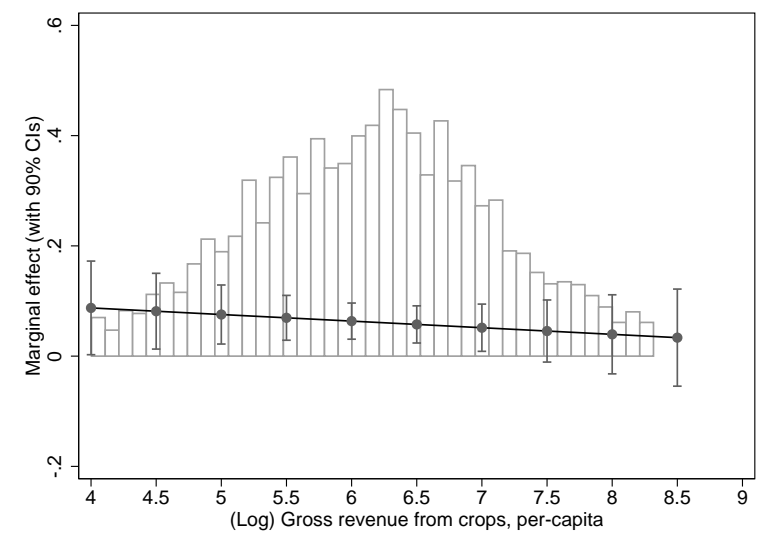

(a) Infectious diseases

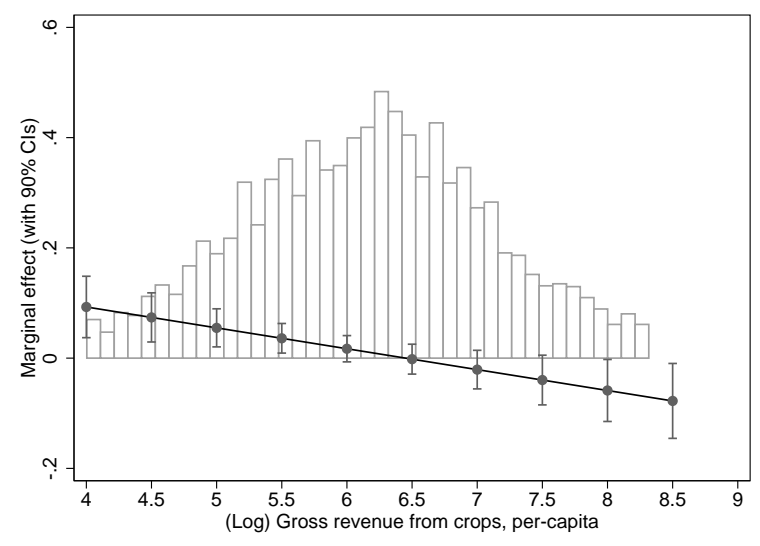

(b) Non-communicable diseases

Figure 3.A.3: The effect of drought on health for varying crop revenues 


\title{
4 Aid and Growth at the Regional Level
}

\begin{abstract}
This paper brings the aid effectiveness debate to the sub-national level. We hypothesize the non-robust results regarding the effects of aid on development in the previous literature to arise due to the effects of aid being insufficiently large to measurably affect aggregate outcomes. Using geo-coded data for World Bank aid to a maximum of 2,221 ADM1 regions and 54,167 ADM2 regions in 130 countries over the 2000-2011 period, we test whether aid affects development, measured as nighttime light growth. Our preferred identification strategy exploits variation arising from interacting a variable that indicates whether or not a country has passed the threshold for receiving IDA's concessional aid with a recipient region's probability to receive aid, in a sample of 478 ADM1 regions and almost 8,400 ADM2 regions from 21 countries. Controlling for the levels of the interacted variables, the interaction provides a powerful and excludable instrument. Overall, we find significant correlations between aid and growth in ADM2 regions, but no causal effects.
\end{abstract}

This essay is joint work with Axel Dreher. We would like to thank seminar participants at the Development Research Group meeting at the University of Goettingen for helpful comments. This essay is furthermore part of a research project on macroeconomic policy in low-income countries supported by the U.K. Department for International Development (DFID). The views expressed in this paper are those of the authors and do not necessarily represent those of the IMF, IMF policy, or DFID. 


\subsection{Introduction}

Consider Malawi's recent World Bank-sponsored Rural Land Development Project. In line with its objectives, the project succeeded in increasing the incomes of about 15,000 poor rural families in the project districts. ${ }^{56}$ Overall, the Bank's Independent Evaluation Group (IEG) rates around 75 percent of the World Bank's projects as successful. ${ }^{57}$ Still, these projects do not seem to measurably increase economic growth at the country level, as indicated by the lack of robustness in empirical studies on the effectiveness of foreign aid. ${ }^{58}$ This striking disparity between micro-level effectiveness and macro-level ineffectiveness is persistent in the empirical literature and has been coined the micro-macro paradox in foreign aid (Mosley, 1987).

We argue that the previous literature's focus on country- rather than regional-level growth in incomes is one important reason for the lack of a robust effect of aid on growth. ${ }^{59}$ While Malawi's World Bank project may increase the incomes of people in some of the targeted areas, it is unlikely that the increase in incomes is sufficiently large to be measurable at the country level. This arguably holds when we consider the total of Malawi's projects. According to data from AidData, total geo-coded aid inflows to Malawi amounted to almost 5.3 billion US dollars over the 2004-11 period (Peratsakis et al., 2012; Rajlakshmi, 2013). ${ }^{60}$ However, the regional allocation of this aid is not uniform across Malawi. For instance, the North receives fewer projects than the South, and aid projects cluster in densely populated areas. ${ }^{61}$ While these projects may fail to measurably promote growth in all of Malawi, the effects of aid might well be discernable at a more disaggregated level.

The lack of evidence on aid effectiveness at the regional level is due to the dearth of available data and the methodological problems in measuring the causal effect of aid below the country-level. With data availability increasing as a consequence of AidData's (and selected recipient countries') geo-coding efforts of aid projects, ${ }^{62}$ some recent studies have looked at the regional allocation of aid. However, with the exception of two studies focusing on Malawi, ${ }^{63}$ aid effectiveness has so far not been analyzed at the sub-national level. With geo-coded data on World Bank aid now being made available, we are able to conduct such an analysis. ${ }^{64}$

\footnotetext{
${ }^{56}$ See http://ieg.worldbankgroup.org/Data/reports/PPAR-75556-P132257-Malawi_Land_Dvlpmt.pdf (accessed March 16, 2014). The project was approved in 2004, and closed in 2011.

${ }^{57}$ See Dreher et al. (2013).

${ }^{58}$ E.g., Rajan and Subramanian (2008); Doucouliagos and Paldam (2009); Bjørnskov (2013); Roodman (2015).

${ }^{59}$ Another reason, of course, is the lack of a credible identification strategy. We return to this below.

${ }^{60}$ This represents around 80 percent of total World Bank commitments there. It amounts to 16 percent of Malawi's GDP over the same period.

${ }^{61}$ See AidData's blog entry on Malawi of April 19, 2012, http://aiddata.org/blog/where-are-donorsworking-in-malawi-a-new-dataset-sheds-light (accessed March 19, 2014).

${ }^{62}$ See Strandow et al. (2011) and AidData (2015).

${ }^{63}$ See Rajlakshmi (2013) and Dionne et al. (2013).

${ }^{64}$ Of course, we would like to test the effectiveness of aid from a larger sample of donors. Such data are not available for a worldwide sample.
} 
The lack of systematic empirical evidence on the effectiveness of aid below the country-level is an important gap in the literature. As we explain in detail in section 4.2, we aim to fill this gap by making use of geo-coded data for 1,662 World Bank aid projects in 2,221 first-level administrative areas (ADM1) regions and 54,167 second-level administrative areas (ADM2) regions in 130 countries that were approved over the 2000-2011 period. ${ }^{65}$ We test whether and to what extent disbursements of this aid and the number of World Bank projects affect development, measured as nighttime light growth. Given that we are the first to investigate the regional effectiveness of aid for a large sample of recipient countries, we start by replicating two prominent identification strategies from the country-level literature as closely as possible. First, we follow the recent analysis of Clemens et al. (2012), who address the potential endogeneity of aid by removing country-specific factors that do not vary over time, allowing for a time lag between the disbursement of aid and growth, and focusing on aid that they assume is particularly likely to affect growth in the short-run - so-called early-impact aid. Second, we rely on Brückner (2013), who suggests using, inter alia, rainfall growth and its square to purge aid of that part that is driven by changes in GDP per capita. As we explain below, these approaches cannot fully address concerns regarding the endogeneity of aid, and thus not necessarily allow us to identify a causal effect. What is more, rainfall turns out to be weak as an instrument for growth in our sample in most specifications.

Our own approach to identify the causal effect of aid on growth is closely connected to recent innovations in the country-level literature on aid effectiveness. We rely on Galiani et al. (2014), who instrument aid inflows with the income threshold of the International Development Association (IDA) for eligibility for the World Bank's concessional aid. This instrument could arguably be correlated with growth for reasons other than aid (Dreher and Langlotz, 2015). We overcome this problem by interacting the indicator of whether or not a country has crossed the IDA's threshold for receiving concessional aid with a recipient region's probability to receive aid, following recent identification strategies in the country-level literature on aid effectiveness (Werker et al., 2009; Ahmed, 2013; Nunn and Qian, 2014; Dreher and Langlotz, 2015). ${ }^{66}$ Controlling for the levels of the interacted variables, the interaction provides a powerful and excludable instrument.

According to our results (shown in section 4.3), aid and nighttime light growth are significantly

\footnotetext{
${ }^{65} \mathrm{ADM} 1$ regions are the governmental units directly below the nation state; ADM2 regions are those below the ADM1 level.

${ }^{66}$ Werker et al. (2009) rely on an interaction between oil prices and Muslim majority countries to instrument for oil-producing donors' aid, Ahmed (2013) and Dreher and Langlotz (2015) interact donor-level political fractionalization (which induces increases in donors' aid budgets) with the probability of a recipient country to get aid, while Nunn and Qian (2014) interact the probability to receive aid with US wheat production (to instrument for food aid from the United States).
} 
correlated at the ADM2 level, but not at the larger ADM1 level. Specifically, when we do not employ instruments, lagged aid shows a positive and significant correlation when region-fixed effects are not included in the specification, but a negative correlation otherwise. Purging aid of its endogenous component relying on rainfall growth and its square, we find the instruments to be weak in most specifications. The exception is at the ADM2 level, where we find a negative effect of aid on growth in our region-fixed effects specification. However, given the strong identifying assumption that this result relies on, we advise caution in interpreting it. When we employ our preferred instrument - the interaction of the probability to receive aid with having passed the IDA income threshold - in a sample of 478 ADM1 regions and almost 8,400 ADM2 regions in 21 countries, we find no effect of aid on development.

We conclude that there is no robust evidence showing that aid increases growth and discuss implications for future research in the final section of the paper.

\subsection{Data and Method}

The literature on the allocation and effectiveness of foreign aid below the country-level is scarce, mainly due to a lack of geo-coded data on aid, relevant outcomes, and adequate control variables. A number of datasets exist however which allow testing for sub-national determinants and consequences of aid. The dataset covering the largest number of countries has recently been provided by AidData (2015) in collaboration with the World Bank and consists of 3,534 geo-coded World Bank projects spread over 141 countries, approved over the 2000-2011 period. ${ }^{67}$ AidData also provides geo-coded information on projects from the African Development Bank (AfD) approved in the 2009-2010 period. ${ }^{68}$ Dreher et al. (2014) provide geo-coded data on Chinese aid to Africa, for the 2000-2012 period. ${ }^{69}$ Cambodia and Malawi share detailed information on the regional allocation of the aid they receive from a large number of donors. ${ }^{70}$

For this project, we make use of AidData's geo-coded data for World Bank projects - the only data available for a worldwide sample of countries over a reasonably long period of time. The raw dataset contains the project's date of approval, the (anticipated) date of termination, and

\footnotetext{
${ }^{67}$ See Findley et al. (2011) for a detailed description of an earlier - partial - release of these data.

${ }^{68}$ The World Bank- and AfD-data have been used in a number of aid allocation studies. Öhler and Nunnenkamp (2014) use an earlier subset of these data to study what determines the allocation of aid across a sample of 27 recipient countries over the 2005-2011 period. Variants of these data have also been used to study the determinants of aid allocation in Nunnenkamp et al. (2012) for India, Jablonski (2014) for Kenya, and Powell and Findley (2012) for six Sub-Sahara African recipient countries. Zhang (2004) relies on data provided by the World Bank to investigate the determinants of World Bank project allocation across Chinese provinces.

${ }^{69}$ Their results show that African regions where the current leader of a country was born receive substantial increases in aid from China, but - controlled for region-fixed effects - not from the World Bank.

${ }^{70}$ Öhler (2013) uses these data to investigate whether and to what extent donors coordinate at the regional level in Cambodia; Rajlakshmi (2013) and Dionne et al. (2013) investigate the allocation of projects from 30 donor agencies in Malawi.
} 
the amounts committed to and disbursed in the project over its entire duration. To calculate project-specific annual disbursements, we link the project database to the Bank's documentation of project-specific financial flows, including the precise date of project disbursements. ${ }^{71} \mathrm{We}$ transform these disbursements into constant 2011 US\$. A second variable of interest is the number of active projects per region rather than amounts of aid. This variable is frequently used in the literature trying to quantify the effects of World Bank involvement, as it might more adequately measure other components that accompany a project, like technical advice or program conditions, than do the amounts of aid alone (Boockmann and Dreher, 2003).

AidData covers projects that have been approved over the 2000-2011 period, comprising total commitments of nearly 370 bn US $\$$. For each project, detailed information on its locations is recorded, with different degrees of precision: Some projects are implemented in a limited geographical area, such as a village or city. Others are realized at more aggregate levels, such as a municipality, a district or greater administrative region. As described in detail Findley et al. (2011) and Strandow et al. (2011), the geo-coding is implemented by experienced coders in a double-blind process. Information on project locations come from various World Bank sources, most importantly project-specific planning or implementation documents. In a next step, coordinates of these locations are extracted from geographic online services providing names and coordinates of administrative divisions, populated areas, and other places of interest. Obviously, the coding precision reflects the sectoral composition of aid. Projects in sectors such as "Finance" or "Public Administration, Law, and Justice" are geo-coded predominantly at the national scale, while projects in sectors like "Transportation" are typically assigned to more precise locations. ${ }^{72}$

In total, about 50 percent of all project locations (amounting to roughly 40 percent of the projects) are assigned to a distinguishable subnational location. Since this paper focuses on sub-national projects' effects on sub-national growth, we exclude projects that are nation-wide in scope, for which no or unclear information on location is provided, and projects that are directly allocated to a government entity, as these cannot be attributed to specific regions. ${ }^{73}$

\footnotetext{
${ }^{71}$ These data are available at the World Bank's project website (http://www.worldbank.org/projects) per project, but not in aggregate form. We downloaded these data and aggregated disbursement flows on a yearly basis, treating negative disbursements as zero. In contrast to Dionne et al. (2013) we therefore do not need to estimate actual disbursements based on commitments or make restrictive assumptions on the spread of financial flows over the duration of a project.

${ }^{72}$ The "Tamil Nadu Road Sector Project" in India as one typical infrastructure project, for example, aims to promote the core road network of Tamil Nadu through upgrading existing state highways, maintaining smaller state roads, and institutional strengthening. In the dataset, twelve geo-coded locations are assigned to the project of which six correspond to an exact location, such as a village or town, five to a smaller administrative region, and one to a greater administrative region. Malawi's "Rural Land Development Project", introduced above, in turn could only be assigned more broadly to five smaller administrative divisions.

${ }^{73}$ In the empirical analysis, any potential country-wide effects of these flows are absorbed through the inclusion of country-period fixed-effects.
} 
We use the available project information on longitude and latitude of respective locations to match the aid projects to the respective country's first and second Administrative Regions (ADM1 and ADM2) using data from the Global Administrative Areas (GADM) database. ${ }^{74}$ ADM1 regions are the governmental units directly below the nation state, such as counties, regions, provinces, municipalities, or districts, among others, depending on the particular country (see Figure 4.1 for the African continent). ADM2 regions are those regions that are directly below the ADM1 level, like districts, municipalities, and communes. Regarding the matching to ADM1 regions, 77 percent of the projects were implemented in more than one region, without information on the share of aid disbursements going to the particular sites. For ADM2 regions, this concerns 88 percent of the projects. Following the previous literature (e.g., Dionne et al., 2013), we assume that aid (disbursements and number of projects) is allocated in proportion to the size of an area's population. ${ }^{75}$

Population data are taken from CIESIN/CIAT's "Gridded Population of the World" (CIESIN, 2005). These data are available for a worldwide grid of 2.5 arc-minutes resolution for the years 2000, 2005, and 2010. We calculate population size per administrative region by taking its mean population density and multiplying it with the area size provided in the GADM file. We use linear interpolation for the missing years, given that population changes slowly over time. Figure 4.1 shows the sum of aid disbursements per-capita over the whole 2000-2011 period for ADM1 regions of Africa. The figure illustrates the wide range of aid-receipts at the regional level within some (but not all) African countries, emphasizing the importance of investigating the effects of aid at the regional level.

As is common in the literature on aid effectiveness, we average our data to smooth changes over the business cycle. We follow Galiani et al. (2014) and build averages over three years. This is useful for our preferred identification strategy below, as donors commit funds to the IDA in so-called replenishment rounds that span these three-year periods. ${ }^{76}$ Our reduced-form

\footnotetext{
${ }^{74}$ See http://www.gadm.org.

${ }^{75} 23 \%$ (12\%) of the projects are located in one ADM1 (ADM2) region exclusively, $37 \%$ (25\%) have locations in between $2-5$ regions, $21 \%(19 \%)$ in 6-10 regions, and $18 \%(44 \%)$ in at least 10 regions. We test robustness by dividing aid amounts and numbers equally per project location, as in Dreher et al. (2014). Our conclusions are not affected by this.

${ }^{76}$ Specifically, we average data over the periods 2000-02, 2003-05, 2006-08, 2009-11, matching the IDA's replenishment rounds. We also include light data for the year 2012 to gain an additional "period", given that aid enters the regressions with a lag.
} 
Figure 4.1: Location-specific World Bank disbursements in Africa, ADM1 regions, 2000-2011

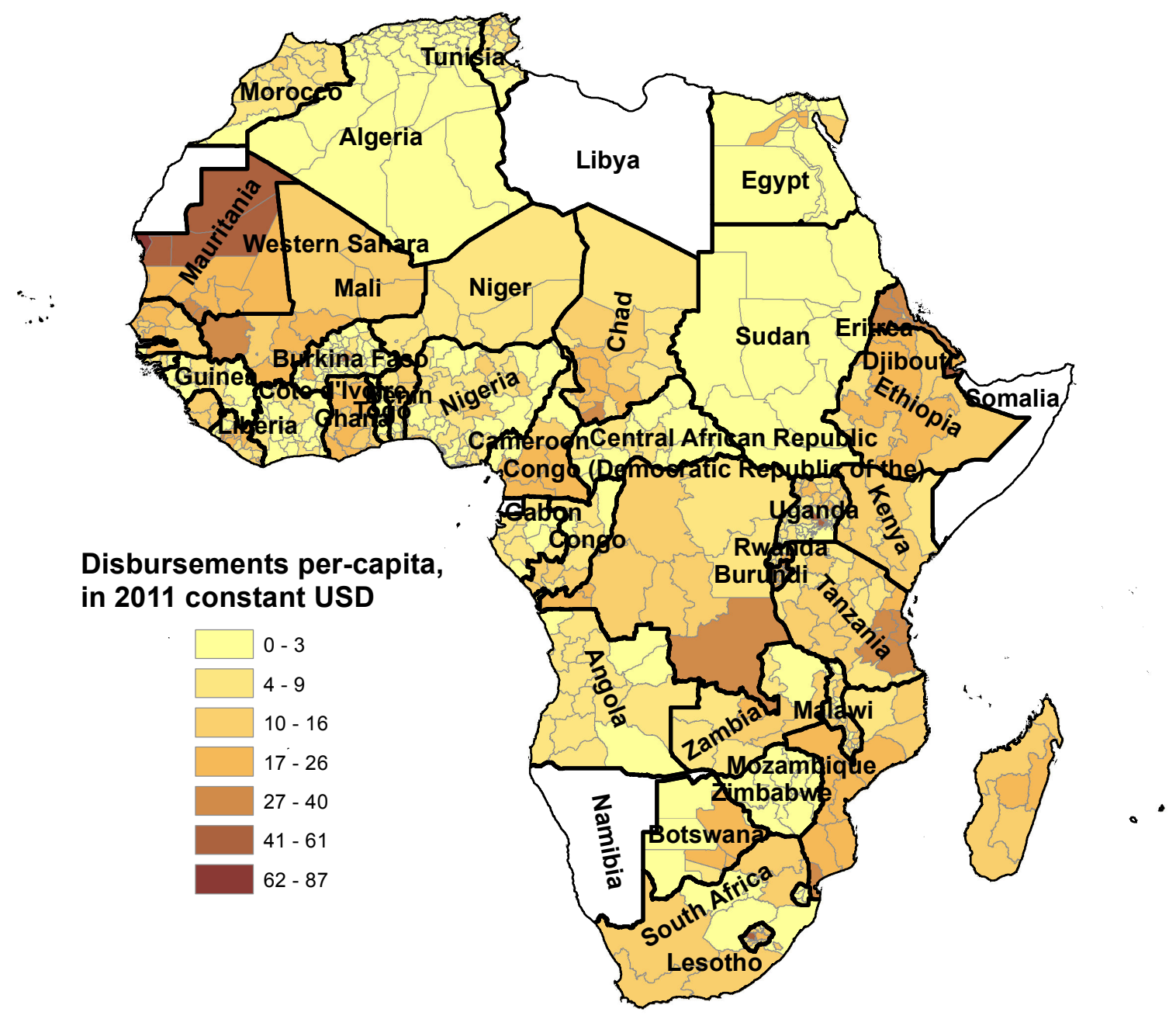

Total disbursements calculated based on AidData (2015). Disbursements for projects in multiple ADM1 regions are divided according to a region's share in population. 
empirical models are at the region-period level:

$$
\begin{aligned}
\text { Growth }_{i, t} & =\alpha+\beta A i d_{i, t-1}+\delta D E V_{i, 2000}+\zeta P O P_{i, t-1}+\theta P O P G R O W T H_{i, t} \\
& +\rho A R E A_{i}+\mu D I S T_{i}+\eta_{c, t}+\epsilon_{i, t} \\
\text { Growth }_{i, t} & =\alpha+\beta A i d_{i, t-1}+\zeta P O P_{i, t-1}+\theta P O P G R O W T H_{i, t}+\eta_{c, t}+\lambda_{i}+\epsilon_{i, t}
\end{aligned}
$$

where $i$ denotes regions and $c$ countries. Growt $h_{i, t}$ measures region $i$ 's average annual growth rate in nighttime light per-capita over period $t-1$ to $t$. $A i d_{i, t-1}$ denotes the natural logarithm of annual per-capita aid disbursements in constant 2011 US $\$$ or - alternatively - the number of projects per capita with ongoing disbursements to the region in the previous period. ${ }^{77}$ All regressions include fixed effects for each country in each period $\left(\eta_{c, t}\right)$. Model (4.1) in addition controls for $D E V_{i, 2000}$ - the (logged) level of a region's development (measured in nighttime light per capita) at the beginning of our sample period, to control for conditional growth convergence. It includes $P O P$ and POPGROWTH, which are the logarithm of a region's population size and its population growth rate, $A R E A$, reflecting the size of the administrative region, and $D I S T$, measuring the (logged) shortest distance from the region's center to the country's capital. It is sometimes argued that population and area size affect growth, either negatively due to less diversified economies and higher exposure to external risk or positively, due to increases in productivity (Easterly and Kraay, 2000). Regarding distance to the country's capital, we hypothesize that more distant regions to experience lower rates of growth.

Model (4.2) includes fixed effects for regions $\lambda_{i}$ in addition to those for country-periods, and therefore excludes control variables that do not vary over time at the regional level. Model (4.1) consequently identifies the potential effect of aid exploiting variation between regions (and over time), while Model (4.2) exploits within-region variation over time exclusively. While being more conservative than Model (4.1), this comes with the disadvantage of few three-year-period observations per region, which makes the identification of significant effects less likely. The error term is $\epsilon_{i, t}$, and we cluster standard errors at the regional level.

Our measure of development relies on nighttime light data as an approximation of regional economic activity. Such data have been introduced to the literature in Elvidge et al. (1997) and Sutton and Costanza (2002), and are frequently used in the recent economics literature

\footnotetext{
${ }^{77}$ We add 0.01 before we take logs to avoid losing observations without disbursements or projects. Note that we also take the number of projects in per-capita terms. Our conclusions hold, however, when taking the absolute number of projects per region. We follow Galiani et al. (2014) and include logged aid rather than the level of aid along with its square, as do, e.g., Clemens et al. (2012). The reason is that we mostly rely on results from instrumental variable estimation but only have one instrument for two endogenous variables in case we include aid squared. Taking the log allows for a decreasing marginal effect of aid (but does not allow its effect to change sign).
} 
(probably most prominently in Henderson et al., 2012). Nighttime light is a practical source of data for regional economic activity when official data on GDP are unavailable or where official statistics might be prone to measurement error or manipulation (Chen and Nordhaus, 2011). ${ }^{78}$ Particularly in the developing world, uncertainty about official GDP estimates can be enormous (Henderson et al., 2012; Jerven, 2013). ${ }^{79}$

Since a large part of economic activity comes in the form of consumption and production using light in the evenings, nighttime light intensity can be considered a meaningful reflection of human economic activity. A range of studies have established a strong empirical relationship between nighttime light intensity and GDP both over time and across regions. Recently, Henderson et al. (2012) document a high correlation between changes in nighttime light intensity and GDP growth at the country-level while Doll et al. (2006) and Hodler and Raschky (2014) provide similar regional-level evidence. Further research also finds strong positive associations between nighttime light intensity and public infrastructure indicators (Michalopoulos and Papaioannou, 2014) as well as composite wealth indices from Demographic and Health Surveys (DHSs) (Noor et al., 2008; Michalopoulos and Papaioannou, 2013), both at the national and the subnational level. $^{80}$

We use satellite images from the National Oceanic and Atmospheric Administration (NOAA, nd), providing information on nighttime light activity for the 1992-2012 period. Images are taken in the evenings, for a global grid in 30 arc-minutes resolution, and measured on a 0-63 scale (with larger values indicating more activity). The data remove background noise and exceptional events such as fires. They are, however, not directly comparable over time. The reason is that the data included in our sample are generated with three different satellites and consequently different sensors. What is more, sensors deteriorate with time, so that images from periods too far apart might hardly be comparable (Elvidge et al., 2014). We therefore rely on recalibrated data provided by Elvidge et al. (2014) at the country-year level, and adjust our regional nighttime light data according to a region's share in total light. ${ }^{81}$ Figure 4.2 compares yearly totals of

\footnotetext{
${ }^{78}$ Since nighttime light data are not directly relevant to governments, they are less likely to be systematically targeted by policy interventions.

${ }^{79}$ See http://qz.com/139051/nigerias-economy-is-about-to-grow-40-in-one-day/\#139051/nigeriaseconomy-is-about-to-grow-40-in-one-day for a case from Nigeria (accessed March 19, 2014).

${ }^{80}$ Possibly, certain World Bank projects, particularly those aiming at infrastructure development, affect this measure through opening up construction sites lit at night. While such sources of light might be the result of economic activity as in any aid effectiveness study, i.e., that of increasing investment, we also check whether our results are robust to the exclusion of those parts of aid. In a sensitivity analysis, we drop projects assigned to the transportation sector (which, however, accounts for the largest share of projects). With the exception of the OLS regressions for ADM2 regions, where the coefficient loses significance, the results remain similar. For this reason and since the identification of construction projects is inexact to some extent - the datasets only allows the identification of a broader sector - we refrain from overemphasizing this channel.

${ }^{81}$ The method relies on reference to a base area where nighttime light can be assumed to vary little over time, with the data range of other areas adjusted in accordance.
} 
Figure 4.2: Raw versus intercalibrated nighttime light, 2000-2012
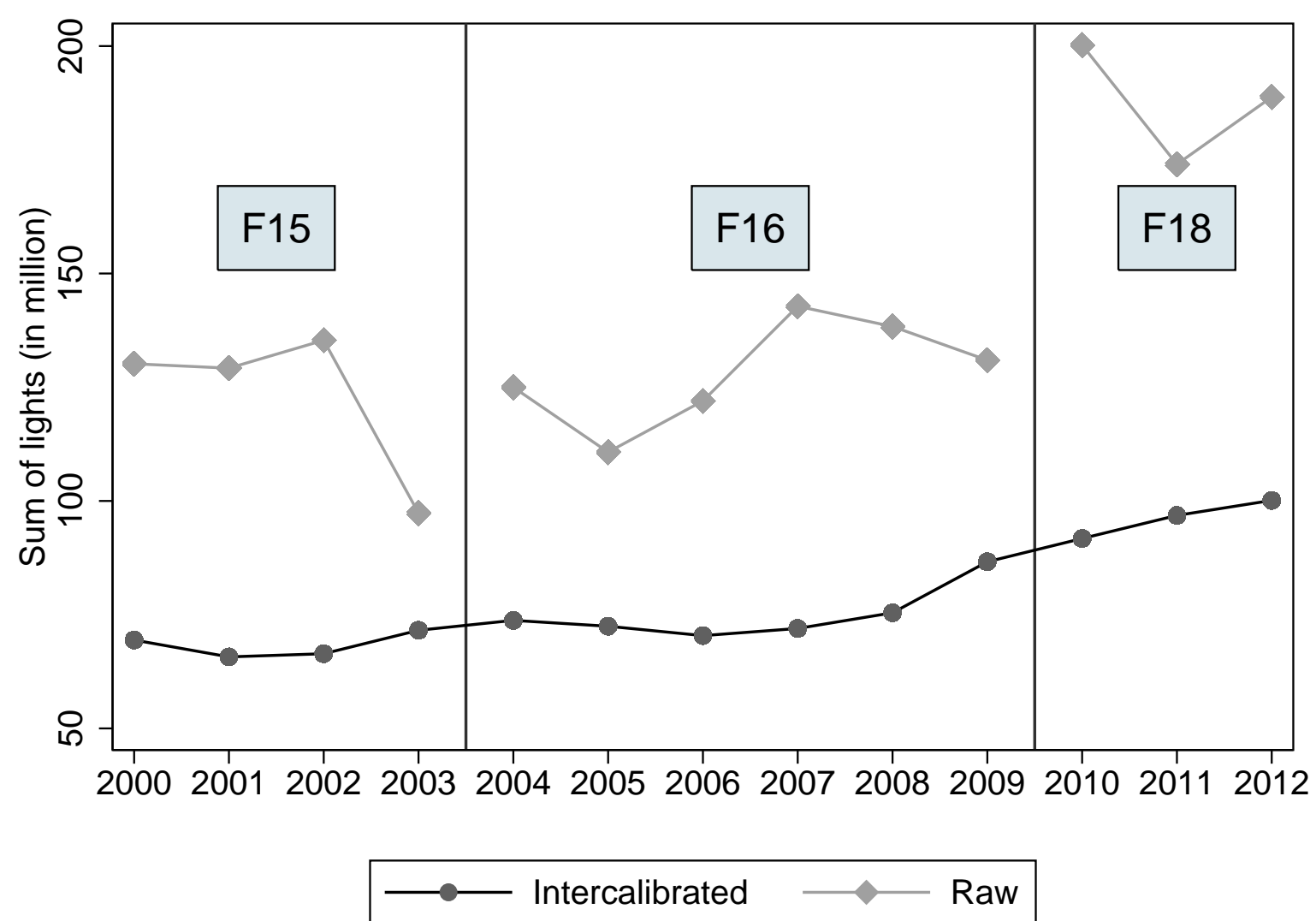

The vertical axis shows the annual sum of nighttime light pixel values throughout our sample period for different satellites (F15/F16/F18). Intercalibrated data are based on adjustment factors calculated from Elvidge et al. (2014) according to a region's share in total light.

nighttime light intensity values for the regions in our sample with the re-calibrated data. As can be seen, the recalibration method smoothes nighttime light substantially, both between satellites and in the years where data are generated by the same satellite, but where sensor sensitivity changes over time.

Our proxy for regional development is calculated as the growth rate of (recalibrated) mean nighttime light intensity in a region and year. We removed the upper and lower 5th-percentiles from the sample, which can be clearly identified as outliers in partial leverage plots based on our baseline specification. ${ }^{82}$ Figure 4.3 shows the resulting nighttime light per capita growth over the 2000/02-2003/05 period for Africa at the ADM1 level. Table 4.A.1 in the Appendix shows the sources and definitions of all variables, while Table 4.A.2 reports descriptive statistics.

The scarce literature on the sub-national determinants of aid effectiveness provides interesting

\footnotetext{
${ }^{82}$ Our results depend on this to some extent. When we do not remove outliers the correlation between aid and growth tends to be more negative.
} 
Figure 4.3: Regional growth in Africa, ADM1 regions, 2000-2002 to 2003-2005

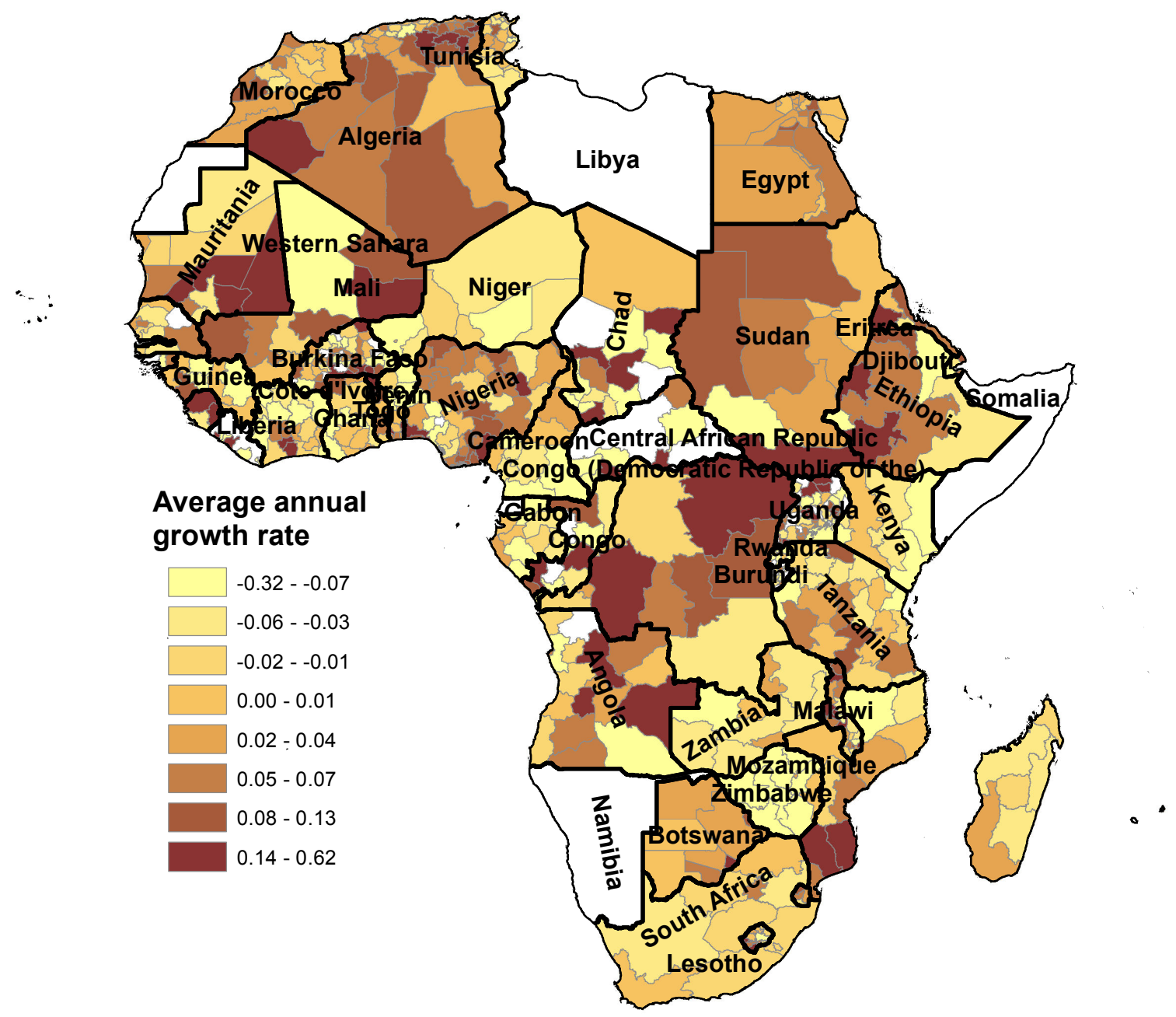

Growth in average nighttime light intensity based on NOAA Version 4 DMSP-OLS Nighttime Lights Time Series. Data have been calibrated in line with Elvidge et al. (2014). 
evidence on the correlates of aid projects on the regional level, but fails to convincingly address causality. ${ }^{83}$ We present results using three different identification strategies. ${ }^{84}$ First, we broadly follow Clemens et al. (2012), not using any instrument for aid, but allowing aid to affect growth with a time lag, and removing influences that do not vary over time (across countries and, in our case, across regions). Clemens et al. categorize all aid into one of two categories, so-called early- and late-impact aid. ${ }^{85}$ Early-impact aid contains those types of aid that can reasonably be expected to affect growth in the short-term, like budget support and program aid and certain categories of project aid (e.g., infrastructure investment or support for production in transportation, agriculture and industry). We use the sector classification included in AidData's project database to characterize a project based on the major sector that it is assigned to. ${ }^{86}$ This identification strategy would be unable to identify a causal effect of aid to the extent that donors (or recipients) are selective and allocate more aid to the regions they expect will use the aid more effectively.

Second, we follow the approach of Brückner (2013). Brückner addresses the endogeneity of aid by instrumenting for changes in per capita GDP with data on rainfall growth and its square and international commodity price shocks in his aid allocation equation. He then uses that part of aid that is not driven by GDP per capita growth as an instrument to identify the causal effect of aid on per capita GDP. We broadly follow this approach at the regional level, using data on rainfall from the Global Precipitation Climatology Centre (GPCC) of the German Weather Service (Schneider et al., 2011). ${ }^{87}$ We do not include commodity price shocks because they do

\footnotetext{
${ }^{83}$ Rajlakshmi (2013) is the only study we are aware of that tries to address the endogeneity of aid below the sub-national level. Rajlakshmi investigates the allocation and effectiveness of geo-coded aid projects from 30 agencies in Malawi over the 2004-2011 period. He identifies his instruments for the aid effectiveness regressions based on the significance of the variables included in his aid allocation regressions. The endogeneity of aid for the outcome variables included in the aid allocation equation is not addressed; what is more, the exclusion restriction of the instruments used in the aid effectiveness regressions is unlikely to hold (regional dummies and an indicator for rural regions are likely to affect disease severity via channels other than aid). His Propensity Score Approach is based on few variables and is thus likely to suffer from unobserved heterogeneity between the treatment and control group.

${ }^{84}$ Alternative strategies to identify the effect of development aid on economic growth can broadly be grouped along three lines (see Dreher et al., 2014). The first relies on instruments related to the size of the population in the recipient country. The second uses internal instruments - the lagged levels and differences of aid - and estimates system GMM regressions. The third relies on insight from the literature on the allocation of aid and uses proxies for political connections between the donors and recipients as instruments. As Bazzi and Clemens (2013) show the first two strategies are unlikely to allow the identification of causal effects, as both population and lagged values of aid are likely to have direct effects on growth. While political connection-based instruments might be more likely to be excludable, Dreher et al. (2014) show that political motives influence the effectiveness of aid, so that the effect of politically motivated aid (the Local Average Treatment Effect) cannot be generalized to represent the effect of aid more broadly.

${ }^{85}$ This measure has however been shown not to be a robust predictor of growth (Rajan and Subramanian, 2008; Bjørnskov, 2013; Roodman, 2015).

${ }^{86}$ Early-impact aid includes agriculture/fishing/forestry, energy/mining, access to finance, industry/trade, information/communications, and transportation. Late-impact aid includes education, health and other social services, public administration, and water and sanitation.

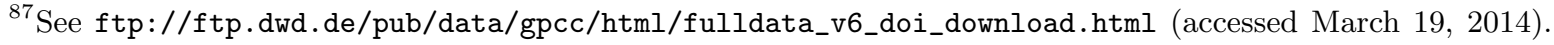
These data are available over the $2000-2010$ period.
} 
not vary across regions and are therefore absorbed by our country-period fixed effects. The identifying assumption is the absence of a direct effect of rainfall growth on aid, other than via its impact on incomes. As holds for Clemens et al. (2012), the identifying assumption might easily be violated.

Our third strategy connects to recent work on aid effectiveness at the country-level, which we are convinced could most plausibly identify a causal effect of foreign aid at the regional level (in case there is any). Our approach builds on Galiani et al. (2014), who instrument aid inflows with passing the IDA's threshold for receiving concessional aid. As Galiani et al. explain, donors pledge their contributions for three-year periods. The IDA threshold is updated annually, and amounts to a GNI per capita of US\$1,215 in the Bank's fiscal year 2015. Countries that pass the threshold are likely to see a substantial reduction in IDA lending, though they do not become ineligible for IDA aid immediately (Galiani et al., 2014). Of course, the decrease in IDA aid might be replaced by increases in other donors' aid, in our case, those of the International Bank for Reconstruction and Development (IBRD), in particular. However, Galiani et al. (2014) show that other donors reduce their aid in line with IDA aid, rather than substituting for it. ${ }^{88}$ They also show that after a country crosses the IDA-threshold, IDA aid to GNI drops by 92 percent, on average. As can be seen in Figure 4.4, the pattern described in Galiani et al. (2014) is prevalent in our data as well. On average, IDA-aid per capita decreases by 75 percent once a country crosses the threshold. The figure also shows that the decrease in IDA aid is not systematically offset by corresponding increases in IBRD funding.

The IDA income-threshold - even if it would be fully exogenous from a recipient country's perspective - could arguably be correlated with growth for reasons other than aid (Dreher and Langlotz, 2015). ${ }^{89}$ As Galiani et al. (2014) explain, countries could pass the income threshold due to a large positive shock that is reversed in later years. ${ }^{90}$ We overcome this potential shortcoming by interacting the indicator of whether or not a country has passed the IDA threshold with a recipient region's probability to receive aid, following recent innovations in the country-level literature on aid effectiveness (Werker et al., 2009; Ahmed, 2013; Nunn and Qian, 2014; Dreher and Langlotz, 2015). As (Nunn and Qian, 2014, pp. 1632, 1638) explain, the resulting regressions resemble difference-in-difference approaches, where - in our application of the method - we

\footnotetext{
${ }^{88}$ For more details on the relation between IDA aid and the income threshold, see Galiani et al. (2014). Knack et al. (2014) provide the years that countries crossed the IDA-threshold. Galiani et al. find that DAC aid decreases by 59 percent after a country crosses the threshold.

${ }^{89}$ Of course, to the extent that aid-dependent countries are less likely to cross the threshold - "cooking their books" - it might well be endogenous to aid; see Kerner et al. (2014) and Galiani et al. (2014) who come to opposite conclusions on whether or not manipulation takes place.

${ }^{90}$ They use alternative instruments using a smoothed income trajectory to rule out the effect of shocks and find similar results however.
} 

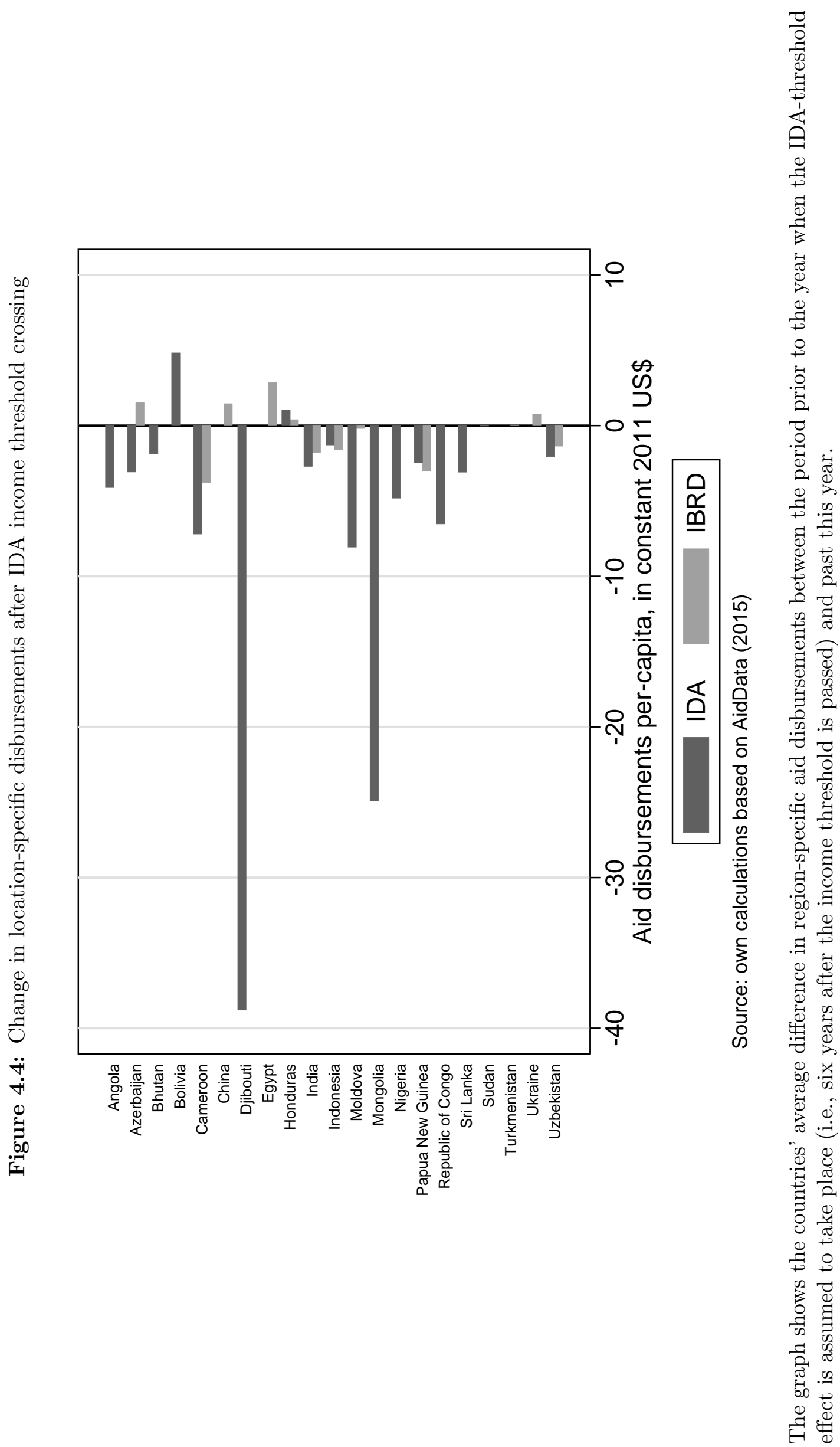
compare regular aid recipients to irregular recipients as the recipient's IDA status changes. ${ }^{91}$ While we report results employing the other two identification strategies described above in order to be comparable with the existing literature at the country-level, we base our conclusions mainly on this, preferred, approach. This comes at the cost of dismissing a large number of countries from the sample, as we prefer to implement our identification strategy only for countries that crossed the IDA-threshold at a point in time that is covered by our sample. The resulting number of countries included here is 21, referring to 478 ADM1 and almost 8,400 ADM2 regions.

Our assumed timing broadly follows the previous literature. Countries are considered as IDA graduates after having been above the income threshold for three consecutive years (Galiani et al., 2014). Galiani et al. therefore expect decreases in aid disbursements to take effect in the next replenishment period rather than instantaneously and lag the instrument by one three-year period. We add an additional three-year period lag, given that commitments are on average disbursed with a delay, broadly in line with the timing suggested in Dreher et al. (2014). Note that ten countries passed the threshold in the last or second-to last period in our sample. We follow Galiani et al. (2014) and keep them in the sample, even though the instrument will be zero for these countries throughout the sample period due to using the instruments in lags. We calculate the probability of receiving aid as the number of years in all years that a region has received any World Bank aid prior to when we assume the IDA-threshold effect to take place (i.e., six years after the income threshold is passed). ${ }^{92}$

The next section reports our results.

\subsection{Results}

Table 4.1 shows the results for our first set of regressions at the ADM1 level, broadly following Clemens et al. (2012). When region-fixed effects are excluded, nighttime light growth decreases with the level of nighttime light in 2000 at the one percent level of significance, indicating within-country convergence in development. At the five percent level, per capita growth increases with the size of the regional population but is unaffected by population growth. More distant and smaller regions grow less, at the one percent level of significance.

Note that we have to exclude nighttime light in 2000, region size, and distance to the capital when we control for region-fixed effects, as they do not vary over time. In these specifications (Model 4.2 above), population is no longer significant at conventional levels, arguably due to

\footnotetext{
${ }^{91}$ As do Galiani et al. we only consider countries that crossed the threshold from below for the first time in constructing the instrumental variable. In our sample, only Bolivia passed the threshold twice. Our results are robust to using the second crossing instead of the first.

${ }^{92}$ The main analyses in Ahmed (2013) and Nunn and Qian (2014) calculate the probability to receive aid over the whole sample period. Our second-stage results are similar when we follow this approach. The resulting first stage for ADM1 regions is substantially weaker however.
} 


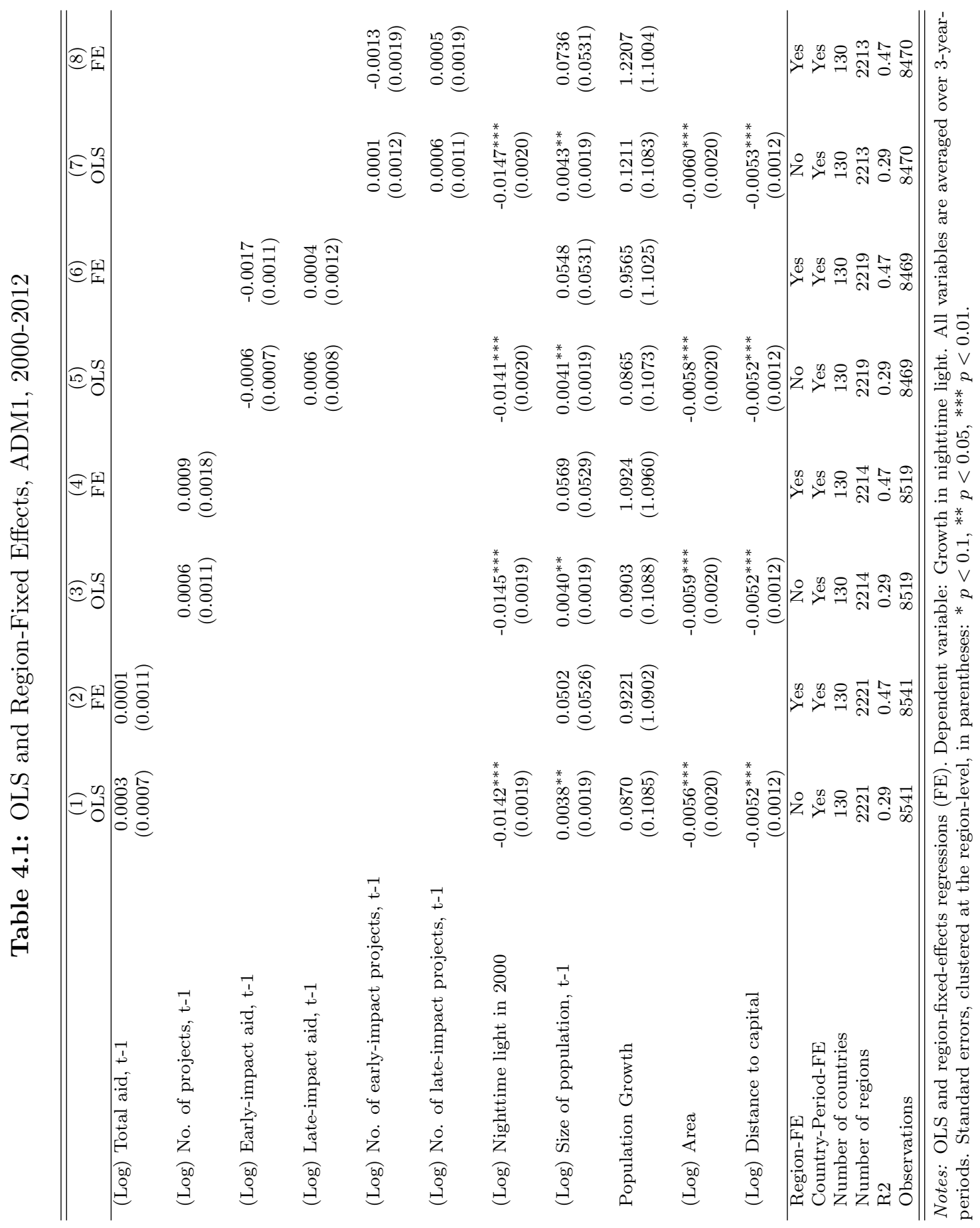


its low variation over time within region (aggravated by using linear interpolation to derive the yearly data).

Columns 1 and 2 of Table 4.1 report results for (log) aid disbursements. As can be seen, aid has no significant effect on growth. This holds regardless of whether region-fixed effects are excluded (column 1) or included (column 2). ${ }^{93}$ The insignificant effect is easy to explain. To the extent that aid is fungible, it might simply substitute for government expenditures that would have flown to the region in the absence of any aid. The true effect of aid on growth in that particular region would then indeed be zero. ${ }^{94}$ Another potential reason for the insignificant coefficient of aid is reversed causality, even in the presence of lags. If crises and aid are persistent, higher aid might be the effect of lower growth, biasing the coefficient of aid downwards. ${ }^{95}$ The coefficient might then turn out to be insignificant, even if the true effect of aid is positive. Third, the low number of periods and the resulting lack of variation might challenge the identification of aid's effect on growth. And finally, of course, the insignificant coefficient could reflect the absence of an effect of aid on growth, even if the aid is not diverted to other regions.

Columns 3 and 4 of Table 4.1 replicate the analysis replacing aid disbursements with the number of aid projects with positive disbursements, while columns 5-8 show regressions that separate early-impact from late-impact aid, following Clemens et al. (2012). The results show insignificant coefficients of aid in all specifications.

Table 4.2 replicates the analysis focusing on the smaller ADM2 regions. If our hypothesis that more disaggregated analysis facilitates identification of significant effects holds true, we would expect stronger effects here compared to the results in Table 4.1 above. Conversely, focusing on smaller regions will make it less likely to identify statistically significant effects if the main reason for the lack of significant coefficients of aid is fungibility, and aid is more likely to be diverted to areas close to the intended region. The results are strikingly different compared to Table 4.1. First, note that with the exception of the distance to the country's capital there are substantial changes for all control variables. Growth increases with the level of nighttime light in the year 2000, the region's size and population growth (in the case where the region-fixed effects are excluded from the regression), but decreases with the size of its population, all at the

\footnotetext{
${ }^{93}$ We also separately included aid from the concessional International Development Association (IDA) and the less concessional loans from the International Bank for Reconstruction and Development (IBRD). The coefficients are not significant at conventional levels. We also separated projects that have been successfully evaluated by the Bank's Independent Evaluation Group from those that have been not. Excluding region-fixed effects, growth is negatively correlated with unsuccessful projects, at the ten percent level of significance.

${ }^{94}$ Recipient governments might use their additional budgetary leeway to finance their own pet projects in other regions - projects that cannot be identified and evaluated, but which potentially increase growth in the regions that get them. The same holds to the extent that positive spillovers increase growth in other regions, even absent any growth effects in the region that receives the aid.

${ }_{95}$ As Roodman (2015) shows, the procedure applied in Clemens et al. (2012) fails to remove contemporaneous endogeneity.
} 


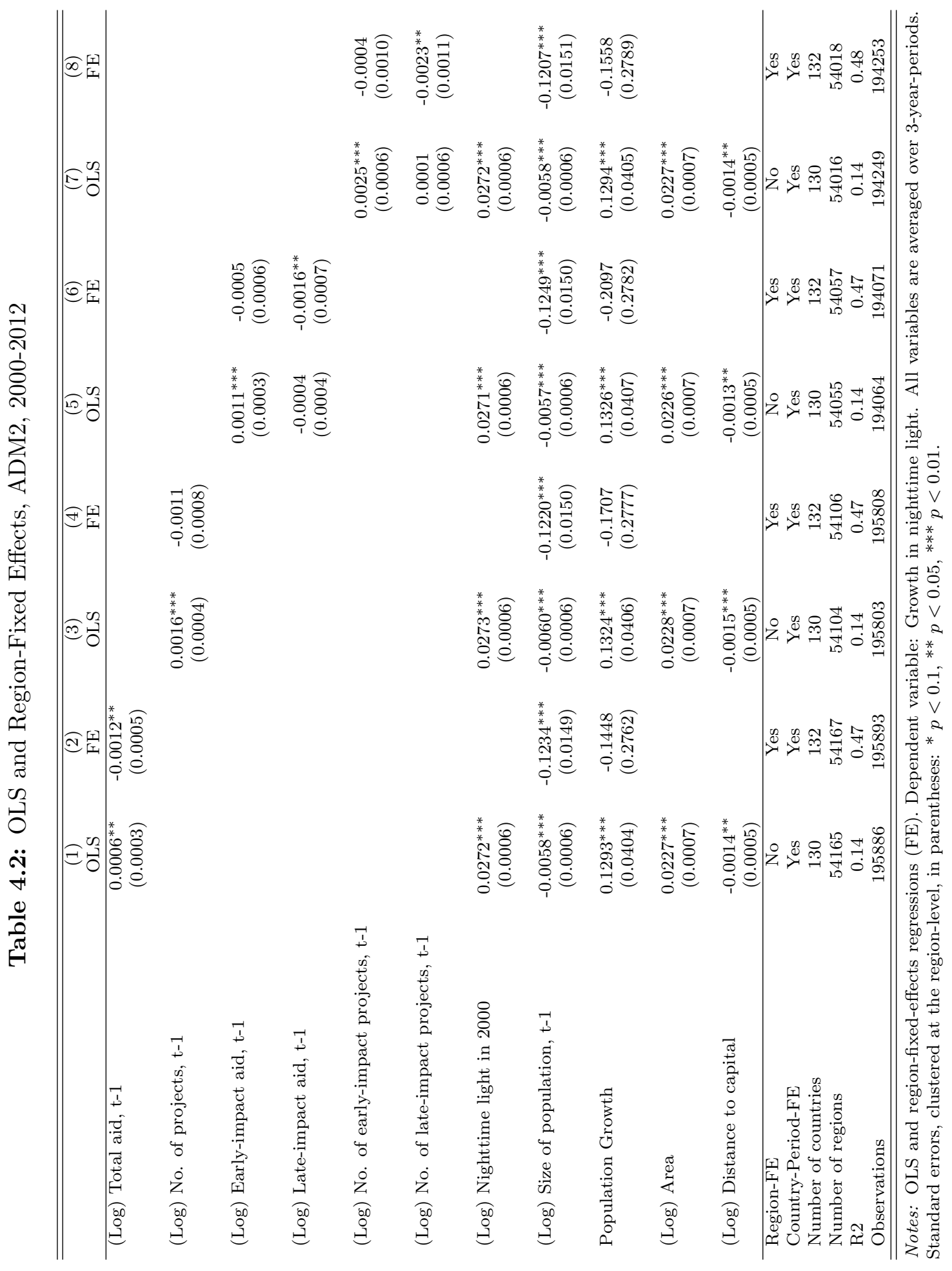


one percent level of significance.

As shown in column 1, when we do not control for region-fixed effects, growth significantly increases with aid disbursements at the five percent level. Conversely, when we include them - in column 2 - growth decreases with aid, also at the five percent level of significance. The coefficient of column 1 shows that an increase in per capita aid by ten percent increases nighttime light growth by 0.006 percentage points. With average disbursements in our sample amounting to US\$ 2.39 and an average population of 2.4 million, this amounts to additional aid in the order of US $\$ 0.58$ million. The corresponding decrease in growth according to column 2 is almost twice as high. These numbers compare to an increase of 0.35 percentage points in GDP per capita growth following a one percentage point increase in the aid to GNI-ratio according to the country-level results in Galiani et al. (2014) and an increase of 0.2 percentage points in Clemens et al. (2012).

The results for aid broadly hold when we replace disbursements with the number of projects in columns 3 and 4, though the negative coefficient in the fixed effects specification is no longer significant at conventional levels.

Columns 5-8 separate early-impact aid from late-impact aid, as suggested in Clemens et al. (2012). The results are indeed substantially more positive for early-impact aid compared to late-impact aid. When we exclude region-fixed effects, growth increases with early-impact aid (columns 5 and 7), with a coefficient roughly twice as high as those of total aid disbursements and 50 percent larger regarding the number of projects, while late-impact aid has no significant effect. ${ }^{96}$ When we include the region-fixed effects, however, early-impact aid is insignificant at conventional levels, while late-impact aid is negatively correlated with growth (columns 6 and 8). Potentially, the negative side effects associated with aid - like Dutch Disease effects, deteriorating governance etc. - materialize immediately, while the potential positive longer term growth-effects of late impact aid are yet to be realized, rendering the short-term net effect negative.

It is instructive to compare these results with regressions at the country level. As reported in Table 4.A.3 in the Appendix, the results show no significant effect of World Bank aid on nightlight growth in any specification, in line with the results reported for ADM1 regions in Table 4.1 above, but in stark contrast to the results at the ADM2 level. This is contrary to results from similar country-level specifications in Clemens et al. (2012). Arguably, the reason is that World Bank aid alone (rather than aid from all donors) is insufficiently large to measurably affect growth at the country level, while such an effect can more easily be identified at the

\footnotetext{
${ }^{96} \mathrm{~A}$ Wald test on equality of both coefficients has a p-value of 0.006 .
} 
regional level. We conclude from this comparison that a sufficiently fine-grained analysis can indeed lead to significant results where the application of analogous methods at the country level does not. This leads us to expect that a regional analysis of aid by a larger number of donors, comprising larger amounts than World Bank aid alone, would produce more robust conclusions than can be found in the current literature. Of course, the identified coefficients do not necessarily represent a causal effect of aid, to the extent that the identifying assumptions proposed by Clemens et al. (2012) are violated.

Table 4.3 turns to our first set of instrumental variables regressions, purging aid of its endogenous component. In line with Brückner (2013), we therefore regress nighttime light growth on annual rainfall growth and its square. Columns 1 and 2 focus on ADM1 regions, excluding and including region-fixed effects, respectively. As can be seen, the rainfall variables are completely insignificant in both regressions, and therefore unsuitable as instruments in this sample. Columns 3 and 4 turn to the ADM2 level instead. Again, rainfall growth and its square are insignificant when we do not control for region-fixed effects (in column 3). However, rainfall growth and its square are jointly significant at the one percent level once we include region-fixed effects (in column 4). We find nightlight growth to decrease with rainfall growth at the one percent level, but to increase with its square (at the five percent level). ${ }^{97}$ In what follows, we apply Brückner's methodology to this specification only, acknowledging that the instruments lack power in our other specifications.

Columns 5 and 6 show the corresponding second stage regressions for aid disbursements and the number of World Bank projects, respectively. The coefficient of growth in this second stage is then used to predict the amount of aid that is due to decreasing growth. The growth-driven part of aid is subtracted from all aid to a particular region and period, and the resulting variable those parts of aid that are not endogenous to nighttime light growth - is used as an instrument for total aid in the growth regressions reported in columns 7 and 8. The F-statistics on the excluded instruments are shown at the bottom of the table. As can be seen, they are reasonably high, but slightly below the rule-of thumb value of 10 in the aid regressions (columns 5 and 6 ) and easily exceed 10 in the growth regressions (columns 7 and 8 ). The results of the aid effectiveness regressions show a large and highly significant negative effect of aid on growth. The coefficients imply that an increase in per capita aid by ten percent decreases growth by 1.1 percentage points, while an increase in the number of projects decreases growth by 1.4 percentage points. These effects are an order of magnitude larger compared to those above. However, due to the strong identifying assumptions we take these results as suggestive rather than definitive.

\footnotetext{
${ }^{97}$ This is contrary to the results in Brückner (2013), who finds that growth increases with rainfall growth, but decreases with its square.
} 


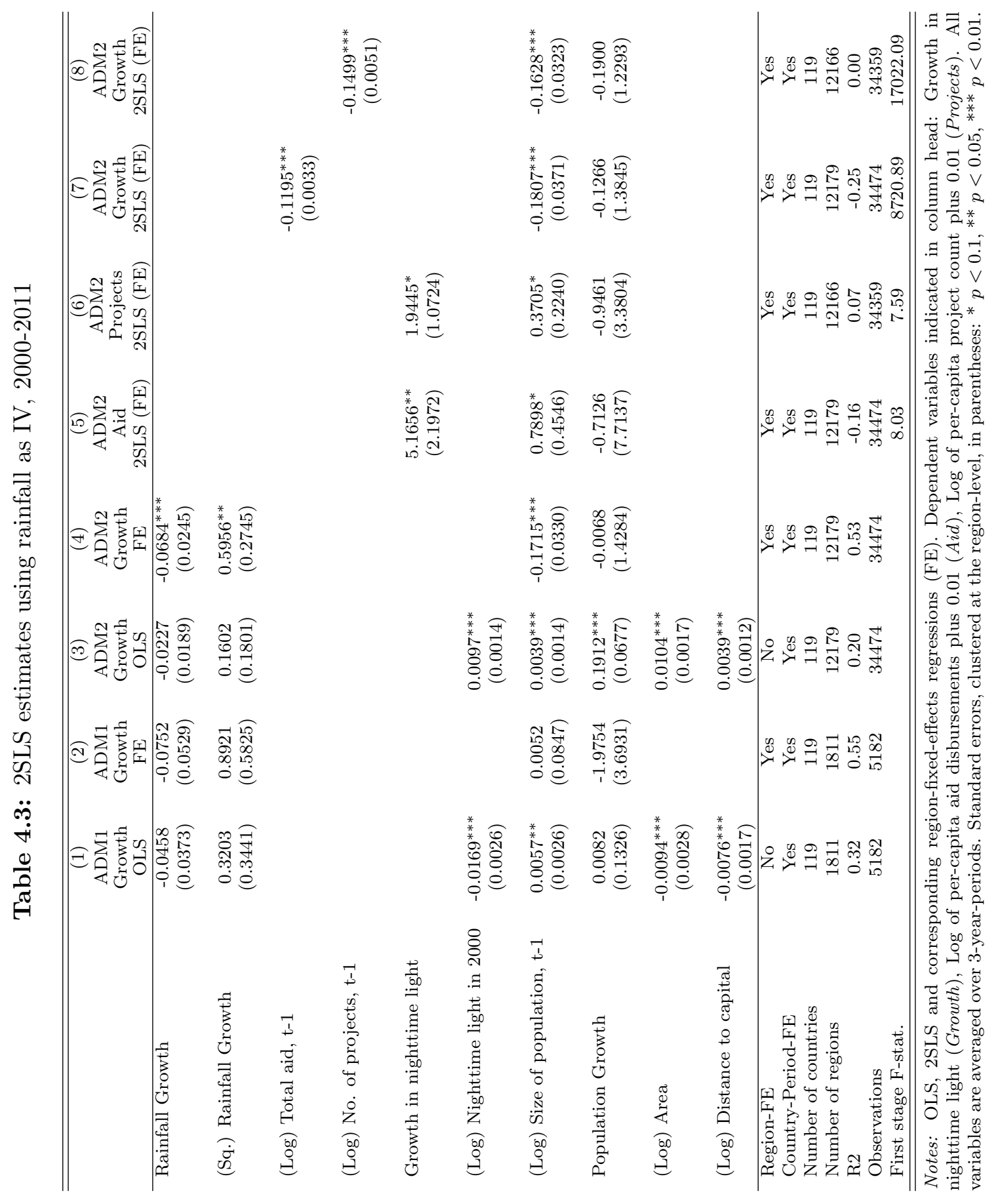


Tables 4.4 and 4.5 turn to our preferred specification, focusing on ADM1 and ADM2 regions respectively. Columns 1-4 replicate the main specifications of Table 4.1 for the greatly reduced sample of countries that crossed the IDA-threshold at any time during our analyzed period. The OLS results for the resulting 478 regions from 21 countries $^{98}$ are very similar compared to Tables 4.1 and 4.2. As in the larger sample, there is no significant effect of aid on growth in ADM1 regions (Table 4.1). Growth in ADM2 regions increases with aid when we do not control for region-fixed effects, but decreases with aid otherwise (Table 4.2). This holds for aid disbursements and the number of World Bank projects, the only substantive difference to the larger sample above being that the negative correlation between project numbers and growth is now significant at the five-percent level in the fixed effects specification.

Columns 5 and 6 show the first-stage regressions of our 2SLS approach. When we explain aid with the interaction of the probability of receiving aid and the IDA-income threshold indicator, we find it to be negative and highly significant in all four regressions. When we exclude region-fixed effects (in column 5), we control for the probability of receiving aid; including region-fixed effects (column 6), the probability of receiving aid is captured by the regional dummies. In any case, the IDA-graduation indicator is captured by the country-period fixed effects. The F-statistic on the excluded instrument indicates strong power. At the ADM1 level, the coefficients of columns 5 and 6 of Table 4.4 imply that passing the IDA threshold reduces aid by 70 percent when comparing a region with a probability of receiving aid of 45 percent (first quartile of the probability's distribution) to a region with a probability of 85 percent (third quartile). The corresponding effect at the ADM2 level is 72 percent (Table 4.5).

The results for the corresponding second-stage regressions in columns 7 and 8 show that aid is completely insignificant once its endogeneity is taken account of. This holds for the formerly positive correlation excluding region-fixed effects for the analysis at the ADM2 level, as well as the negative correlation including them. The results are very similar when we focus on the number of World Bank projects rather than aid amounts, as shown in columns 9-12. ${ }^{99}$ In summary, our results differ tremendously across specifications. Controlling for region-fixed effects, we do not find any significant effect of aid on growth at the ADM1 level. This holds for the specification following Clemens et al. (2012) and according to our preferred identification strategy. Rainfall growth and its square turned out to be weak instruments at this level so that we did not run an aid-growth regression here. At the smaller ADM2 level, we find that growth decreases with aid according to the fixed-effects specifications following Clemens et al. (2012) and

\footnotetext{
${ }^{98}$ This compares to 35 countries in Galiani et al. (2014).

${ }^{99}$ Note however that the instrument is weak at the ADM2 level when we exclude region-fixed effects (see column 9 in Table 4.5).
} 


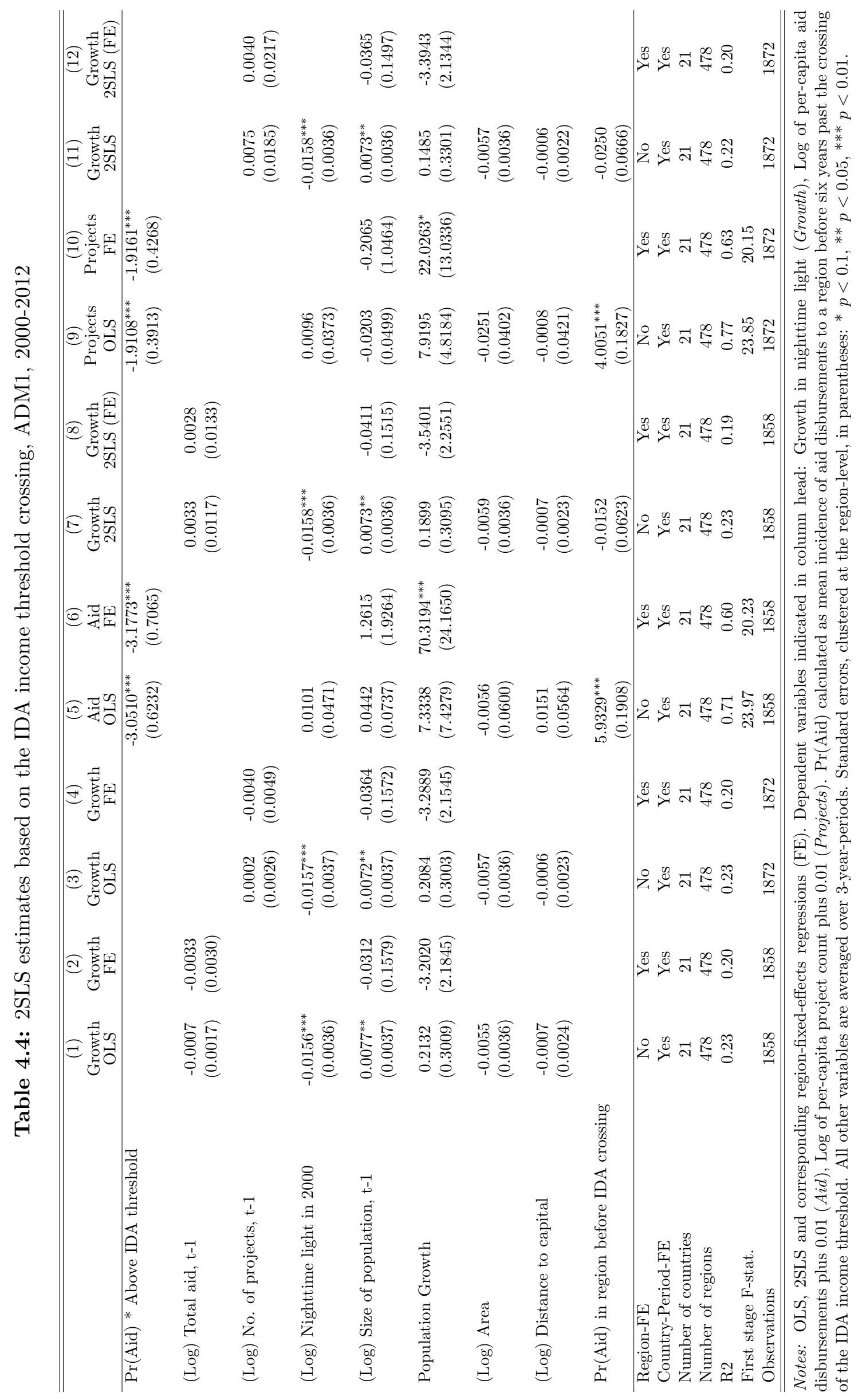




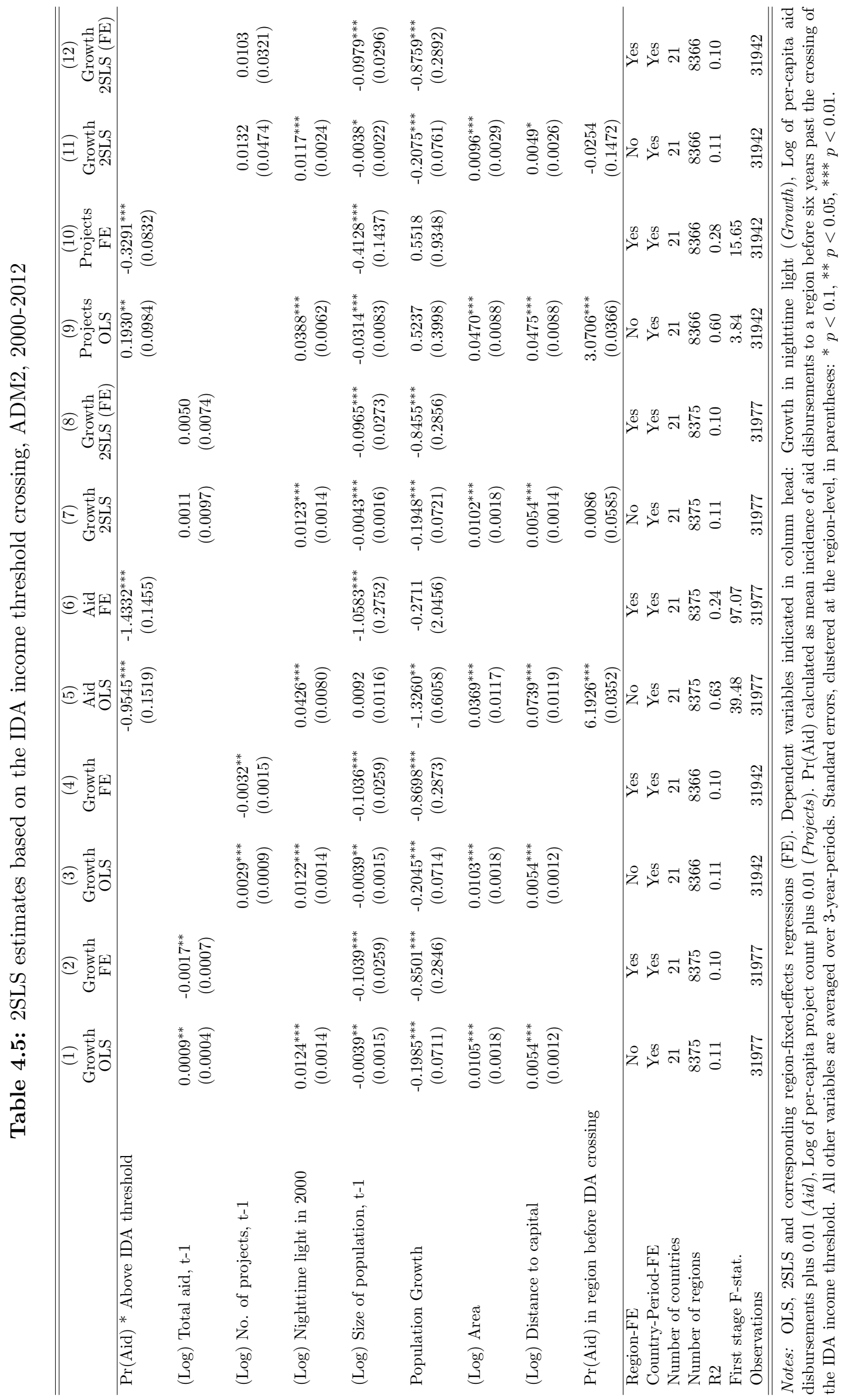




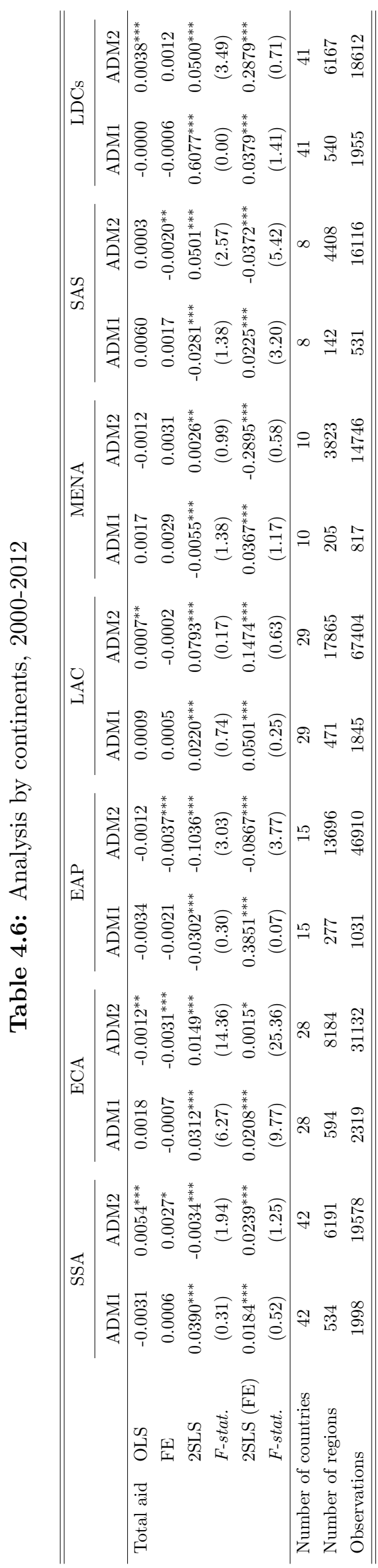

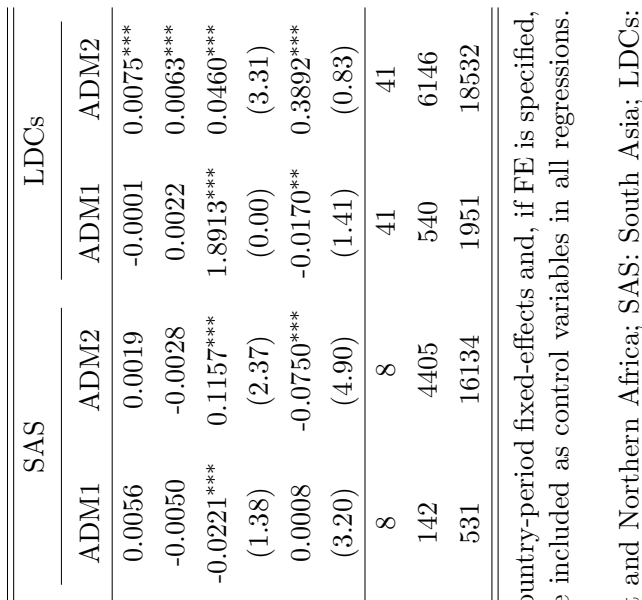

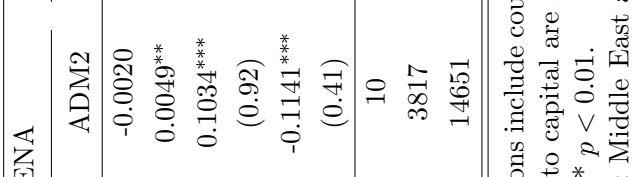

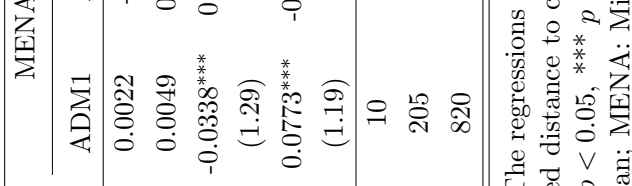

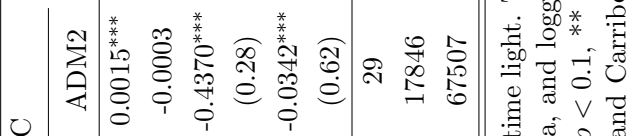

岁

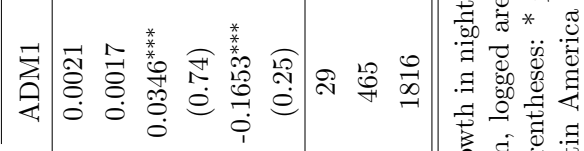

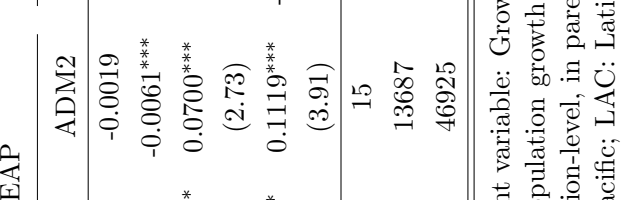

凷

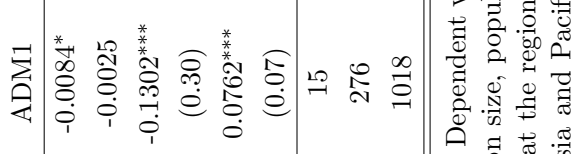

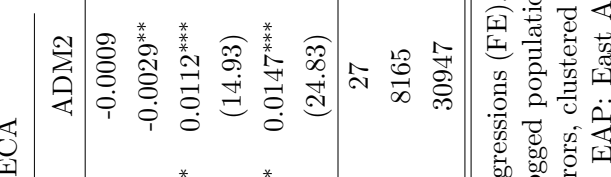

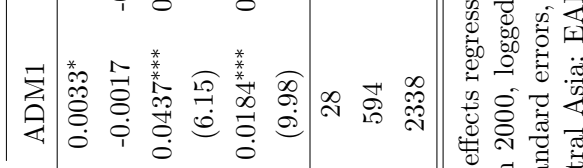

|

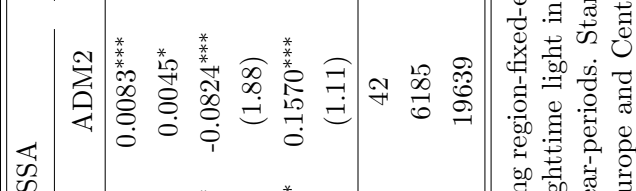

㟧

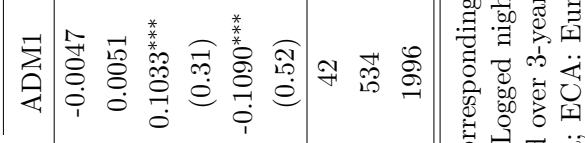

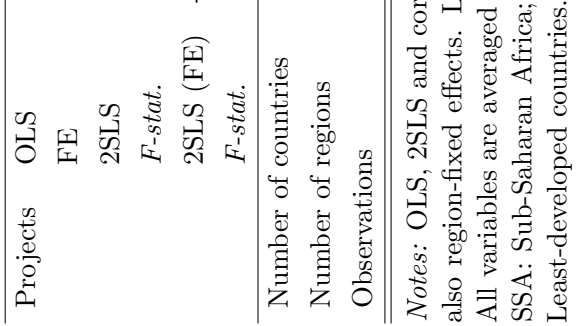


Brückner (2013). Readers that are convinced of the identification strategies suggested there, and the way we adopt them to suit our purpose of analyzing the effectiveness of aid at the regional level, might thus conclude that aid reduces growth. However, we remain insufficiently convinced that these strategies allow deriving causal effects of aid. Instead, we prefer to conclude in line with the results from the regressions using our preferred identification strategy, the interaction of the probability of receiving aid with having passed the IDA's income threshold, that there is no evidence that aid affects growth. While this comes at the cost of a reduced sample of those countries crossing the IDA income threshold, the results might still be meaningful for a greater range of countries. Investigating a similar set of countries, Galiani et al. (2014) do not find evidence that countries crossing the IDA income threshold display systematically different growth patterns than countries still below the income threshold.

Putting these results in perspective of our expectation of a stronger link between aid and growth at the regional level compared to the country level, our estimates are suggestive. Where we were able to directly compare results for the regional level with results at the country level - the analysis following Clemens et al. (2012) - we indeed find the coefficients to be significant in the regional analysis but not at the country level. While our results for the instrumental variables estimates are not directly comparable to results from the cross-country literature, comparing the larger ADM1 regions to the smaller ADM2 regions indeed shows stronger correlations between aid and growth at the ADM2 level. This suggests that analyses at smaller regional levels might indeed lead to larger correlations between aid from a larger number of donors than we could consider here and (nighttime light) growth.

In what follows, we disaggregate our results according to continents and income-status, following the United Nations' classification as of $2014 .{ }^{100}$ Table 4.6 shows the results for the amount of aid disbursed and the number of projects, following the specification of Tables 4.1-4.3. We show the resulting coefficient of aid disbursements or project numbers and indicate whether the coefficient is statistically significant. For the 2SLS regressions we include the first-stage F-statistics in parentheses. We do not separate the sample using our preferred instrument - the interaction of crossing the IDA-threshold with the probability to receive aid - given that the resulting number of countries and regions would be too low for meaningful regressions.

The results show some differences across continents. Focusing on the region-fixed effects specifications without using instruments, there is no significant correlation between aid and growth

\footnotetext{
${ }^{100}$ We also tested whether aid is more effective in certain policy environments than others. We do not find this to be the case. Specifically, we interacted aid disbursements with the Polity IV indicator of democracy, the share of people with secondary education in the population, the Fraser Index of Economic Freedom, as well as three different indicators for the intensity of civil conflict, measured by the number of fatalities within a region and period. None of the interactions is robustly significant at conventional levels. Detailed results are available on request.
} 
at the ADM1 level. At the ADM2 level, growth increases with aid in Sub-Saharan Africa, but decreases with aid in Europe and Central Asia, East Asia and Pacific, and South Asia. If we focus on the least developed countries only, there is no significant correlation between aid and growth. Turning to the 2SLS regressions employing rainfall growth and its square as instruments, the first-stage F-statistic exceeds 10 only in the regressions restricted to Europe and Central Asia. Contrary to the results with OLS, these regressions show that growth increases with aid. The lower panel of Table 4.6 shows results corresponding to the number of projects. Overall, these results are very similar, with the exception of an insignificant coefficient for South Asia in the fixed effects regression at the ADM2 level and a significant and positive correlation between projects and growth in this specification in least developed countries. Overall, while not showing strong evidence of a positive causal effect of aid and growth, these results imply that the effects of aid on growth are likely to be heterogeneous across groups of countries. Unfortunately, rainfall growth and its square turned out to be weak in most specifications, so that these coefficients hardly show more than interesting correlations however. We thus leave a deeper analysis of heterogeneous effects of aid for future research.

\subsection{Conclusion}

The aim of this paper was to bring the aid effectiveness debate to the regional level. We hypothesized that the effects of aid might be discernible regionally, even if aid amounts are too low to be measurable at the country level. The lack of sub-regional analyses might thus contribute to the lack of robust evidence in the aid effectiveness literature.

Our regressions used geo-coded data for World Bank aid to a maximum of 2,283 regions in 130 countries over the 2000-2011 period, testing whether and to what extent aid affects development, measured as nighttime light growth. We presented results using three different identification strategies. First, we followed Clemens et al. (2012), relying on aid that can reasonably be expected to affect growth in the short run, controlling for country- and region-fixed effects, and lagging aid appropriately to allow time for it to become effective. Second, we purge aid of those parts that are endogenous to growth, using data on rainfall growth and its square in the spirit of Brückner (2013). However, our instruments are too weak to allow us to draw any strong conclusions.

Our preferred identification strategy exploited variation arising from interacting a variable that indicates whether or not a country crossed the IDA's income threshold for concessional aid with a recipient region's probability of receiving aid. This comes with the disadvantage that the analysis only includes those countries that crossed the IDA threshold during the time our 
sample covers. Controlling for the levels of the interacted variables, the interaction provides a powerful and excludable instrument for a sample of 478 regions from 21 countries.

Overall, our results show significant correlations between aid and (nighttime light) growth. Our results highlight the importance of measuring aid flows at the regional level, showing correlations that are markedly stronger at the smaller ADM2 regional level, compared to the larger ADM1 and the country level. However, once we take account of the endogeneity of aid and potential attenuation bias, e.g., through measurement error in the geo-coding process - we find no significant effect of World Bank aid on growth, neither at the ADM1 nor the ADM2 level. While the World Bank is one of the world's largest donors, the amounts of aid we could track here only represent a share of all World Bank project aid, and are of course comparably small when put in perspective to aid amounts included in most aid effectiveness studies at the country level (usually using aid from all major Western donors). One reason for the insignificant result might thus be that the amounts of (region-specific) World Bank aid alone are too low to measurably affect growth, even at the regional level. Our failure to detect a significant effect of aid on growth is likely to be aggravated by the potential fungibility of aid. ${ }^{101}$ To the extent that aid is fungible, the aid might have positive growth effects in other regions that we fail to measure with our analysis. The same might hold if regional spill-overs are important. Of course, this would not threaten our conclusion regarding the effect of aid on growth in the regions that receive the aid.

Analyzing the effect of aid on growth at the regional level for a broader set of donors is currently largely prevented by the unavailability of aid data on the regional level. Other than for the World Bank, current data availability would allow a similar analysis for Chinese aid in Africa, where geo-coded data for a similar period of time as we have used here has recently been made available (Dreher et al., 2014). More broadly, another promising extension includes the analysis of the effects of aid on broader indicators of social development than growth at the subnational level, which is equally missing from the current literature. Geo-coding aid flows for a larger number of donors across the world remains a challenge for future research on the effectiveness of aid.

\footnotetext{
${ }^{101}$ Fungibility is likely to be partial rather than full (van de Sijpe, 2013). Van de Walle and Mu (2007) find evidence of a "flypaper effect" rather than full fungibility in their study of a road rehabilitation project co-financed by the World Bank in Vietnam.
} 
4.A Appendix 


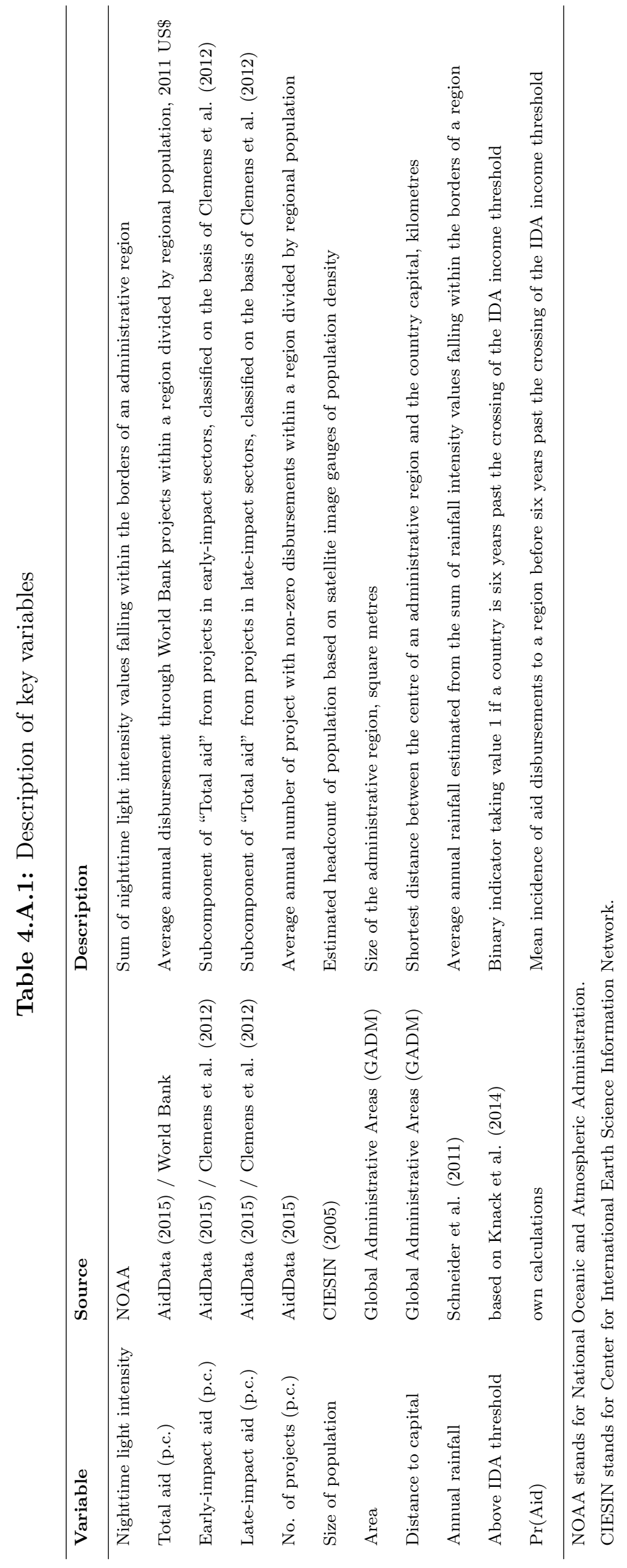


Table 4.A.2: Descriptive Statistics, ADM1, Estimation sample (2000-2012)

\begin{tabular}{|c|c|c|c|c|c|}
\hline & Mean & Median & $\mathrm{SD}$ & Min. & Max. \\
\hline Nighttime light intensity & 2.45 & 0.60 & 5.89 & 0.00 & 63.00 \\
\hline Growth in nighttime light & 0.06 & 0.04 & 0.12 & -0.33 & 0.62 \\
\hline Size of population, t-1 (in 1,000 ) & 2361.73 & 498.43 & 9115.85 & 0.79 & 189844.11 \\
\hline Area (in mn sq. km) & 41037.08 & 7396.56 & 122254.88 & 17.38 & 3066310.00 \\
\hline Distance to capital (in km) & 403.97 & 227.15 & 643.78 & 0.61 & 11212.19 \\
\hline Total aid, t-1 (per capita) & 2.39 & 0.60 & 4.43 & 0.00 & 37.65 \\
\hline Early-impact aid, t-1 (per capita) & 1.20 & 0.00 & 2.75 & 0.00 & 22.56 \\
\hline Late-impact aid, t-1 (per capita) & 0.99 & 0.07 & 1.95 & 0.00 & 18.02 \\
\hline No. of projects, t-1 (per 1,000 capita) & 0.00 & 0.00 & 0.00 & 0.00 & 0.01 \\
\hline No. of early-impact projects, t-1 (per 1,000 capita) & 0.00 & 0.00 & 0.00 & 0.00 & 0.00 \\
\hline No. of late-impact projects, t-1 (per 1,000 capita) & 0.00 & 0.00 & 0.00 & 0.00 & 0.01 \\
\hline Rainfall Growth & 0.01 & 0.01 & 0.06 & -0.15 & 0.21 \\
\hline $\operatorname{Pr}($ Aid) in region before IDA crossing & 0.62 & 0.70 & 0.31 & 0.00 & 1.00 \\
\hline Observations & 9124 & & & & \\
\hline Number of countries & 130 & & & & \\
\hline Number of regions & 2281 & & & & \\
\hline
\end{tabular}

Table 4.A.3: Specification at country-level, 2000-2012

\begin{tabular}{|c|c|c|c|c|}
\hline & $\begin{array}{l}(1) \\
\mathrm{FE}\end{array}$ & $\begin{array}{l}(2) \\
\text { FE }\end{array}$ & $\begin{array}{l}(3) \\
\mathrm{FE}\end{array}$ & $\begin{array}{l}(4) \\
\mathrm{FE}\end{array}$ \\
\hline (Log) Total aid, t-1 & $\begin{array}{l}-0.0006 \\
(0.0022)\end{array}$ & & & \\
\hline$(\log )$ No. of projects, $t-1$ & & $\begin{array}{l}-0.0010 \\
(0.0024)\end{array}$ & & \\
\hline (Log) Early-impact aid, t-1 & & & $\begin{array}{c}0.0020 \\
(0.0020)\end{array}$ & \\
\hline (Log) Late-impact aid, t-1 & & & $\begin{array}{c}-0.0003 \\
(0.0020)\end{array}$ & \\
\hline (Log) No. of early-impact projects, t-1 & & & & $\begin{array}{c}0.0010 \\
(0.0019)\end{array}$ \\
\hline$(\log )$ No. of late-impact projects, $t-1$ & & & & $\begin{array}{c}0.0003 \\
(0.0027)\end{array}$ \\
\hline (Log) Size of population, t-1 & $\begin{array}{l}-0.0079 \\
(0.0967)\end{array}$ & $\begin{array}{c}-0.0079 \\
(0.0970)\end{array}$ & $\begin{array}{c}-0.0179 \\
(0.0975)\end{array}$ & $\begin{array}{c}-0.0123 \\
(0.0970)\end{array}$ \\
\hline Country-FE & Yes & Yes & Yes & Yes \\
\hline Period-FE & Yes & Yes & Yes & Yes \\
\hline Number of countries & 130 & 130 & 130 & 130 \\
\hline R2 & 0.22 & 0.22 & 0.22 & 0.22 \\
\hline Observations & 1529 & 1529 & 1529 & 1529 \\
\hline
\end{tabular}

Notes: Within-country regressions (FE). Dependent variable: Growth in nighttime light. All variables are averaged over 3 -year-periods. Standard errors, clustered at the countrylevel, in parentheses: ${ }^{*} p<0.1,{ }^{* *} p<0.05,{ }^{* * *} p<0.01$. 


\section{Bibliography}

Adger, W. N. (1999). Social Vulnerability to Climate Change and Extremes in Coastal Vietnam. World Development, 27(2):249-269.

Ahmed, F. Z. (2013). The Impact of US Economic Aid on Political Rights. Working Paper, Oxford University.

Ai, C. and Norton, E. (2003). Interaction Terms in Logit and Probit Models. Economics Letters, 80(1):123-129.

AidData (2015). Geocoded data from the world bank ibrd-ida, version 1.0. http://aiddata. org.

Alderman, H., Hoddinott, J., and Kinsey, B. (2006). Long Term Consequences of Early Childhood Malnutrition. Oxford Economic Papers, 58(3):450-474.

Alderman, H., Hoogeveen, H., and Rossi, M. (2009). Preschool Nutrition and Subsequent Schooling Attainment: Longitudinal Evidence From Tanzania. Economic Development and Cultural Change, 57(2):239-260.

Arouri, M., Nguyen, C., and Youssef, A. B. (2015). Natural Disasters, Household Welfare, and Resilience: Evidence from Rural Vietnam. World Development, 70:59-77.

Axelson, H., Bales, S., Minh, P., Ekman, B., and Gerdtham, U.-G. (2009). Health Financing for the Poor Produces Promising Short-Term Effects on Utilization and Out-of-Pocket Expenditure: Evidence from Vietnam. International Journal for Equity in Health, 8.

Banerjee, A. and Duflo, E. (2011). Poor Economics: A Radical Rethinking of the Way to Fight Global Poverty. Public Affairs, New York.

Bazzi, S. and Clemens, M. A. (2013). Blunt Instruments: Avoiding Common Pitfalls in Identifying the Causes of Economic Growth. American Economic Journal: Macroeconomics, $5(2): 152-186$.

Benjamin, D., Heffetz, O., Kimball, M., and Rees-Jones, A. (2012). What Do You Think Would Make You Happier? What Do You Think You Would Choose? American Economic Review, 102(5):2083-2110.

Bjørnskov, C. (2013). Types of Foreign Aid. Working Paper, School of Economics and Management, University of Aarhus. 
Bjørnskov, C., Dreher, A., and Fischer, J. (2008). Cross-Country Determinants of Life Satisfaction: Exploring Different Determinants Across Groups in Society. Social Choice and Welfare, 30(1):119-173.

Bjørnskov, C., Dreher, A., Fischer, J. A., Schnellenbach, J., and Gehring, K. (2013). Inequality and Happiness: When Perceived Social Mobility and Economic Reality Do Not Match. Journal of Economic Behavior \& Organization, 91:75-92.

Boockmann, B. and Dreher, A. (2003). The Contribution of the IMF and the World Bank to Economic Freedom. European Journal of Political Economy, 19(3):633-649.

Brosnan, S. and De Waal, F. (2003). Monkeys Reject Unequal Pay. Nature, 425:297-299.

Brückner, M. (2013). On the Simultaneity Problem in the Aid and Growth Debate. Journal of Applied Econometrics, 28(1):126-150.

Bruni, L. and Stanca, L. (2006). Income Aspirations, Television and Happiness: Evidence from the World Values Survey. Kyklos, 59(2):209-225.

Burgess, R., Deschenes, O., Donaldson, D., and Greenstone, M. (2011). Weather and Death in India. Working Paper, London School of Economics.

Carter, M. R. and Maluccio, J. A. (2003). Social Capital and Coping with Economic Shocks: An Analysis of Stunting of South African Children. World Development, 31:1147-1163.

Castronova, E. and Wagner, G. G. (2011). Virtual Life Satisfaction. Kyklos, 64(3):313-328.

CDC (2010). When Every Drop Counts: Protecting Public Health during Drought Conditions. Centre for Disease Control and Prevention.

Chase, J. M. and Knight, T. M. (2003). Drought-Induced Mosquito Outbreaks in Wetlands. Ecology Letters, 6(11):1017-1024.

Chaudhuri, A., Flamm, K., and Horrigan, J. (2005). An Analysis of the Determinants of Internet Access. Telecommunications Policy, 29(9-10):731-755.

Chen, X. and Nordhaus, W. D. (2011). Using Luminosity Data as a Proxy for Economic Statistics. Proceedings of the National Academy of Sciences, 108(21):8589-8594.

CIESIN (2005). Gridded population of the world, version 3, center for international earth science information network - columbia university, united nations food and agricultural programme, and centro internactional de agricultura tropical. 
Clark, A., Frijters, P., and Shields, M. (2008). Relative Income, Happiness, and Utility: An Explanation for the Easterlin Paradox and Other Puzzles. Journal of Economic Literature, 46(1):95-144.

Clark, A. and Oswald, A. (1996). Satisfaction and Comparison Income. Journal of Public Economics, 61(3):359-381.

Clark, A. and Senik, C. (2010a). Who Compares to Whom? The Anatomy of Income Comparisons in Europe. The Economic Journal, 120(544):573-594.

Clark, A. and Senik, C. (2010b). Will GDP Growth Increase Happiness in Developing Countries? CEPRE Working Paper No. 1024, CEPREMAP, Paris.

Clemens, M. A., Radelet, S., Bhavnani, R. R., and Bazzi, S. (2012). Counting Chickens when They Hatch: Timing and the Effects of Aid on Growth. Economic Journal, 122(561):590-617.

Del Ninno, C., Dorosh, P. A., and Smith, L. C. (2003). Public Policy, Markets and Household Coping Strategies in Bangladesh: Avoiding a Food Security Crisis Following the 1998 Floods. World Development, 31(7):1221-1238.

Dell, M., Jones, B., and Olken, B. (2014). What Do We Learn from the Weather? The New Climate-Economy Literature. Journal of Economic Literature, 52(3):740-798.

Di Tella, R., MacCulloch, R., and Oswald, A. (2003). The Macroeconomics of Happiness. Review of Economics and Statistics, 85(4):809-827.

Diener, E. and Fujita, F. (1997). Social Comparison and Subjective Well-being. In Buunk, B. P. and Gibbons, F. X., editors, Health, Coping and Well-being, pages 329-357. Mahwah, NJ, US: Lawrence Erlbaum Associates Publishers.

Diener, E. and Oishi, S. (2004). Are Scandinavians Happier than Asians? Issues in Comparing Nations on Subjective Well-being. Asian Economic and Political Issues, 10:1-25.

Dionne, K. Y., Kramon, E., and Roberts, T. (2013). Aid Effectiveness and Allocation: Evidence from Malawi. Paper Presentation, ASA 2013 Annual Meeting.

Dolan, P., Peasgood, T., and White, M. (2008). Do We Really Know What Makes Us Happy? A Review of the Economic Literature on the Factors Associated with Subjective Well-being. Journal of Economic Psychology, 29(1):94-122.

Doll, C. N., Muller, J.-P., and Morley, J. G. (2006). Mapping Regional Economic Activity from Night-Time Light Satellite Imagery. Ecological Economics, 57(1):75-92. 
Dollar, D. and Kraay, A. (2002). Growth Is Good for the Poor. Journal of Economic Growth, $7(3): 195-225$.

Doucouliagos, H. and Paldam, M. (2009). The Aid Effectiveness Literature: The Sad Results Of 40 Years Of Research. Journal of Economic Surveys, 23(3):433-461.

Dreher, A., Fuchs, A., Hodler, R., Parks, B., Raschky, P. A., and Tierney, M. J. (2014). Aid on Demand: African Leaders and the Geography of China's Foreign Assistance. AidData Working Paper No. 3, AidData.

Dreher, A., Gaston, N., and Martens, P. (2008). Measuring Globalisation. Springer.

Dreher, A., Klasen, S., Vreeland, J. R., and Werker, E. (2013). The Costs of Favoritism: Is Politically Driven Aid Less Effective? Economic Development and Cultural Change, 62(1):157-191.

Dreher, A. and Langlotz, S. (2015). Aid and Growth: New Evidence Using an Excludable Instrument. Mimeo, University of Heidelberg.

Duesenberry, J. (1949). Income, Saving, and the Theory of Consumer Behavior. Harvard University Press, Cambridge, MA.

DWD (2013). Global Precipitation Climatology Product, provided by the German Weather Service. Retrieved from ftp://ftp.dwd.de/pub/data/gpcc/html/gpcc_normals_v2011_ doi_download.html.

Dynan, K. E. and Ravina, E. (2007). Increasing Income Inequality, External Habits, and SelfReported Happiness. American Economic Review, 97(2):226-231.

Easterlin, R. (1995). Will Raising the Incomes of all Increase the Happiness of All? Journal of Economic Behavior \& Organization, 27(1):35-47.

Easterly, W. and Kraay, A. (2000). Small States, Small Problems? Income, Growth, and Volatility in Small States. World Development, 28(11):2013-2027.

Ekman, B., Liem, N. T., Duc, H. A., and Axelson, H. (2008). Health Insurance Reform in Vietnam: A Review of Recent Developments and Future Challenges. Health Policy and Planning, 23(4):252-263.

Elvidge, C. D., Baugh, K. E., Kihn, E. A., Kroehl, H. W., and Davis, E. R. (1997). Mapping City Lights with Nighttime Data from the DMSP Operational Linescan System. Photogrammetric Engineering and Remote Sensing, 63(6):727-734. 
Elvidge, C. D., Hsu, F.-C., Baugh, K. E., and Ghosh, T. (2014). National Trends in SatelliteObserved Lighting: 1992-2012. In Weng, Q., editor, Global Urban Monitoring and Assessment Through Earth Observation, pages 97-118. CRC Press.

EUROSTAT (2012). Information Society Database. Retrieved from http://epp. eurostat.ec. europa.eu/portal/page/portal/information_society/data/database.

Fafchamps, M. and Lund, S. (2003). Risk-Sharing Networks in Rural Philippines. Journal of Development Economics, 71(2):261-287.

Ferrer-i-Carbonell, A. (2005). Income and Well-being: An Empirical Analysis of the Comparison Income Effect. Journal of Public Economics, 89(5-6):997-1019.

Ferrer-i-Carbonell, A. (2012). Happiness Economics. Journal of the Spanish Economic Association, 4(1):1-26.

Fichera, E. and Savage, D. (2015). Income and Health in Tanzania. An Instrumental Cariable approach. World Development, 66:500-515.

Findley, M. G., Powell, J., Strandow, D., and Tanner, J. (2011). The Localized Geography of Foreign Aid: A New Dataset and Application to Violent Armed Conflict. World Development, 39(11):1995-2009.

Fischer, J. A. and Torgler, B. (2013). Do Positional Concerns Destroy Social Capital: Evidence From 26 Countries. Economic Inquiry, 51(2):1542-1565.

Frey, B., Benesch, C., and Stutzer, A. (2007). Does Watching TV Make Us Happy? Journal of Economic Psychology, 28(3):283-313.

Frey, B. and Stutzer, A. (2002). What Can Economists Learn From Happiness Research? Journal of Economic Literature, 40(2):402-435.

Galiani, S., Knack, S., Xu, L. C., and Zou, B. (2014). The Effect of Aid on Growth: Evidence From a Quasi-Experiment. World Bank Policy Research Paper No. 6865, Washington DC.

Gaurav, S. (2015). Are Rainfed Agricultural Households Insured? Evidence from Five Villages in Vidarbha, India. World Development, 66:719-736.

Gibson, J. and Kim, B. (2013). Quality, Quantity, and Nutritional Impacts of Rice Price Changes in Vietnam. World Development, 43:329-340.

Gustavsson, M. and Jordahl, H. (2008). Inequality and Trust in Sweden: Some Inequalities are More Harmful Than Others. Journal of Public Economics, 92(1-2):348-365. 
Hardeweg, B., Praneetvatakul, S., Tung, P. D., and Waibel, H. (2007). Sampling for Vulnerability to Poverty: Cost Effectiveness versus Precision. Paper Presentation, Tropentag, University of Kassel-Witzenhausen and University of Göttingen.

Henderson, J. V., Storeygard, A., and Weil, D. N. (2012). Measuring Economic Growth from Outer Space. American Economic Review, 102(2):994-1028.

Hill, S. E. and Buss, D. M. (2010). Risk and Relative Social Rank: Positional Concerns and Risky Shifts in Probabilistic Decision-Making. Evolution and Human Behavior, 31(3):219-226.

Hoddinott, J. and Kinsey, B. (2001). Child Growth in the Time of Drought. Oxford Bulletin of Economics and Statistics, 63(4):409-436.

Hodler, R. and Raschky, P. A. (2014). Regional Favoritism. The Quarterly Journal of Economics, 129(2):995-1033.

Hyll, W. and Schneider, L. (2013). The Causal Effect of Watching TV on Material Aspirations: Evidence From the "Valley of the Innocent". Journal of Economic Behavior \& Organization, $86: 37-51$.

IPCC (2012). Managing the Risks of Extreme Events and Disasters to Advance Climate Change Adaptation. A Special Report of Working Groups I and II. Intergovernmental Panel on Climate Change.

IRIN (2013). Coping with Volatile Weather in Laos. Retrieved from http://www.irinnews. org/printreport . aspx?reportid=98847.

Jablonski, R. S. (2014). How Aid Targets Votes: The Impact of Electoral Incentives on Foreign Aid Distribution. World Politics, 66(2):293-330.

James, J. (1987). Positional Goods, Conspicuous Consumption and the International Demonstration Effect Reconsidered. World Development, 15(4):449-462.

Jayachandran, S. (2006). Selling Labor Low: Wage Responses to Productivity Shocks in Developing Countries. Journal of Political Economy, 114(3):538-575.

Jerven, M. (2013). Poor Numbers: How We Are Misled by African Development Statistics and What to Do About It. Cornell University Press, New York.

Kahneman, D., Krueger, A., Schkade, D., Schwarz, N., and Stone, A. (2004). Toward National Well-being Accounts. American Economic Review, 94(2):429-434. 
Kazianga, H. and Udry, C. (2006). Consumption Smoothing? Livestock, Insurance and Drought in Rural Burkina Faso. Journal of Development Economics, 79(2):413-446.

Kemper, N. and Lechtenfeld, T. (2012). Targeting and Impact of Vietnam's Social Health Insurance for the Poor. Mimeo, University of Mannheim.

Kerner, A., Beatty, A., and Jerven, M. (2014). Real Money, Fake Data: The Political Economy of World Bank Data Manipulation. Working Paper, University of Michigan.

Klasen, S., Lechtenfeld, T., and Povel, F. (2014). A Feminization of Vulnerability? Female Headship, Poverty, and Vulnerability in Thailand and Vietnam. World Development, forthcoming.

Klasen, S. and Waibel, H. (2010). Vulnerability to Poverty: Theory, Measurement and Determinants. Palgrave Macmillan.

Knack, S., Xu, L. C., and Zou, B. (2014). Interactions Among Donors' Aid Allocations: Evidence From an Exogenous World Bank Income Threshold. World Bank Policy Research Paper No. 7039, Washington DC.

Knight, J., Song, L., and Gunatilaka, R. (2009). Subjective Well-being and its Determinants in Rural China. China Economic Review, 20(4):635-649.

Kovats, R. S., Bouma, M. J., Hajat, S., Worrall, E., and Haines, A. (2003). El Niño and Health. The Lancet, 362:1481-1489.

Layard, R. (2003). Happiness: Has Social Science a Clue? (Lionel Robbins Memorial Lecture at the Centre for Economic Performance, London).

Lieberman, S. S. and Wagstaff, A. (2009). Health Financing and Delivery in Vietnam: Looking Forward. The World Bank, Washington DC.

Loayza, N. V., Olaberría, E., Rigolini, J., and Christiaensen, L. (2012). Natural Disasters and Growth: Going beyond the Averages. World Development, 40(7):1317-1336.

Luttmer, E. (2005). Neighbors as Negatives: Relative Earnings and Well-being. The Quarterly Journal of Economics, 120(3):963-1002.

Maccini, S. and Yang, D. (2009). Under the Weather: Health, Schooling, and Economic Consequences of Early-Life Rainfall. American Economic Review, 99(3):1006-1026.

Manski, C. (2000). Economic Analysis of Social Interactions. The Journal of Economic Perspectives, 14(3):115-136. 
Mayraz, G., Wagner, G., and Schupp, J. (2009). Life Satisfaction and Relative Income Perceptions and Evidence. SOEPpapers on Multidisciplinary Panel Data Research No. 4390, DIW Berlin.

McBride, M. (2001). Relative-Income Effects on Subjective Well-being in the Cross-Section. Journal of Economic Behavior $\& 3$ Organization, 45(3):251-278.

McKee, T., Doesken, J., and Kleist, J. (1995). Drought Monitoring with Multiple Time Scales. Proceedings of the Ninth Conference On Applied Climatology, American Meteorological Society,Dallas, TX.

Michalopoulos, S. and Papaioannou, E. (2013). Pre-Colonial Ethnic Institutions and Contemporary African Development. Econometrica, 81(1):113-152.

Michalopoulos, S. and Papaioannou, E. (2014). National Institutions and Subnational Development in Africa. The Quarterly Journal of Economics, 129(1):151-213.

Morduch, J. (1995). Income Smoothing and Consumption Smoothing. Journal of Economic Perspectives, 9(3):103-114.

Mosley, P. (1987). Foreign Aid, its Defense and Reform. University Press of Kentucky, Lexington, KY.

Mujcic, R. and Frijters, P. (2013). Economic Choices and Status: Measuring Preferences for Income Rank. Oxford Economic Papers, 65(1):47-73.

NCHMF (2013). General Facts about Droughts in Vietnam, National Centre for Hydro-Meteorological Forecasting. Retrieved from http://www.nchmf.gov.vn/web/vi-vN/ 71/38/47/Default.aspx.

Nguyen, V. V. (2011). Climate Change and Agricultural Production in Vietnam. In Filho, W., editor, The Economic, Social and Political Elements of Climate Change, pages 227-243. Springer.

NOAA (n.d.). Version 4 dmsp-ols nighttime lights time series, national oceanic and atmospheric administration, boulder: National geophysical data center.

Noor, A. M., Alegana, V. A., Gething, P. W., Tatem, A. J., Snow, R. W., et al. (2008). Using Remotely Sensed Night-Time Light as a Proxy for Poverty in Africa. Population Health Metrics, 6(5). 
Nunn, N. and Qian, N. (2014). US Food Aid and Civil Conflict. American Economic Review, 104(6):1630-1666.

Nunnenkamp, P., Öhler, H., and Andr'es, M. S. (2012). Need, Merit, and Politics in Multilateral Aid Allocation: A District-Level Analysis of World Bank Projects in India. Working Paper No. 1783, Kiel Institute for the World Economy.

Öhler, H. (2013). Do Aid Donors Coordinate within Recipient Countries? Department of Economic Discussion Paper No. 539, University of Heidelberg.

Öhler, H. and Nunnenkamp, P. (2014). Needs-Based Targeting or Favoritism? The Regional Allocation of Multilateral Aid within Recipient Countries. Kyklos, 67(3):420-446.

Oishi, S., Kesebir, S., and Diener, E. (2011). Income Inequality and Happiness. Psychological Science, 22(9):1095-1100.

Overseas Development Institute (2013). The Geography of Poverty, Disasters and Climate Extremes in 2030.

Palmer, M. G. (2014). Inequalities in Universal Health Coverage: Evidence from Vietnam. World Development, 64:384-394.

Peratsakis, C., Powell, J., Findley, M., Baker, J., and Weaver, C. (2012). Geocoded Activity-level Data from the Government of Malawi's Aid Management Platform. Working Paper, AidData and the Robert S. Strauss Center for International Security and Law.

Powell, J. and Findley, M. G. (2012). The Swarm Principle? A Sub-national Spatial Analysis of Donor Coordination in Sub-Saharan Africa. Mimeo, mimeo.

Pradhan, M. and Ravallion, M. (2000). Measuring Poverty Using Qualitative Perceptions of Consumption Adequacy. The Review of Economics and Statistics, 82(3):462-471.

Rabassa, M., Skoufias, E., and Jacoby, H. G. (2012). Weather and Child Health in Rural Nigeria. World Bank Policy Research Paper No. 6214, World Bank, Washington DC.

Rajan, R. G. and Subramanian, A. (2008). Aid and Growth: What Does the Cross-Country Evidence Really Show? The Review of Economics and Statistics, 90(4):643-665.

Rajlakshmi, D. (2013). Foreign Aid Allocation and Impact: A Sub-National Analysis of Malawi. Dissertation, Duke University.

Roodman, D. (2015). A Replication of "Counting Chickens when They Hatch" (Economic Journal 2012). Public Finance Review, 43(2):256-281. 
Rose, E. (1999). Consumption Smoothing and Excess Female Mortality in Rural India. Review of Economics and Statistics, 81(1):41-49.

Schneider, U., Becker, A., Finger, P., Meyer-Christoffer, A., Rudolf, B., and Ziese, M. (2011). GPCC Full Data Reanalysis Version 6.0 at $0.5^{\circ}$ : Monthly Land-Surface Precipitation from Rain-Gauges built on GTS-based and Historic Data.

Senik, C. (2008). Ambition and Jealousy: Income Interactions in the Old Europe versus the New Europe and the United States. Economica, 75(299):495-513.

Sims, A. P., Nigoyi, D., and Raman, S. (2002). Adopting Drought Indices for Estimating Soil Moisture: A North Carolina Case Study. Geophysical Research Letters, 29(8):1-4.

Skoufias, E. (2003). Economic Crises and Natural Disasters: Coping Strategies and Policy Implications. World Development, 31(7):1087-1102.

Strandow, D., Findley, M., Nielson, D., and Powell, J. (2011). The UCDP-AidData Codebook on Geo-Referencing Foreign Aid. Version 1.1. Uppsala Conflict Data Program, Uppsala, Sweden.

Stutzer, A. (2004). The Role of Income Aspirations in Individual Happiness. Journal of Economic Behavior \& Organization, 54(1):89-109.

Sutton, P. C. and Costanza, R. (2002). Global Estimates of Market and Non-market Values Derived From Nighttime Satellite Imagery, Land Cover, and Ecosystem Service Valuation. Ecological Economics, 41(3):509-527.

Thiede, B. C. (2014). Rainfall Shocks and Within-Community Wealth Inequality: Evidence from Rural Ethiopia. World Development, 64:181-193.

Thomas, T., Christiaensen, L., Do, Q. T., and Trung, L. D. (2010). Natural Disasters and Household Welfare: Evidence from Vietnam. World Bank Policy Research Paper No. 5491, World Bank, Washington DC.

Toulmin, C. (1987). Drought and the Farming Sector: Loss of Farm Animals and Post-Drought Rehabilitation. Development Policy Review, 5(2):125-148.

UNISDR (2011). Global Assessment Report on Disaster Risk Reduction 2011. United Nations International Strategy for Disaster Reduction Secretariat, Geneva.

van de Sijpe, N. (2013). Is Foreign Aid Fungible? Evidence from the Education and Health Sectors. World Bank Economic Review, 27(2):320-356. 
van de Walle, D. and Mu, R. (2007). Fungibility and the Flypaper Effect of Project Aid: Micro-Evidence for Vietnam. Journal of Development Economics, 84(2):667-685.

van Praag, B. (2011). Well-being Inequality and Reference Groups: An Agenda for New Research. Journal of Economic Inequality, 9(1):111-127.

van Praag, B., Goedhart, T., and Kapteyn, A. (1980). The Poverty Line - A Pilot Survey in Europe. The Review of Economics and Statistics, 62(3):461-465.

van Praag, B., Kapteyn, A., and Van Herwaarden, F. (1979). The Definition and Measurement of Social Reference Spaces. The Netherlands' Journal of Sociology, 15:13-25.

Vicente-Serrano, S. M. (2006). Differences in Spatial Patterns of Drought on Different Time Scales: An Analysis of the Iberian Peninsula. Water Resources Management, 20(1):37-60.

Vos, K. and Garner, T. (1991). An Evaluation of Subjective Poverty Definitions: Comparing Results from the US and the Netherlands. Review of Income and Wealth, 37(3):267-285.

Vu, L. and Glewwe, P. (2011). Impacts of Rising Food Prices on Poverty and Welfare in Vietnam. Journal of Agricultural and Resource Economics, 36(1):14-27.

Wagstaff, A. (2007). Health insurance for the Poor: Initial impacts of Vietnam's Health Care Fund for the Poor. World Bank Policy Research Paper No. 4134, World Bank, Washington DC.

Wagstaff, A. and van Doorslaer, E. (2003). Catastrophe and Impoverishment in Paying for Health Care: With Applications to Vietnam 1993-1998. Health Economics, 12(11):921-933.

Warner, K. and van der Geest, K. (2013). Loss and Damage from Climate Change: LocalLevel Evidence from Nine Vulnerable Countries. International Journal of Global Warming, $5(4): 367-386$.

Werker, E., Ahmed, F. Z., and Cohen, C. (2009). How Is Foreign Aid Spent? Evidence from a Natural Experiment. American Economic Journal: Macroeconomics, 1(2):225-244.

World Bank (2010). World Development Report 2010: Climate Change and Development. Washington, DC.

World Bank (2012a). Country and Lending Groups. Retrieved from http://data.worldbank. org/about/country-classifications/country-and-lending-groups.

World Bank (2012b). The Welfare Effects of Extreme Weather Events - Insights from Three APEC Case Studies. Washington, DC. 
World Bank (2012c). Vietnam Development Report. Washington, DC.

World Bank (2013). World Development Report 2014: Risk and Opportunity - Managing Risk for Development. Washington, DC.

World Bank (2014). World Development Indicators.

WVS (2009). World Values Survey 1981-2008 Official Aggregate v.20090901, World Values Survey Association (www.worldvaluessurvey.org). Aggregate File Producer: ASEP/JDS, Madrid.

Xu, K., Evans, D. B., Kawabata, K., Zeramdini, R., Klavus, J., and Murray, C. J. (2003). Household Catastrophic Health Expenditure: A Multicountry Analysis. The Lancet, 362(9378):111-117.

Yamano, T., Alderman, H., and Christiaensen, L. (2005). Child Growth, Shocks, and Food Aid in Rural Ethiopia. American Journal of Agricultural Economics, 87(2):273-288.

Zhang, G. (2004). The Determinants of Foreign Aid Allocation Across China: The Case of World Bank Loans. Asian Survey, 44(5):691-710. 


\section{Eidesstattliche Erklärung}

\section{Versicherung gemäß $§ 16$ Prüfungs- und Studienordnung für den Promotionsstudiengang Wirtschaftswissenschaften}

1. Die Gelegenheit zum vorliegenden Promotionsvorhaben ist mir nicht kommerziell vermittelt worden. Insbesondere habe ich keine Organisation eingeschaltet, die gegen Entgelt Betreuerinnen und Betreuer für die Anfertigung von Dissertationen sucht oder die mir obliegenden Pflichten hinsichtlich der Prüfungsleistungen für mich ganz oder teilweise erledigt.

2. Ich versichere, dass ich die eingereichte Dissertation "A Contribution to the Empirics of Development and Globalization" selbstständig und ohne unerlaubte Hilfsmittel verfasst habe; fremde Hilfe habe ich dazu weder unentgeltlich noch entgeltlich entgegengenommen und werde dies auch zukünftig so halten. Anderer als der von mir angegebenen Hilfsmittel und Schriften habe ich mich nicht bedient. Alle wörtlich oder sinngemäß den Schriften anderer Autoren entnommenen Stellen habe ich kenntlich gemacht.

3. Die Richtlinien zur Sicherung der guten wissenschaftlichen Praxis an der Universität Göttingen werden von mir beachtet.

4. Eine entsprechende Promotion wurde an keiner anderen Hochschule im In- oder Ausland beantragt; die eingereichte Dissertation oder Teile von ihr wurden nicht für ein anderes Promotionsvorhaben verwendet.

5. Des Weiteren ist mir bekannt, dass Unwahrhaftigkeiten hinsichtlich der vorstehenden Erklärung die Zulassung zur Promotion ausschließen bzw. später zum Verfahrensabbruch oder zur Rücknahme des erlangten Titels berechtigen.

Datum, Unterschrift 